\title{
Influences of Central Units and Terminal Chains on the Banana-Shaped Liquid Crystals
}

\author{
Tang Xin Ting, Mohd Sani Sarjadi $\odot$ and Md Lutfor Rahman * \\ Faculty of Science and Nature Resources, University Sabah Malaysia, Kota Kinabalu 88400, Malaysia; \\ tangxinting_0917@hotmail.com (T.X.T.); msani@ums.edu.my (M.S.S.) \\ * Correspondence: lotfor@ums.edu.my
}

Received: 17 August 2020; Accepted: 7 September 2020; Published: 24 September 2020

\begin{abstract}
Azo-functionalized materials are one of the appealing groups of the functionalized materials owing to their photoswitching behaviour and have been explored for various potential applications viz., optical data storage, sensor, display devices, nonlinear materials and molecular switches. Recently, azo-functionalized bent-core liquid crystals (BCLCs) have gained significant attention because they have dual properties of BCLCs and azobenzene, which enables to generate new multifaceted functional and smart materials. In this report, the recently synthesized azobenzene containing bent-core mesogens and its subclass, the so-called hockey stick and V-shaped molecules are summarized. The mesomorphic behaviour of reported BCLCs affected by the type of central core unit, the nature, number and position of the lateral substituents and the type and length of the terminal chain are discussed. The photoisomerization process of these photoresponsive BCLCs in solid, solution and mesophase, as well as the impact of light on the chemical and electrical properties of them, are discussed.
\end{abstract}

Keywords: azobenzene; bent-core liquid crystals; banana-shaped liquid crystals; banana phases; photoisomerization; potential applications

\section{Introduction}

The bent-core molecules or banana liquid crystals (LCs) have attracted significant attention in the field of soft matter science due to their remarkable and unique properties. They exhibit macroscopic polar order and chirality in their mesophases, although the constituent molecules of these mesophases are achiral [1,2]. Historically, the first bent-core molecules were synthesized and reported by Vorländer without any impact for over 60 years [3,4]. The theoretical and technological interest towards the ferroelectricity in mesophases leads to the rebirth in interest for bent-core mesogens. Until the 1990s, the ferroelectric property was only discovered in tilted smectic phases of chiral calamitic and discotic molecules [5-10]. However, the synthesis of chiral rod and dis-shape molecules with tilted smectic phases is relatively expensive. Therefore, a great deal of theoretical and experimental efforts was put into finding ferroelectric mesophases using achiral molecules [11-23]. In 1996, a novel type of mesogenic material breathed new life into the liquid crystal field and brought new expectations: the so-called bent-core liquid crystals (BCLCs) or banana liquid crystals [1]. BCLCs exhibit a wide variety of bent-core mesophases such as $\mathrm{B}_{1}, \mathrm{~B}_{2}, \ldots, \mathrm{B}_{8}$, bent-core nematics $(\mathrm{BCN})$ and dark conglomerates (DC), in addition to the conventional nematic and smectic phases. A few previous studies have summarized the design and remarkable characteristics of BCLCs [6,24-31]. In general, eight different banana phases have been identified until today and are designated as $B_{1}-B_{8}$ phases based on the sequence of their discovery. Among the banana phases $\left(B_{1}-B_{8}\right)$, the smectic $B_{2}$ phase, now designated as the SmCP phase, is the most widely studied phase due to its ferroelectric switching behaviour that can be used in fast switching electro-optical devices [24,32]. Nowadays, the primary concern of many 
research groups is to create advanced materials using BCLCs where their properties can be adjusted by different external stimuli, in particular, the light [33].

Podruczna et al. mentioned that azobenzene derivatives were among the first recognized groups of liquid crystalline molecules $[34,35]$. The significant interest in using the azobenzene as a fundamental component for LC molecules is based on two reasons. Firstly, it is a photosensitive chromophore that undergoes trans-cis isomerization upon light exposure, causing the configurational modifications that bring significant changes in physical properties [36-41]. When an azobenzene-containing molecule is exposed to UV light with $\lambda=365 \mathrm{~nm}$, the energetically more stable trans configuration will change into the cis configuration and reverse back to the original configuration upon the illumination with visible light (within the range 400-500 nm) [42]. Cis-trans isomerization can also occur by keeping the excited trans isomers in the dark place. This spontaneous process is called thermal back relaxation, where the metastable cis isomers revert back to the thermodynamically more stable trans form [43]. This particular aspect of photonics, in which molecular configuration can be manipulated by light, is crucial especially in the research fields such as holographic media [44,45], photoalignment of LC system [46], optical storage [47-49] and photochemical molecular switches [45,50]. In the case of optical data storage devices, one of the most requirement for azobenzene to be utilized is long thermal back relaxation [51]. Secondly, molecules based on azobenzene have delocalized electronic charge distribution between acceptor and donor atom or group of atoms substituted with it. This feature may be used to design materials with good nonlinear optical (NLO) properties. In particular, for optical second-harmonic generation (SHG), the azobenzene moiety seems to be a good candidate to be incorporated in bent-core LCs [52].

In recent years, azo functionalized bent-core liquid crystals received great attention because they combine the photoswitching behaviour of azobenzene and liquid crystalline properties of BCLCs, creating potential new multi-functional and smart materials [53]. For this reason, azobenzene-containing BCLCs draw the attention of many researchers in the past few years. Many different azo functionalized BCLCs have been synthesized to understand their rich mesomorphism and multifaceted properties [52,54-62]. This paper focuses on reviewing the most recent development of azobenzene-containing BCLCs of different molecular structures understands the structure-property relationship. In the following sections, the observed mesophases along with the transition temperatures for each compound are shown below the chemical structure. It should be noted that some detailed information of mesophases observed in the discussed BCLCs will not be included in this paper. Therefore, readers are suggested to refer to the original publications for more details.

\section{Bent-Core Liquid Crystals (BCLCs)}

Banana/bent-shaped compounds can be classified into three categories: (i) molecules incorporating a rather rigid bent aromatic core, such as compound $\mathbf{1}$ derived from the rigid resorcinol core, (ii) mesogenic dimers consists of two mesogenic units linked via a flexible spacer, usually, an alkyl chain (compounds 2 and 3) [63], and (iii) hockey-stick molecules, where an alkyl chain is attached to the meta-position at one end of the aromatic core (type 1 hockey-stick molecule 4) [64-66] and type 2, where the aromatic ring is attached to the meta-position at one end of the aromatic core (compound 5). The molecular structure and carbon view of BCLCs are shown in Figure 1. 


\section{Bent-core Molecule}
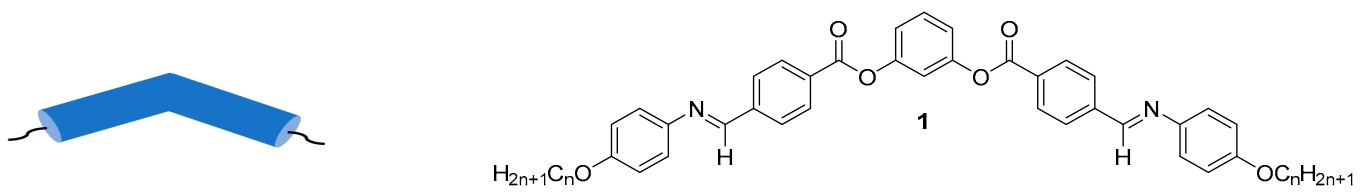

\section{Mesogenic Dimer}
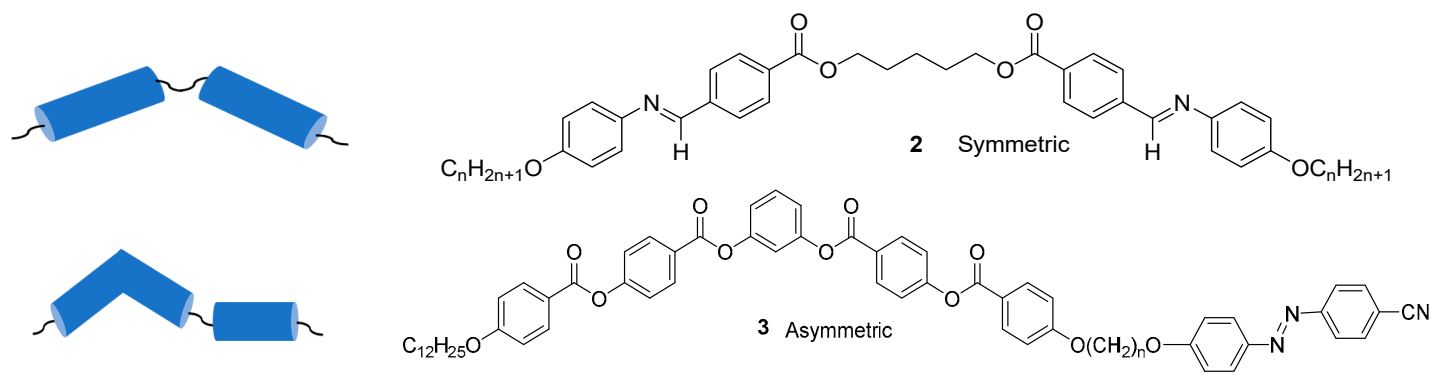

Hockey-stick Molecule
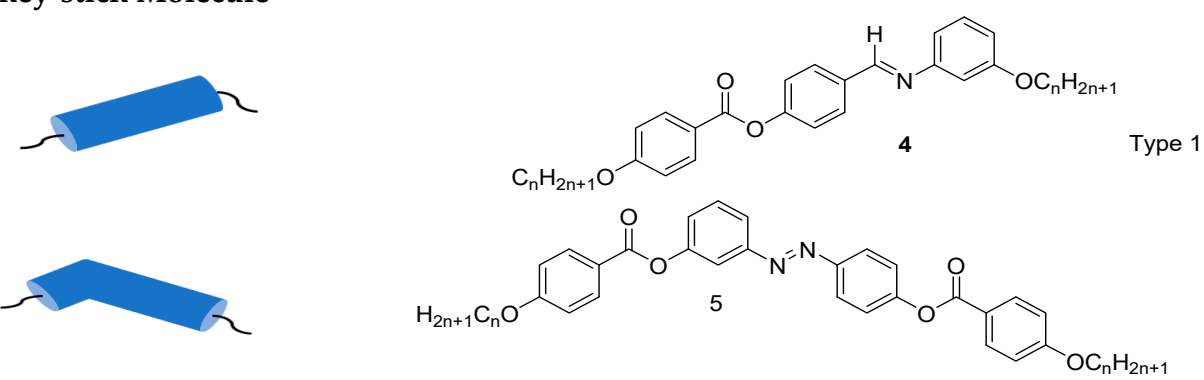

Type 2

Figure 1. Schematic representation of three types of bent-core liquid crystals and their chemical structures [67-69].

As mention earlier, BCLCs bearing with azo moiety exhibit remarkable properties because they possess the photochromic properties of azobenzene and the unusual physical properties of bent-core mesogens [57,70]. Alaasar [57] pointed out that it is crucial to note that Vorländer, the pioneering scientist in the field of LCs, had prepared the first azo-containing BCLC derived from the isophthalic acid as the bent-core unit (compound 6) in 1929 [3] although Prasad et al. initiated the research on BCLCs incorporating with azobenzene groups [36,71,72]. In 1932, Vorländer et al. reported another bent-core mesogen that consists of resorcinol as the central core unit and azoxy as the linker (compound 7) (see Figure 2) [4]. This mesogen exhibited an unidentified smectic phase which was later known as the $\mathrm{B}_{6}$ phase after the further investigation conducted by Pelzl et al. $[57,73]$.<smiles>COc1ccc(N=Nc2ccc(OC(=O)c3cccc(C(=O)Oc4ccc(NNc5ccc(OC)cc5)cc4)c3)cc2)cc1</smiles><smiles>CCOc1ccc(N(O)N=Nc2ccc(C(=O)Oc3cccc(OC(=O)c4ccc(N(O)N(O)c5ccc(OCC)cc5)cc4)c3)cc2)cc1</smiles>

Figure 2. Chemical structure of historical bent-core molecules 6 and 7 synthesized by Vorländer [73]. 


\subsection{Molecular Structure of Bent-Core Liquid Crystals}

The existence of chirality and polar order in mesophases of BCLCs is strongly affected by the molecular structure and intermolecular interactions [67]. BCLCs are built up from three basic parts, which are the central bent unit (BU), linking groups and rod-like wings. The general structure of the BCLC and some of the reported central bent units are shown in Figure 3.
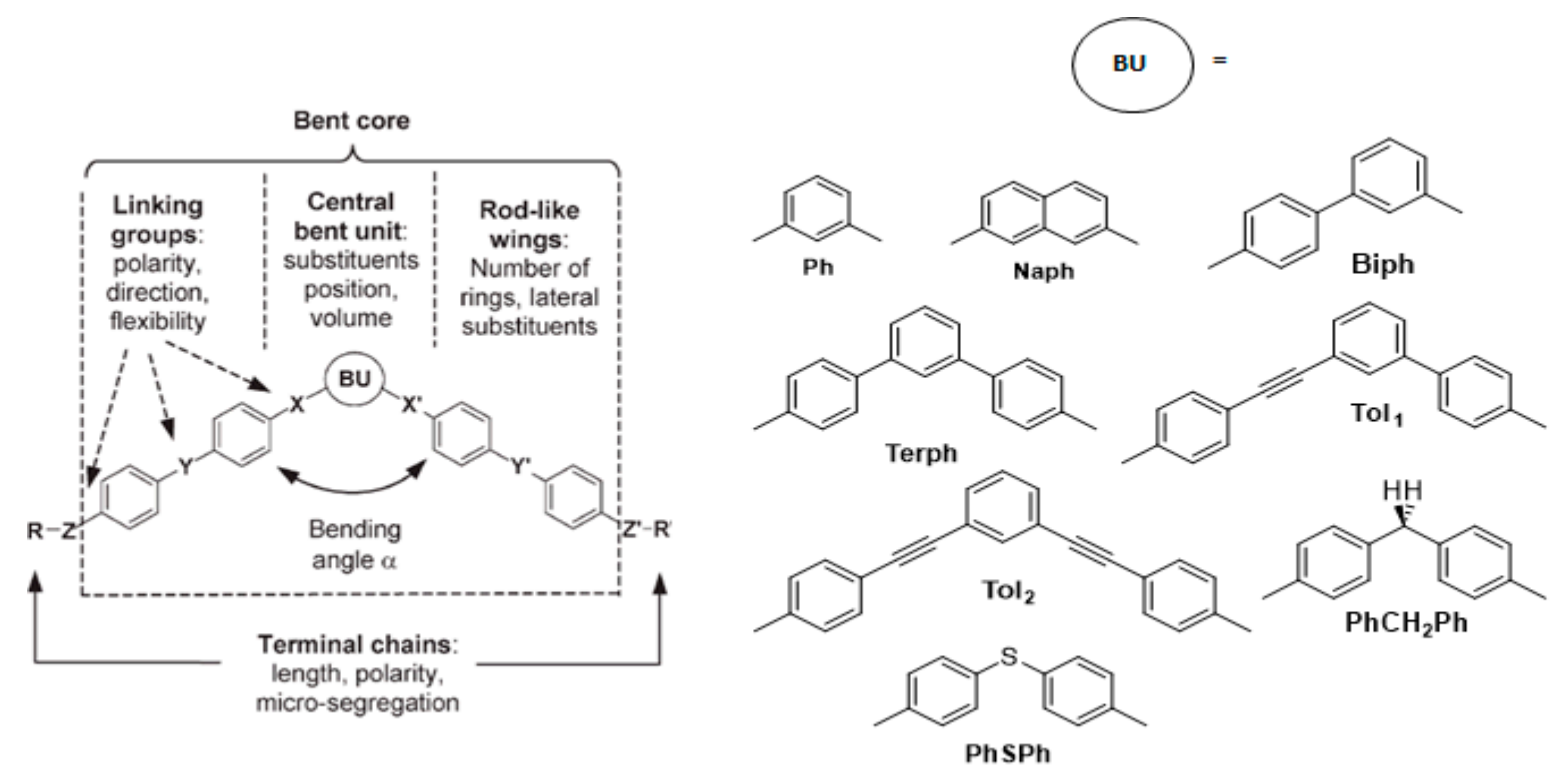

Figure 3. The general structure of bent-core mesogens and some central units [67].

In the designing of BCLCs, choosing the right central bent unit $(\mathrm{BU})$ is very important because the length and the bending angle of the $\mathrm{BU}$ are the most crucial parameters for the formation of polar ordered mesophases in BCLCs. The bending angle of the central BU has to be within the range between $105^{\circ}$ and $140^{\circ}$ is to show the layer polarity $[67,74]$. Modification of the bending angle can be done by introducing a five-membered heterocycles core unit $[75,76]$, instead of a six-membered ring, or by attaching the substituents at the $B U$ close to the linkages $X$ and $X^{\prime}[67,77,78]$. Among the linking groups, the ester linkage $\left(X, X^{\prime}\right)$ is the most often linking group used to connect the central core unit to rod-like wings due to the enhanced chemical stability [57,79]. However, other linking groups such as azomethine $(\mathrm{C}=\mathrm{N})$ and double bond $(\mathrm{C}=\mathrm{C})$ are also employed as the linker between $\mathrm{BU}$ and rod-like wings [57]. Linking groups $\left(\mathrm{Y}, \mathrm{Y}^{\prime}\right)$ that can be inserted within the rod-like wings of BCLCs are Schiffs base, azo $(N=N)$, double bond $(C=C)$ and triple bond $(C \equiv C)$ [67]. The function of linkers within the rod-like wings $\left(\mathrm{Y}, \mathrm{Y}^{\prime}\right)$ is to preserve a certain degree of flexibility of BCLCs to promote the mesomorphism and prevent crystallization. Besides, their direction also has a significant impact on the mesomorphic behaviour of BCLCs. Besides the BU and linkage groups, the mesogenic properties of BCLCs can also be tuned by the lateral substitution on the rod-like wings, the type and length of terminal chains as well as the number of aromatic units in the molecular structure $[57,67]$. In the following sections, the recent reported azobenzene-containing BCLCs are classified according to the central BU incorporated in its molecular structure.

\subsubsection{1,3-Dihydroxybenzene/Resorcinol}

Resorcinol is the most widely used central BU in designing bent-core liquid crystals (BCLCs) that display banana phases as well as smectic or nematic phases $[57,78,80-85]$. Compound 8 is formed by connecting the resorcinol central core to azobenzene sidearms with the double bond as the terminal chain via the ester linkage. When the fluorine atom is inserted to the periphery of the azobenzene sidearm in compound $\mathbf{8}$, compound $\mathbf{9}$ that shows the similar phase sequence with compound $\mathbf{8}$ is formed. However, it has the lower phase transition temperature compared to that of compound 8 [86]. 


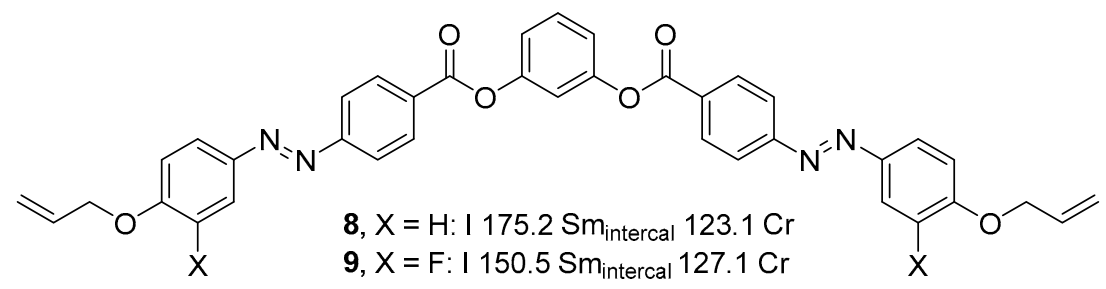

Compound $\mathbf{1 0}$ is formed when there is an addition of a $-\mathrm{O}\left(\mathrm{CH}_{3}\right)_{\mathrm{n}}$ unit inserted between the azobenzene sidearm and the alkoxy double bond terminal chain. The homologues of monomers 10 ( $n=4,5$ and 6) exhibit an enantiotropic intercalated smectic A phase, the so-called $\mathrm{B}_{6}$ phase, in a broad temperature range [42].<smiles>C=CCOCOc1ccc(N=Nc2ccc(C(=O)Oc3cccc(C(=O)Oc4ccc(NN=Nc5ccc(OCC=C)cc5)cc4)c3)cc2)cc1</smiles>

Substituted 1,3-Dihydroxybenzene/Resorcinol

As mentioned in Section 2.1, the mesomorphic behaviour of BCLCs is significantly affected by the slight modification of the molecular structure. The lateral substitution at different positions in the central BU is one of the possible modifications. 4-substituted resorcinol represents a typical structure of this kind affecting the bend angle of the bent-core mesogen greatly as a result of the effects of the lateral group on the conformation of the adjacent ester group, especially in the case of 4-cyanoresorcinol [57,87]. For example, the 4-cyanoresorcinol core is a beneficial BU with a reduced bending angle that used to generate new mesophases and/or new phase sequences [57,88,89]. For simplicity, the chiral phase is given a symbol [*].

Alaasar et al. reported three series of BCLCs $(\mathbf{1 1}, \mathbf{1 2}$ and 13) that consist of a 4-cyanoresorcinol as the central core unit combined with fluorinated rod-like azobenzene sidearms [90-94]. This research provides important clues to understand the development of polar order in lamellar LC phases of achiral bent-core molecules, depending on the chain length, temperature and position of fluorine substitution structure. The longest homologue of series 11 where $n=20$, was reported previously [95]. Only the shorter homologues of compound $\mathbf{1 1}(n=4$ and 6) exhibit the cybotactic bent-core nematic phase constituted by non-tilted SmA clusters $\left(\mathrm{N}_{\mathrm{cybA}}\right)$ (see Table 1$)$. This type of bent-core nematic is rare compared to that of $N_{c y b C}$ phase, which is formed by the tilted SmC clusters $[29,52,87,96]$. Bent-core nematics $\left(\mathrm{N}_{\mathrm{cybc}} / \mathrm{N}_{\mathrm{cybA}}\right)$ are very unusual compared to the conventional $\mathrm{N}$ phase of the calamitic LCs because they are responsible for possible bixiality [29,97-99], giant flexoelectricity [100] and ferroelectricity [101]. Unlike the conventional smectic and columnar phases, the existence of the nematic phase in BCLCs is not that often. As the length of alkyl chains increases, the macroscopic polar order developed continuously from the low-permittivity SmA phases (SmA) through a series of uniaxial $\left(\mathrm{SmAP}_{\mathrm{R}}, \mathrm{SmAP}_{\mathrm{AR}}\right)$ and biaxial high-permittivity paraelectric smectic phases $\left(\mathrm{SmC}_{\mathrm{S}} \mathrm{P}_{\mathrm{R}}[*]\right.$, $\mathrm{SmC}_{\mathrm{S}} \mathrm{P}_{\mathrm{AR}}$ ) to the antiferroelectric polar smectic phases $\left(\mathrm{SmC}_{\mathrm{S}} \mathrm{P}_{\mathrm{A}}\right.$ and $\mathrm{SmC}_{\mathrm{a}} \mathrm{P}_{\mathrm{A}}$ ) (see Table 1). In fact, the overall phase sequence of homologues 11 is actually affected by the core-chain nanosegregation, a phenomenon that is controlled by the chain length $[90,102]$. 
Table 1. Phase transition of homologues of compounds 11.

\begin{tabular}{|c|c|c|}
\hline Compound & $n$ & Phase Transition \\
\hline 11a & 4 & Cr $164 \mathrm{~N}_{\text {cybA }} 136$ Iso \\
\hline $11 b$ & 6 & Cr $112 \mathrm{SmAP}_{\mathrm{AR}} 101 \mathrm{SmAP}_{\mathrm{R}} 117 \mathrm{~N}_{\mathrm{cybA}} 128$ Iso \\
\hline 11c & 8 & Cr $112 \mathrm{SmC}_{\mathrm{a}} \mathrm{P}_{\mathrm{A}} 104 \mathrm{SmAP}_{\mathrm{AR}} 110 \mathrm{SmAP}_{\mathrm{R}} 137$ Iso \\
\hline 11d & 10 & Cr $108 \mathrm{SmC}_{\mathrm{a}} \mathrm{P}_{\mathrm{A}} 108 \mathrm{SmC}_{\mathrm{S}} \mathrm{P}_{\mathrm{AR}} 112 \mathrm{SmAP}_{\mathrm{R}} 143$ Iso \\
\hline 11e & 12 & Cr $104 \mathrm{SmC}_{\mathrm{a}} \mathrm{P}_{\mathrm{A}} 98 \mathrm{SmC}_{\mathrm{s}} \mathrm{P}_{\mathrm{A}} 108 \mathrm{SmC}_{\mathrm{s}} \mathrm{P}_{\mathrm{AR}} \approx 111 \mathrm{SmC}_{\mathrm{s}} \mathrm{P}_{\mathrm{R}}^{[*]} 135 \mathrm{SmA} 147$ Iso \\
\hline $11 f$ & 14 & Cr $101 \mathrm{SmC}_{\mathrm{a}} \mathrm{P}_{\mathrm{A}} 98 \mathrm{SmC}_{\mathrm{s}} \mathrm{P}_{\mathrm{A}} 107 \mathrm{SmC}_{\mathrm{S}} \mathrm{P}_{\mathrm{AR}} \approx 112 \mathrm{SmC}_{\mathrm{s}} \mathrm{P}_{\mathrm{R}}^{[*]} 134 \mathrm{SmC}_{\mathrm{s}}^{[*]} 142 \mathrm{SmA} 147$ Iso \\
\hline $11 \mathrm{~g}$ & 16 & Cr $101 \mathrm{SmC}_{\mathrm{a}} \mathrm{P}_{\mathrm{A}} 93 \mathrm{SmC}_{\mathrm{s}} \mathrm{P}_{\mathrm{A}} 105 \mathrm{SmC}_{\mathrm{s}} \mathrm{P}_{\mathrm{AR}} \approx 112 \mathrm{SmC}_{\mathrm{s}} \mathrm{P}_{\mathrm{R}}^{[*]} 126 \mathrm{SmC}_{\mathrm{s}}^{[*]} 145 \mathrm{SmA} 149$ Iso \\
\hline $11 \mathrm{~h}$ & 18 & Cr $102 \mathrm{SmC}_{\mathrm{a}} \mathrm{P}_{\mathrm{A}} 94 \mathrm{SmC}_{\mathrm{s}} \mathrm{P}_{\mathrm{A}} 101 \mathrm{SmC}_{\mathrm{s}} \mathrm{P}_{\mathrm{AR}} \approx 108 \mathrm{SmC}_{\mathrm{s}} \mathrm{P}_{\mathrm{R}}^{[*]} 121 \mathrm{SmC}_{\mathrm{s}}^{[*]} 143 \mathrm{SmA} 148$ Iso \\
\hline
\end{tabular}

When the fluorine is shifted from the peripheral 3-position to the inner 2-position, homologues of compound $12(n=8-16)$ are formed. The change in the position of the fluorine atom from the peripheral 3-position to the inner 2-position reduces the melting point and clearing temperature [90]. The $\mathrm{B}_{2} / \mathrm{SmCP}$ phase is disappeared in series $\mathbf{1 2}$ due to the unfavourable steric hindrance of fluorine-substitution in this position, regardless of the alkyl chain length. This observation is in line with the previous observations made for rod-like mesogens [103-105].

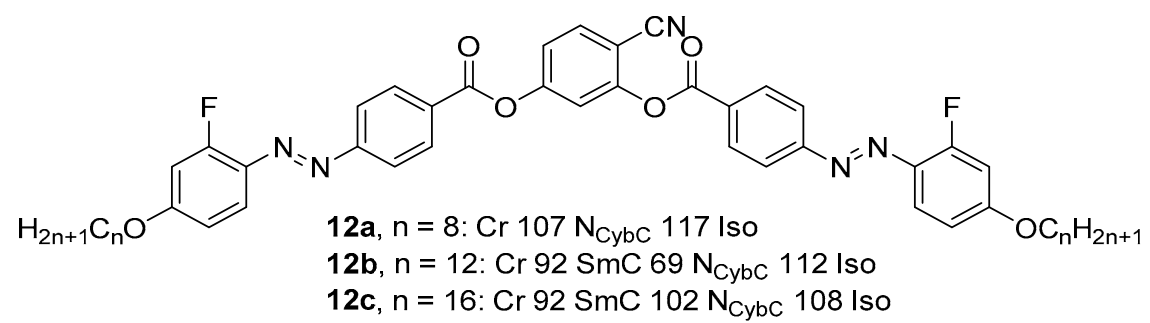

Homologues of compound $\mathbf{1 3}$ are generated by substituting the fluorine atom at the ortho and meta positions with respect to the terminal alkoxy chain. The transition temperatures of this series are higher compared to series 12, but lower than the series 11. No nematic phase could be observed in homologues of compound 13, as it is exhibited by homologues in series 11 and 12. Although homologues 13 with $n \geq 12$ exhibit the chiral synclinic tilted $\mathrm{SmC}_{\mathrm{s}}{ }^{[*]}$ phases, no polarization current peaks could be observed in the triangular wave experiment. The formation of chiral conglomerates in homeotropic alignment indicates the presence of $\mathrm{SmC}_{\mathrm{s}}{ }^{[*]}$ phase (see Figure 4) [90].

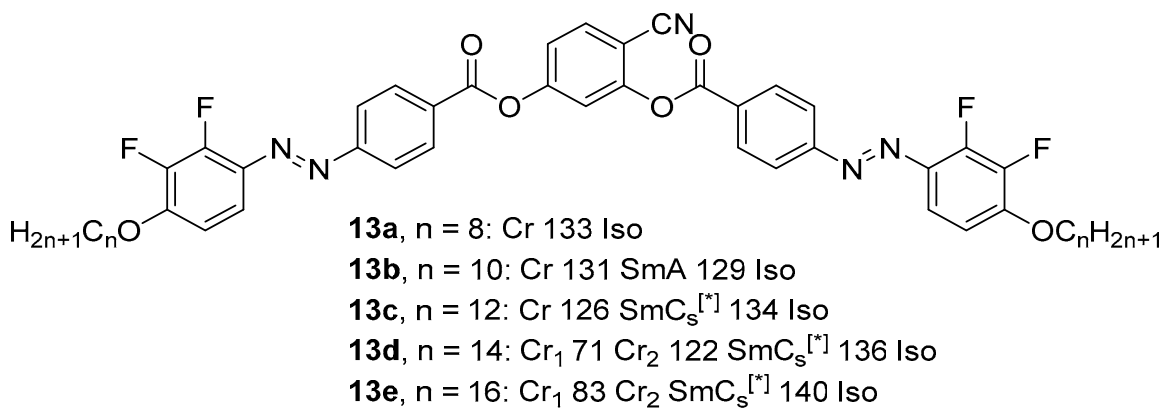



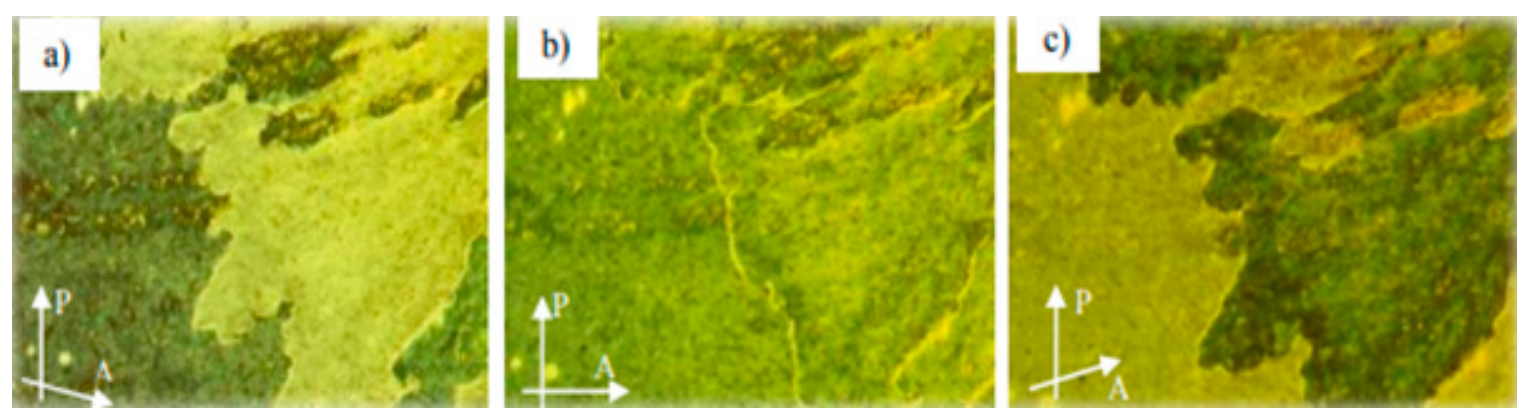

Figure 4. Textures of the chiral $\mathrm{SmC}_{\mathrm{s}}{ }^{[*]}$ phase of compound $13 \mathrm{e}$ at $\mathrm{T}=127^{\circ} \mathrm{C},(\mathbf{a}, \mathbf{c})$ between slightly uncrossed polarizers and (b) between crossed polarisers, exhibiting dark and bright domains that indicate the presence of chiral domains with opposite handedness. (Reproduced with permission from ref. [90], copyright John Wiley and Sons 2017, https://doi.org/10.1002/chem.201606035).

The replacement of the fluorine atom in compound $11 \mathrm{~h}$ with less polar bromine atom results in the formation of compound $\mathbf{1 4}$ with the reduced phase transition temperature, although the Iso-SmA-SmC ${ }_{s}{ }^{[*]}{ }_{-} \mathrm{SmC}_{\mathrm{S}} \mathrm{P}_{\mathrm{AR}}$ phase sequence has remained. When the bromine atom in compound 14 is replaced by the non-polar methyl group with similar volume (compound 15), the stability of mesophases is further reduced and leave only a nonpolar and non-chiral SmC and nematic phases $\left(\mathrm{N}_{\mathrm{cybC}}\right)$. This is mostly attributed to the unfavourable reduction in core-core interactions by the non-polar and electron-donating methyl group [90].

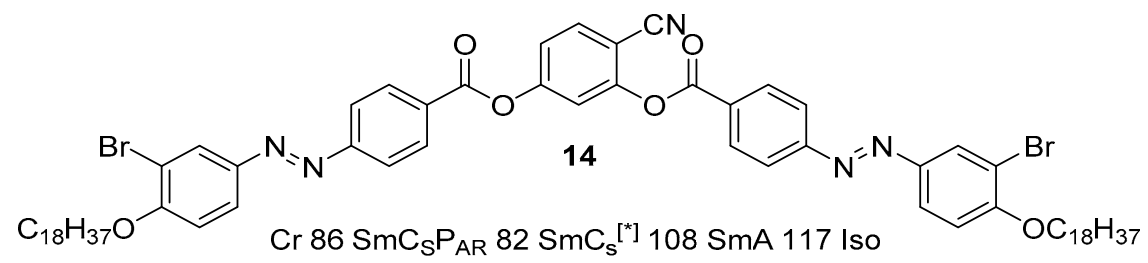<smiles>CCCCCCCOc1ccc(N=Nc2ccc(C(=O)Oc3ccc(C)c(OC(=O)c4ccc(N=Nc5ccc(OCCCCC)c(C)c5)cc4)c3)cc2)cc1C</smiles>

Recently, Alaasar et al. had reported asymmetric BCLCs derived from the 4-cyanoresorcinol $\mathrm{BU}$ connected to two different rod-like wings [91]. Homologues of compound $\mathbf{1 6}$ were prepared by connecting the 4-cyanoresorcinol to the azobenzene wing and the phenyl terephthalate wing with the -COO linkage inverting downward. All homologues of compound $\mathbf{1 6}(n=8,12,16$ and 20), except for the shortest homologue 16a, exhibit the same phase transition sequence of a non-polar SmA phase, a paraelectric $S m C_{s}$ phase involving the $\mathrm{SmC}_{\mathrm{s}}{ }^{[*]}, \mathrm{SmC}_{\mathrm{S}} \mathrm{P}_{\mathrm{R}}{ }^{[*]}$ and $\mathrm{SmC}_{\mathrm{S}} \mathrm{P}_{\mathrm{AR}}$, the polar modulated $\mathrm{SmC}_{\mathrm{S}} \mathrm{P}_{\mathrm{A}}$ and the non-modulated $\mathrm{SmC}_{\mathrm{S}} \mathrm{P}_{\mathrm{A}}$ phases as the temperature decreases (see Table 2). It should be noted that $\mathrm{SmC}_{\mathrm{s}}{ }^{[*]}, \mathrm{SmC}_{\mathrm{S}} \mathrm{P}_{\mathrm{R}}{ }^{[*]}$ and $\mathrm{SmC}_{\mathrm{S}} \mathrm{P}_{\mathrm{AR}}$ phases have distinct properties even they are considered in temperature ranges of the paraelectric $S_{m} C_{s}$ phase. The compound 16a behaves differently from the higher homologues due to the reduced tilt, leading to the formation of a non-tilted and achiral paraelectric $S m A P_{R}$ phase followed by a transition to an anticlinic $S m C_{a} P_{A R}$ (see Figure 5a). The discovery of new $\mathrm{SmC}_{\mathrm{a}} \mathrm{P}_{\mathrm{AR}}$ phase in this study completes the presently known series of synclinic tilted $\mathrm{SmC}_{S} \mathrm{P}_{\mathrm{AR}}[106]$ and non-tilted $\mathrm{SmAP}_{\mathrm{AR}}$ phases types $[95,107]$. Substituting the outer azobenzene ring with a lateral fluorine atom in compound $\mathbf{1 6 b}(n=16)$ results in the formation of compound $\mathbf{1 7}$. The result indicated that there is almost no difference in phase sequence between compounds $\mathbf{1 6} \mathbf{b}$ and 17, except for the absence of $\mathrm{SmC}_{\mathrm{s}}{ }^{[*]}$ phase in compound 17 (see Table 2). Besides, textures and 
polarization current curves of compound $\mathbf{1 7}$ are very similar to compound 16b. (Figure $5 \mathrm{~b}, \mathrm{c}$ ) Therefore, it seems to be no significant effect of the monofluorination of a single benzene ring on the sequence and LC behaviour [91].

Replacing the phenyl terephthalate wing in homologues series of compound $\mathbf{1 6}$ with a benzoylated 4-hydroxybenzoate wing in the molecular structure leads to homologues series of compound $\mathbf{1 8 .}$ This series has the narrower mesophases, higher melting temperatures and a larger tilt compared to series 16. Except for the longest homologue $\mathbf{1 8 b}(n=20)$, all homologues 18 show a skewed cybotactic nematic phase $\left(\mathrm{N}_{\mathrm{CybC}}\right)$ instead of the SmA phase as it exhibited by compounds $\mathbf{1 6}$ (see Table 3). The $\mathrm{N}_{\text {Cybc }}$ phase is wholly disappeared and replaced by the $\mathrm{SmC}_{s} \mathrm{P}_{\mathrm{R}}{ }^{[*]}$ phase for the longest homologue 18 [91]. The fluorinated compound $19(n=16)$ is formed by substituting the fluorine atom on the outer phenyl of the azobenzene wing. Unlike compound 18a $(n=16)$, it does not show $\mathrm{N}_{C y b C}$ phase. The mesophases and the phase sequence of compound 19 are almost similar to the $\mathbf{1 8 b}$ (see Table 3), indicating that decreasing the electron density of the core by fluorination has the same impact as elongation of the alkyl chain [91].

Table 2. Phase transition of homologues of compounds 16 and their derivative 17.
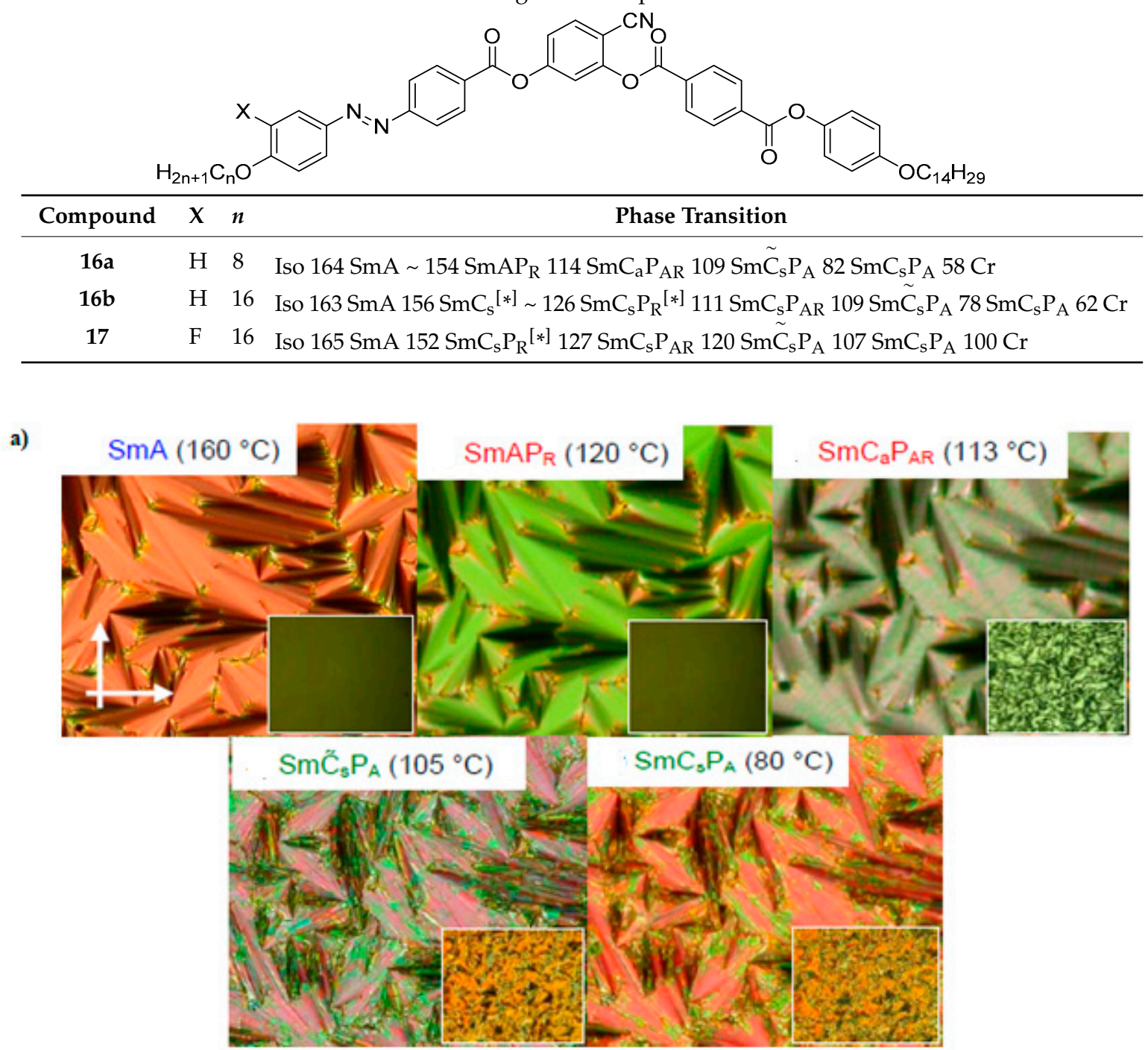

Figure 5. Cont. 
b)
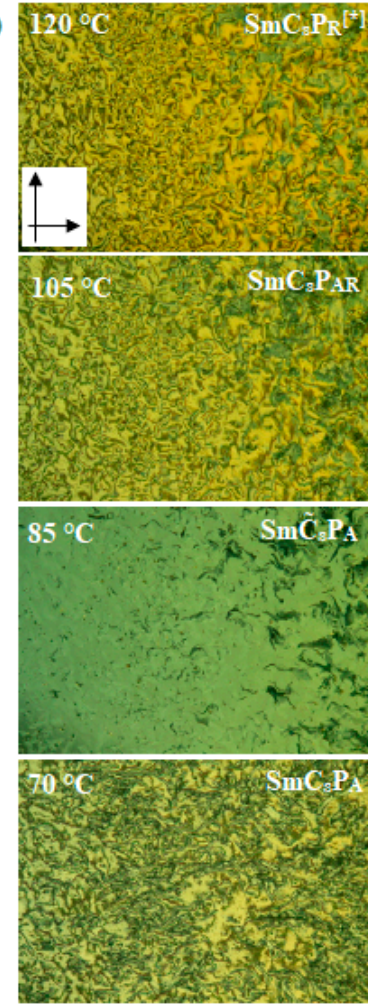
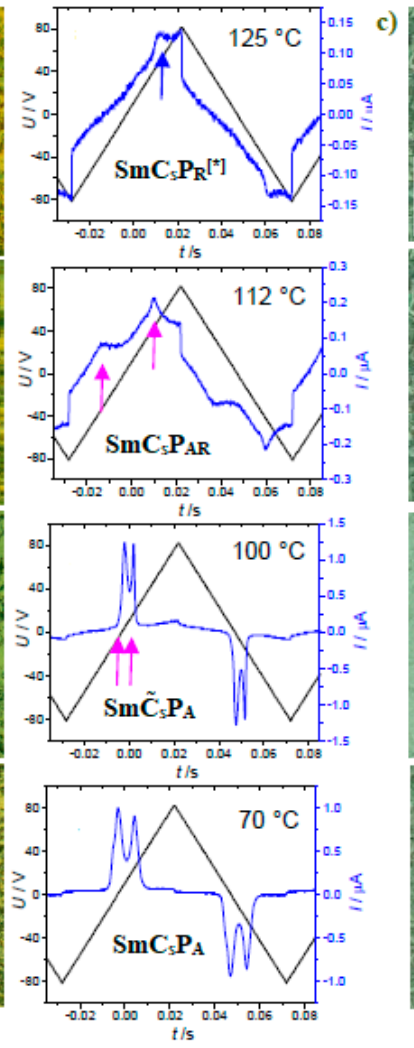
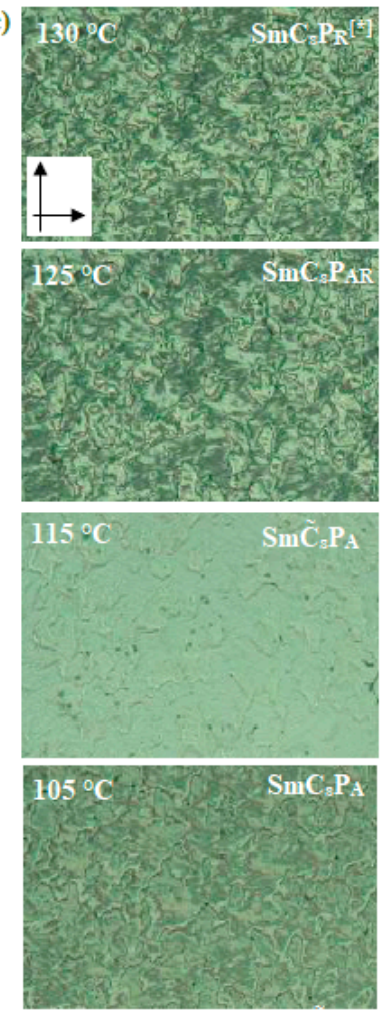
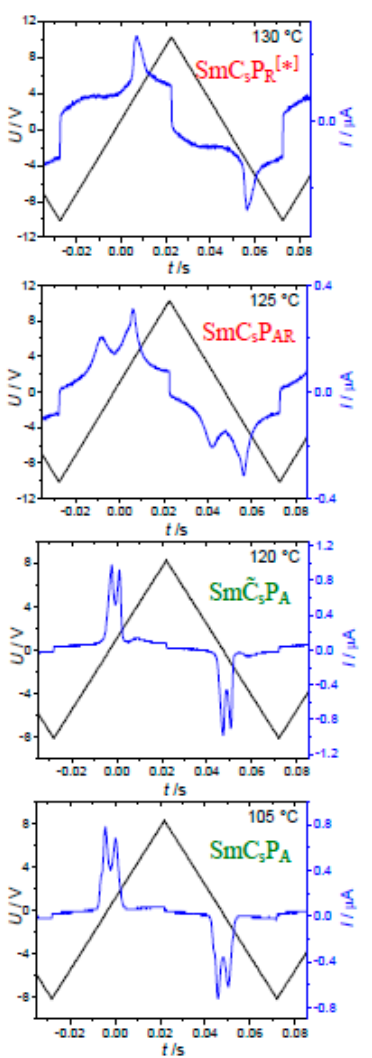

Figure 5. Optical textures of compound 16a: (a) observed under polarizing optical microscope (POM) between crossed polarisers at the given temperatures in the distinct phases in a planar cell $(6 \mu \mathrm{m}$ polyimide (PI) coated indium tin oxide (ITO) cell). The insets represent the corresponding textures in a homeotropic cell, (b) optical textures of compound $\mathbf{1 6 b}$ in the homeotropic cell (6 $\mu \mathrm{m}$ PI coated ITO cell) and its switching current response curve on applying a triangular wave field and (c) optical textures of compound 17 in the homeotropic cell (6 $\mu \mathrm{m}$ PI coated ITO cell) and its switching current response curve on applying a triangular wave field (Reproduced with permission from ref. [91], copyright John Wiley and Sons 2019, https://doi.org/10.1002/chem.201806180).

Table 3. Phase transition of homologues of compounds 18 and their derivative 19.

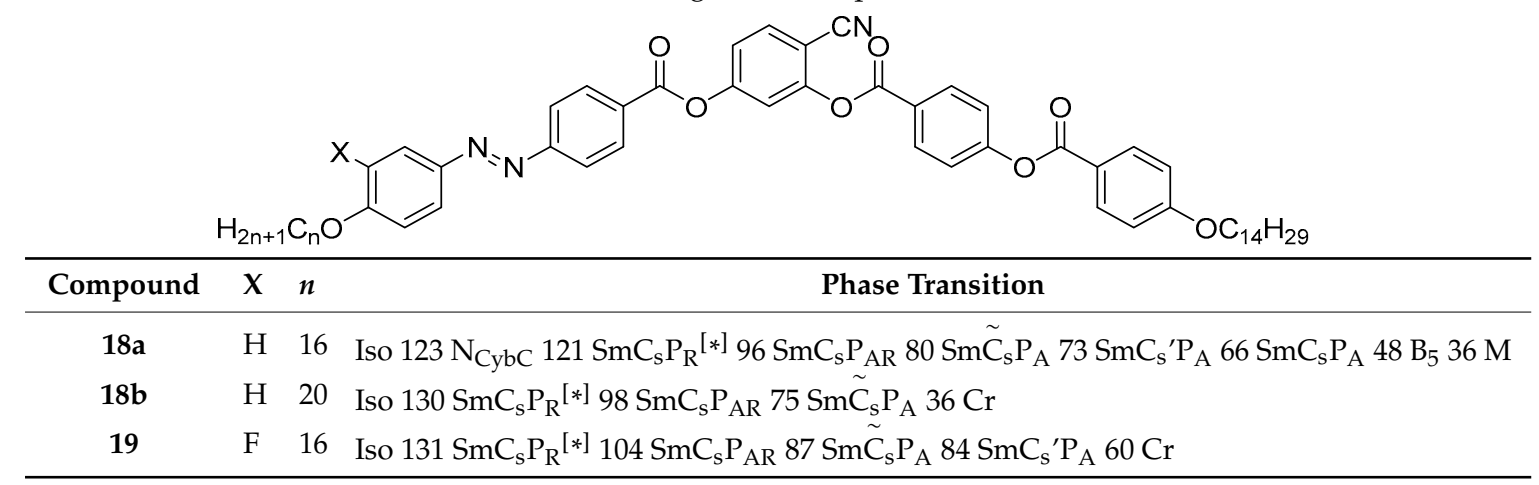

Although a 4-chlororesorcinol is a commonly used BU in the bent-core system [82,108,109], only a relatively limited number of compounds employing both these motifs (4-chlororesorcinol and azo group) has been synthesized and studied. Šmahel et al. prepared two isomeric series of nonsymmetrical BCLCs (series 20 and 21), which possesses the 4-chlororesorcinol as the central unit and various linking groups with different rigidity (benzoate ester, biphenyl, cinnamate, Schiff base and stilbene) in the lengthening arm, aiming to tune the properties of the bent-core nematic (BCN) phase. 
This study raises the question of how much of the rigidity of the lengthening arms can preserve the preferential formation of nematic to lamellar phases. Besides, the position of the lateral chlorine substituent in the central resorcinol unit respect to azobenzene will additionally affect the mesogenic properties of the studied compounds. The compound of series $\mathbf{2 0}$ with the lateral chlorine substituent is located next to the photosensitive azo side arm exhibit SmC-type of phases below the nematic phase (Table 4). For compound $\mathbf{2 0 b}$, the unidentified $S m C_{X}$ phase was found below the nematic phase (Figure 6). In contrast, compounds of series $\mathbf{2 1}$ with the lateral chlorine substituent opposite to the photosensitive azo side arm form only the nematic phase or crystalline, except for the compound $\mathbf{2 1 d}$ (Table 5) [110].

Substituting the $-\mathrm{Cl}$ and $-\mathrm{COOH}$ groups are at position 5 of the central core in the compound 8 results in the formation of compounds 22 . Compound 22a and $22 b$ show the $B_{6}$ and crystalline phases, respectively (Table 6). Their mesomorphic behaviour remained the same even there is the electronegative $-F$ group attaching to the outer ring of azobenzene sidearm (compounds $\mathbf{2 3} \mathbf{a}$ and $\mathbf{2 3 b}$ ). However, the presence of the fluorine atom at the peripheral of the azobenzene reduces the transition temperature of fluorinated compounds [86].

Table 4. Phase transition of compounds of series 20.

\begin{tabular}{|c|c|c|c|}
\hline Compound & $\mathrm{x}$ & L & Phase Transition \\
\hline $20 \mathrm{a}$ & $\mathrm{H}$ & OOC & Iso $92 \mathrm{~N} 64 \mathrm{SmC}_{\mathrm{A}} \mathrm{P}_{\mathrm{A}} 46 \mathrm{Cr}$ \\
\hline $20 \mathrm{~b}$ & $\mathrm{H}$ & $-*$ & Iso $98 \mathrm{~N} 79 \mathrm{SmC} \times 71 \mathrm{Cr}$ \\
\hline 20c & $\mathrm{H}$ & $\mathrm{OOC}-\mathrm{CH}=\mathrm{CH}$ & Iso $107 \mathrm{~N} 70 \mathrm{Cr}$ \\
\hline $20 \mathrm{~d}$ & $\mathrm{OH}$ & $\mathrm{N}=\mathrm{CH}$ & Iso $105 \mathrm{SmC}_{\mathrm{A}} \mathrm{P}_{\mathrm{A}} 64 \mathrm{Cr}$ \\
\hline $20 \mathrm{e}$ & $\mathrm{H}$ & $\mathrm{CH}=\mathrm{CH}$ & Iso $113 \mathrm{~N} 95 \mathrm{SmC}_{\mathrm{A}} \mathrm{P}_{\mathrm{A}} 88 \mathrm{Cr}$ \\
\hline
\end{tabular}

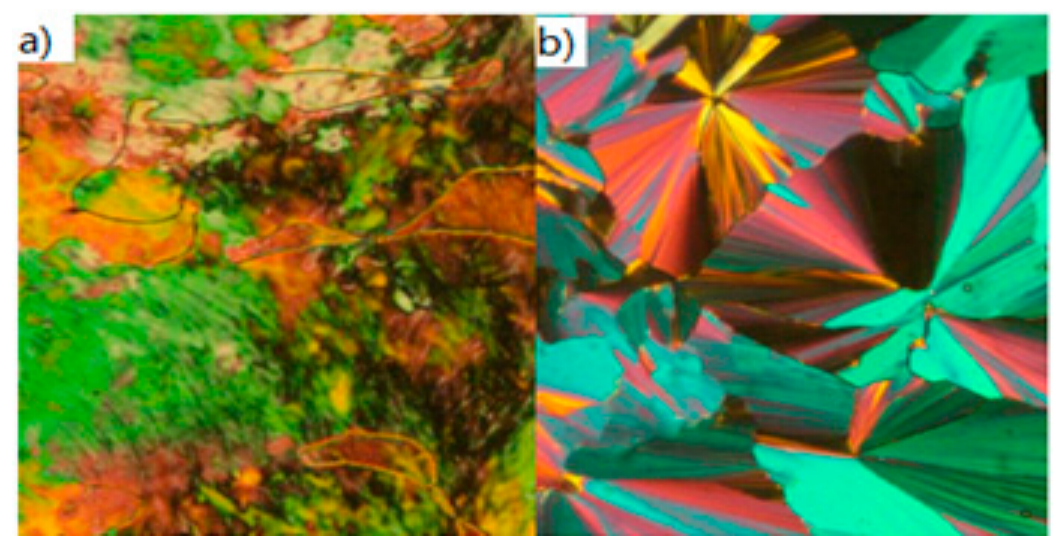

Figure 6. Optical texture for $20 \mathrm{~b}$ in (a) the nematic phase at $\mathrm{T}=90{ }^{\circ} \mathrm{C}$ and (b) the unidentified $\mathrm{SmC}_{\mathrm{x}}$ phase at $\mathrm{T}=75^{\circ} \mathrm{C}$. (Reproduced with permission from ref. [110], copyright Elsevier 2020, https://doi.org/10.1016/j.molliq.2020.112743). 
Table 5. Phase transition of compounds of series 21.

\begin{tabular}{|c|c|c|c|}
\hline Compound & $x$ & L & Phase Transition \\
\hline $21 \mathrm{a}$ & $\mathrm{H}$ & OOC & Iso $97 \mathrm{Cr}$ \\
\hline $21 b$ & $\mathrm{H}$ & $-{ }^{*}$ & Iso $94 \mathrm{~N} 78 \mathrm{Cr}$ \\
\hline 21c & $\mathrm{H}$ & $\mathrm{OOC}-\mathrm{CH}=\mathrm{CH}$ & Iso $110 \mathrm{~N} 83 \mathrm{Cr}$ \\
\hline 21d & $\mathrm{OH}$ & $\mathrm{N}=\mathrm{CH}$ & Iso $113 \mathrm{~N} 110 \mathrm{SmC}_{\mathrm{A}} \mathrm{P}_{\mathrm{A}} 99 \mathrm{Cr}$ \\
\hline 21e & $\mathrm{H}$ & $\mathrm{CH}=\mathrm{CH}$ & Iso $123 \mathrm{Cr}$ \\
\hline
\end{tabular}

Table 6. Phase transition of compounds 22 and 23.

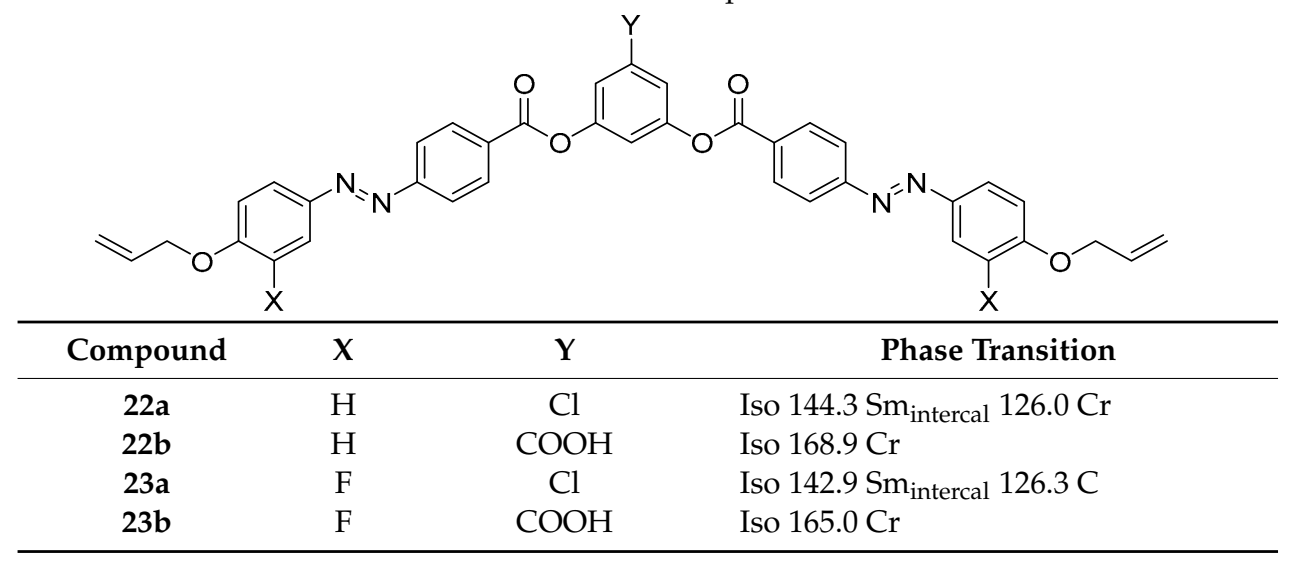

\subsubsection{3-Hydroxybenzaldehyde}

3-Hydroxybenzaldehyde has been used to prepare different asymmetric five-ring containing azobenzene-based BCLCs. Compounds $\mathbf{2 4 b}$ and $24 \mathrm{c}$ are synthesized by lateral substituting $\mathrm{X}=\mathrm{H}$ with the electronegative halogens ( $\mathrm{Cl}$ and $\mathrm{F}$ ) in the compound 24a, respectively. All of them exhibit an enantiotropic $B_{2}$ phase, regardless of the nature of lateral substituents. However, the transition temperatures were affected because the mesophase of compound $\mathbf{2 4 b}$ was found to supercool up to the room temperature [111].

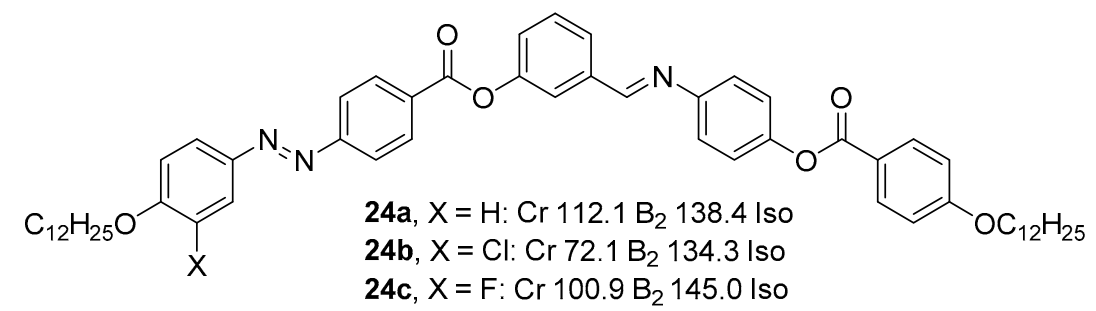

Substituted 3-Hydroxybenzaldehyde

In 2018, Hedge et al. reported achiral bent-core salicylaldimine compounds derived from 2,5-dihydroxybenzaldehyde as the central core, and they are found to exhibit dark conglomerate (DC) and $B_{2}$ mesophases. There are three types of DC phases which are spongy, helical nano-crystalline (HNC) and helical nano-filament (HNF) mesophases [112,113], depending on the local structure and packing density of BCLCs. The DC* phase is characterized by the optically isotropic activity or has little 
birefringence. Therefore, conglomerates of macroscopically chiral domains with opposite handedness can be observed under the polarizing optical microscope (POM). BCLCs exhibiting DC* phases are of significant importance $[92,114]$ because they may be considered as smart materials using in various applications, such as LC phase grating, fibre-optic core and optical waveguides. However, only the spongy phase is electrically switchable among the DC phases. All the homologues of compound $25\left(n=12,14\right.$ and 16) exhibit enantiotropic sponge $\left(\mathrm{DC}_{1}{ }^{*}\right)$ and $\mathrm{HNC}\left(\mathrm{DC}_{2}{ }^{*}\right)$ mesophases, where the existence of the $\mathrm{DC}^{*}$ phase is proven by the presence of chiral domains (Figure 7a-f). When $\mathrm{X}=$ $\mathrm{H}$ is substituted with $\mathrm{F}$ and $\mathrm{Cl}$ in homologue 25a, compound $\mathbf{2 6}$ and $\mathbf{2 7}$ are formed. Compound 26 exhibits both the sponge $\left(\mathrm{DC}_{1}{ }^{*}\right)$ and $\mathrm{HNC}\left(\mathrm{DC}_{2}{ }^{*}\right)$ mesophases as exhibited by homologues 25 , whereas compound 27 shows only a sponge mesophase [115].
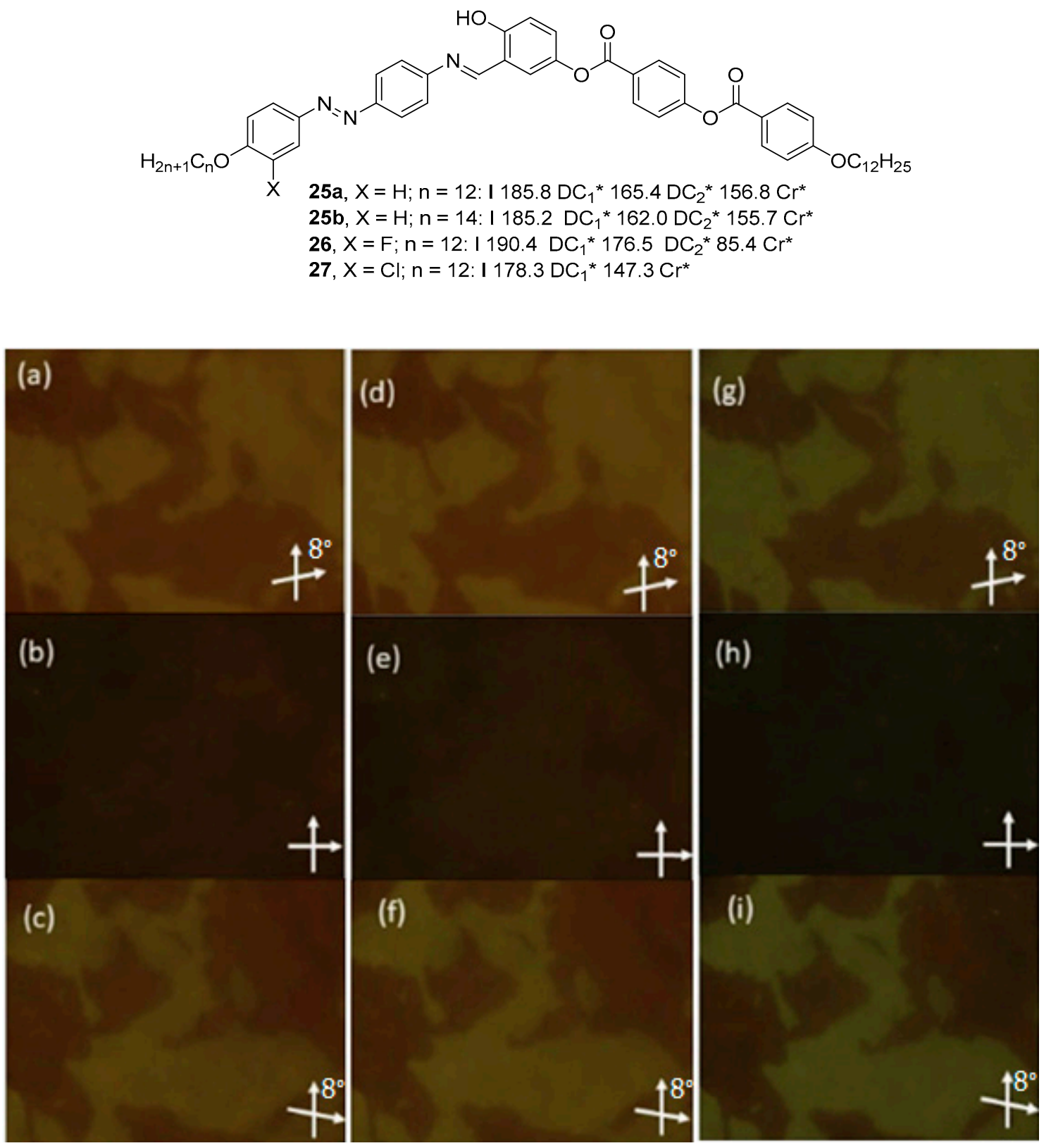

Figure 7. The optical texture of $\mathrm{DC}_{1}{ }^{*}$ obtained for compound $25 \mathbf{b}$ at $170{ }^{\circ} \mathrm{C}:(\mathbf{a}, \mathbf{c})$ between the uncrossed polarizers by an angle of about $8^{\circ}$ and $(\mathbf{b})$ between crossed polarisers; $(\mathbf{d}-\mathbf{f})$ textures $\mathrm{DC}_{2}{ }^{*}$ obtained under the same conditions as observed $(\mathbf{a}-\mathbf{c})$, at $158{ }^{\circ} \mathrm{C} ;(\mathrm{g}-\mathbf{i})$ textures of $\mathrm{Cr}^{*}$ obtained at the room temperature [115]. 
Reversing two arms of compounds 25 results in the formation of compounds 28 ( $n=12,14$ and 16), whereas replacing the ester linkage with azo linkage in one arm of compounds 28 results in the formation of compounds 31 ( $n=12,14$ and 16). Both of the compounds ( 28 and $\mathbf{3 1}$ ) shows a similar trend in their mesomorphic behaviour where they display only the $B_{2}$ mesophase. The $B_{2}$ mesophase is changed to the $\mathrm{DC}_{1}{ }^{*}$ mesophase when $\mathrm{X}=\mathrm{H}$ is replaced by $\mathrm{F}$ ( 29 and 32$)$ and $\mathrm{Cl}$ (30 and 33) atoms. The $\mathrm{DC}_{2}{ }^{*}$ phase that presents in compounds 25 is completely removed in compounds 28 and 31 . An interesting phenomenon has been found in series 25, 28 and 31, where the chirality observed in the mesophases is maintained even in their crystalline form $\left(\mathrm{Cr}^{*}\right.$ phase) (Figure $\left.7 \mathrm{~g}-\mathrm{i}\right)$. Compared to compounds 36 with the salicylaldimine group is present in one of the side arms, series 25, 28 and 31 (the salicylaldimine group is present at the centre of BCLCs) tend to form $\mathrm{DC}^{*}$ mesophase rather than the $B_{2}$ phase, regardless the type of lateral substituent. Besides, compounds of these three series have very high transition temperatures compared to that of $\mathbf{3 6}$ [115].

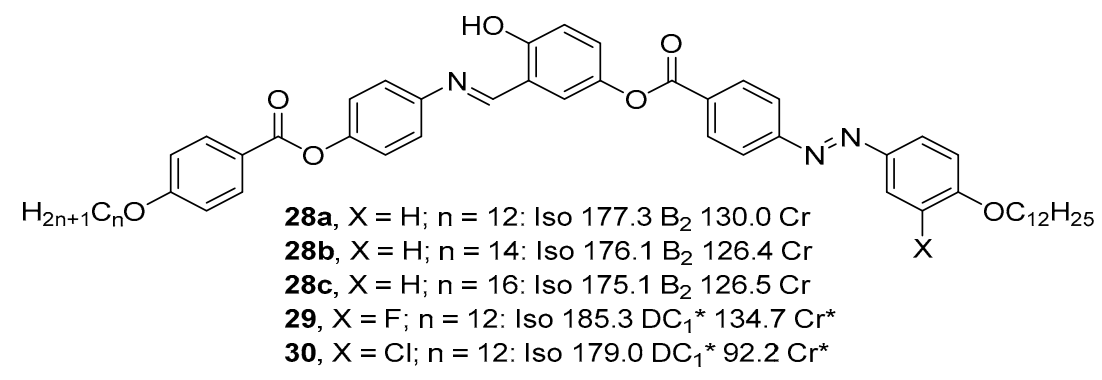

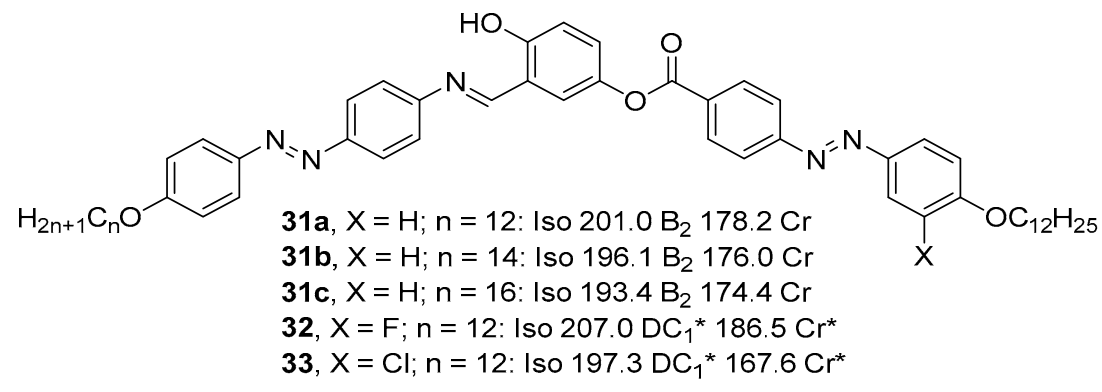

\subsubsection{3-Hydroxybenzoic Acid}

Similar to 3-hydroxybenzaldehyde BU, 3-hydroxybenzoic acid is used to prepare the asymmetric photoresponsive BCLC. The first report about this kind of BCLCs was done by Prasad et al. in 2004 [116]. However, compounds derived from the 3-hydroxybenzoic acid as the BU have been studied much less compared to compounds based on resorcinol. Most of the reported compounds consist of one azo unit in their structures and exhibited a columnar $B_{1}$ phase, a lamellar $B_{2}$ phase or a modulated smectic $B_{7}$-typed mesophases. Compounds with two azo groups do not show the liquid crystalline phase $[57,60]$.

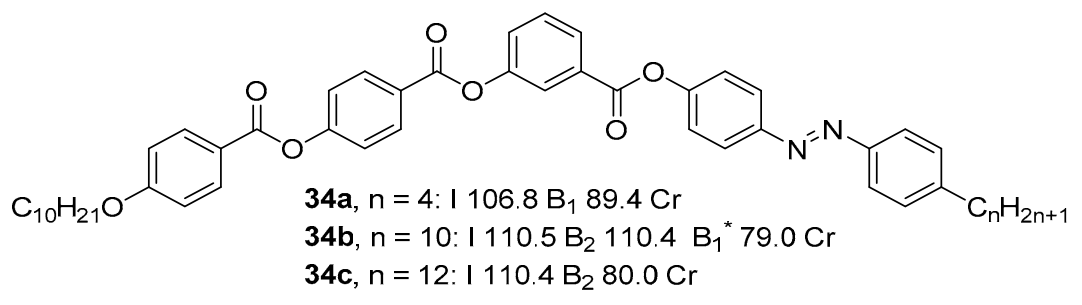




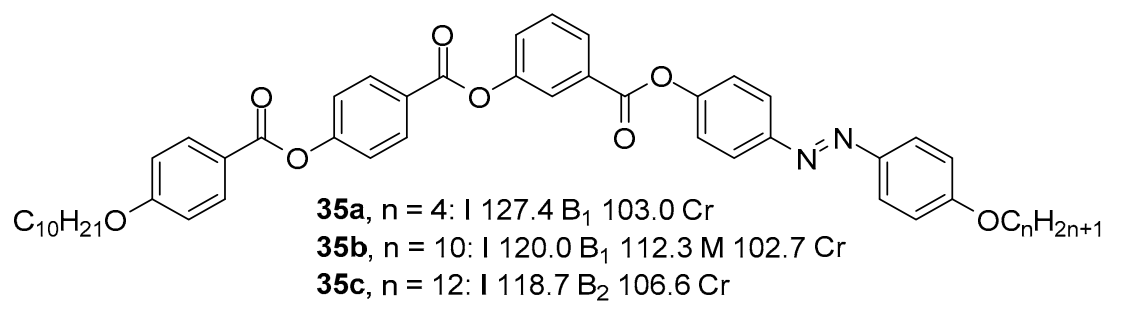

Recently, Hedge et al. had synthesized two series of photosensitive BCLCs based on a slight modification of the previously reported compounds [116]. For both homologue series 34 and $35(n=4$, $6,8,10$ and 12), the length of the terminal chain at one end is remained constant as $n=\mathrm{OC}_{10} \mathrm{H}_{21}$, while the other end is either terminated with the alkyl (34) or alkoxy chain (35). Both of them exhibit a similar trend in which the lower homologues $(n<12)$ show the $\mathrm{B}_{1}$ mesophase, whereas the higher homologues $(n=12)$ exhibit the $B_{2}$ mesophase. In the case of compound $\mathbf{3 5} \mathbf{b}$, an unknown monotropic mesophase $\mathrm{M}$ was observed on cooling from the isotropic phase, in addition to $\mathrm{B}_{1}$ mesophase [117]. The homologues of compounds $36(n=12,14,16)$, wherein one of the side arms of the BCLC bearing with the salicylaldimine group, show only $B_{2}$ mesophase (Figure 8 ). Similar to homologues 36 , both fluorinated (37) and chlorinated (38) compounds exhibit the $B_{2}$ mesophase [115].
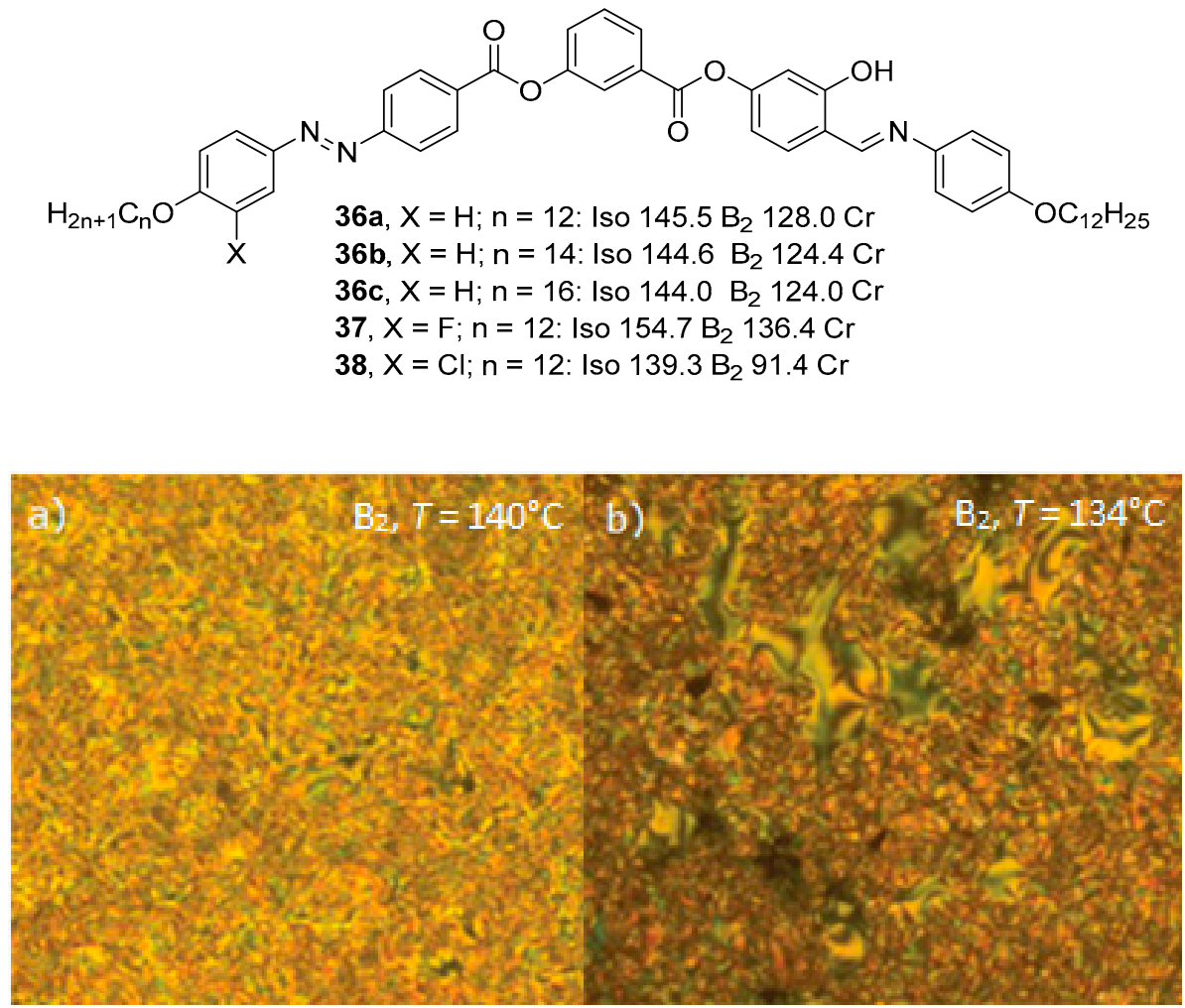

Figure 8. The $\mathrm{B}_{2}$ mesophase observed under the POM for compound (a) $36 \mathbf{c}$ at $\mathrm{T}=140{ }^{\circ} \mathrm{C}$ and $(\mathbf{b}) \mathbf{3 6} \mathbf{b}$ at $\mathrm{T}=134^{\circ} \mathrm{C}[115]$.

Substituted 3-Hydroxybenzoic Acid

Compounds 39 derived from a 4-methyl substituted 3-hydroxybenzoic acid was done by Kohout et al. in 2017. Compound 39a with the lateral $-\mathrm{CH}_{3}$ on the $\mathrm{BU}$ opposite to the azo-bearing sidearm was found to have rich polymorphism. On cooling from the isotropic phase, the nematic phase followed by three synclinic smectic phases $\left(\mathrm{SmC}_{\mathrm{s} 1}, \mathrm{SmC}_{\mathrm{s} 2}\right.$ and $\left.\mathrm{SmC}_{\mathrm{s} 3}\right)$ and a DC phase had been identified (Table 7 and Figure 9). The X-ray diffraction (XRD) result revealed that the DC phase of 39a is different from those of $\mathrm{B}_{4}$ phases and DC sponge phases, but very similar to the recently described new-type of a 
DC phase exhibited by the related 4-methylresorcinol derived BCLCs (Figure 10) [118]. In contrast, reversing the positions of the ester and azo groups in compound 39a causes compound $39 b$ lost the mesomorphic behaviour (Table 7). When the ester linkage is replaced with the azo linkage in the compound 39a or 39b, a compound 39c with the nematic phase appeared above the $\mathrm{SmC}_{\mathrm{s}}$ phase is formed (Table 7). Non-polar character is displayed in both compounds 39a and 39c, although the tilted SmC phase had been identified in their phase sequence [33].

Table 7. Phase transition of compounds 39.
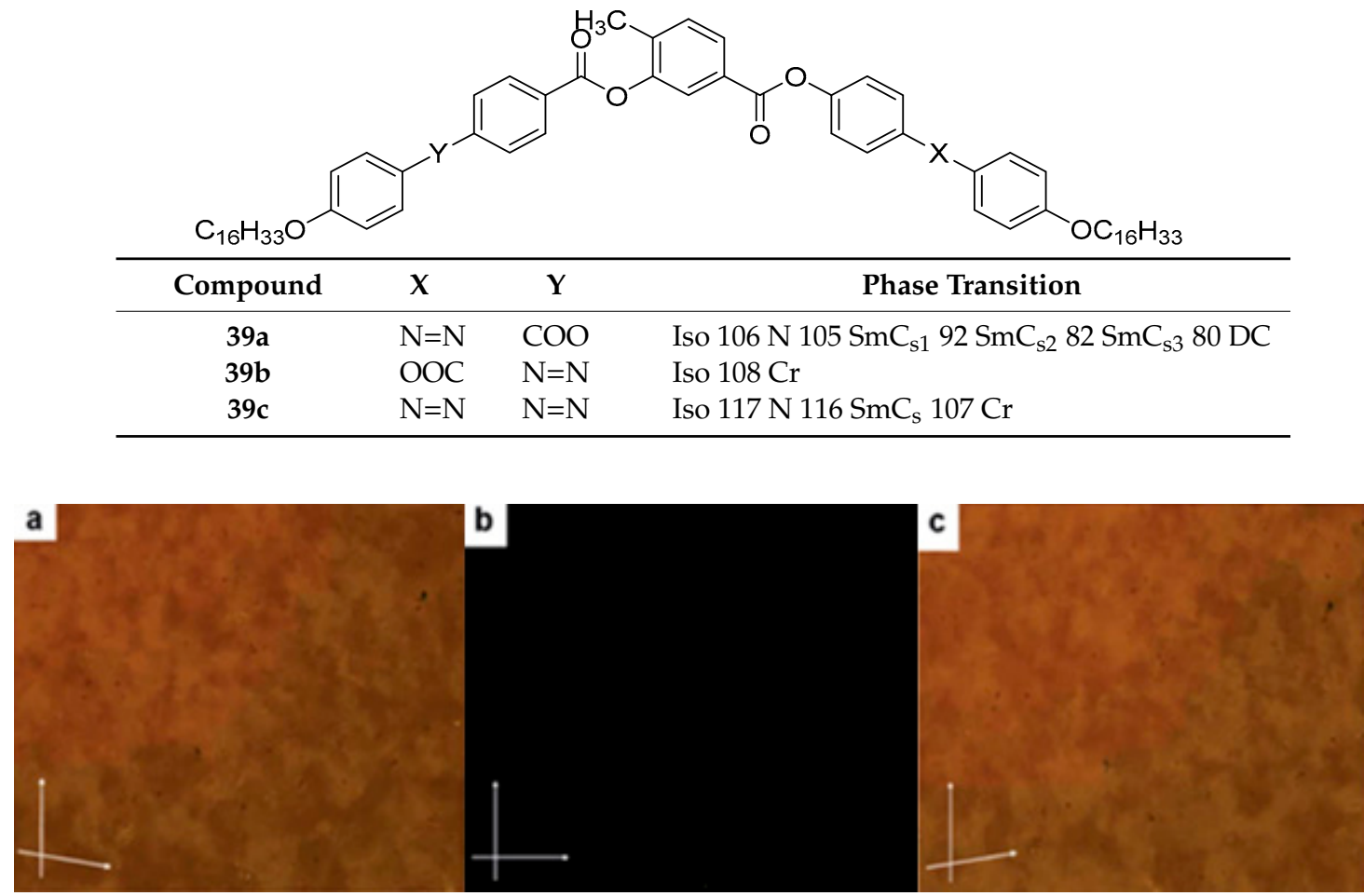

Figure 9. Textures of the DC phase obtained for compound 39a at $\mathrm{T}=50^{\circ} \mathrm{C}(\mathbf{a}, \mathbf{c})$ between the uncrossed polarizers by an angle of $10^{\circ}$ in a clockwise direction and an anticlockwise direction, respectively, and (b) under crossed polarizers. Dark and bright domains represent the presence of chiral domains with opposite handedness. (Reproduced with permission from ref. [33], copyright The Royal Society of Chemistry 2017, https://doi.org/10.1039/C7RA05632J).
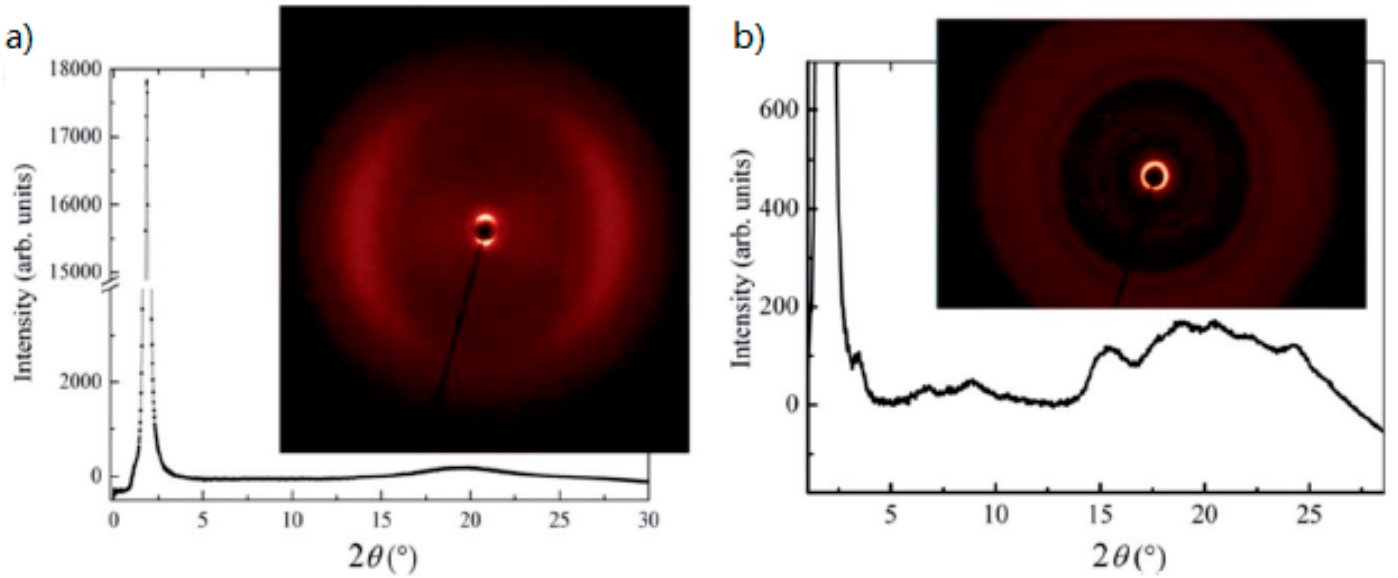

Figure 10. X-ray diffraction (XRD) profile of compound 39a, (a) at $\mathrm{T}=100{ }^{\circ} \mathrm{C}$ in the $\mathrm{SmC}_{\mathrm{S} 1}$ phase and (b) at $\mathrm{T}=70{ }^{\circ} \mathrm{C}$ in the $\mathrm{DC}$ phase. The insets represent the corresponding $2 \mathrm{D} X$-ray pattern at the indicated temperature. (Reproduced with permission from ref. [33], copyright The Royal Society of Chemistry 2017, https://doi.org/10.1039/C7RA05632J). 
Compounds of series 40 , which are the analogues of compounds 39 , are formed when the lateral methyl group is changed to position 6 of 3-hydroxybenzoic acid. They have mesomorphic properties that differ from compounds 39. The $\mathrm{SmC}_{\mathrm{S}}$ phases exhibited by compounds 39 were replaced by either $\mathrm{SmC}_{\mathrm{a}} \mathrm{P}_{\mathrm{A}}$ phases or crystalline phases in series 40. The formation of the $\mathrm{SmC}_{\mathrm{a}} \mathrm{P}_{\mathrm{A}}$ phase in compound $40 \mathrm{~b}$ is probably due to the preferred bent shape of the compound. For compound 40a and 40c, the non-mesomorphic behaviour can be explained by the limited flexibility of the azo-bearing side-chain next to the lateral substituent [33].

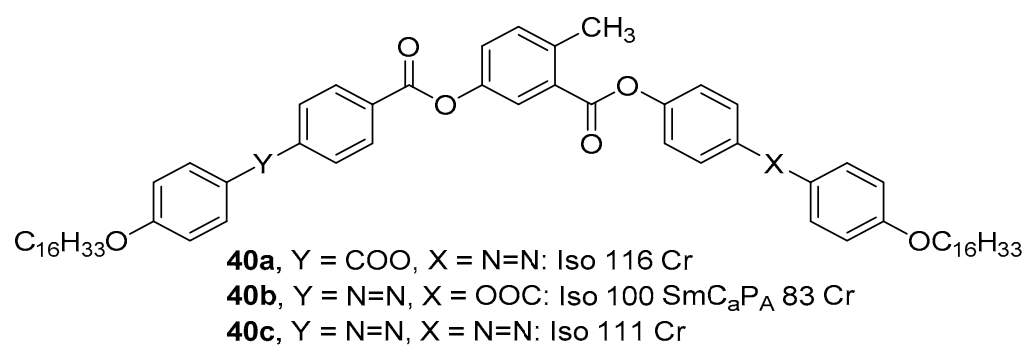

Replacing the methyl group at the central unit in the compound $39 \mathrm{~b}$ with the fluorine atom leads to the formation of compound 41. Instead of using the longer alkoxy chain $-\mathrm{OC}_{16} \mathrm{H}_{33}$ as the terminal end chain, the shorter alkoxy chain where $n=8$ is used. The DSC result shows the nematic phase and the low-temperature smectic phase (SmX) on the cooling cycle [119].

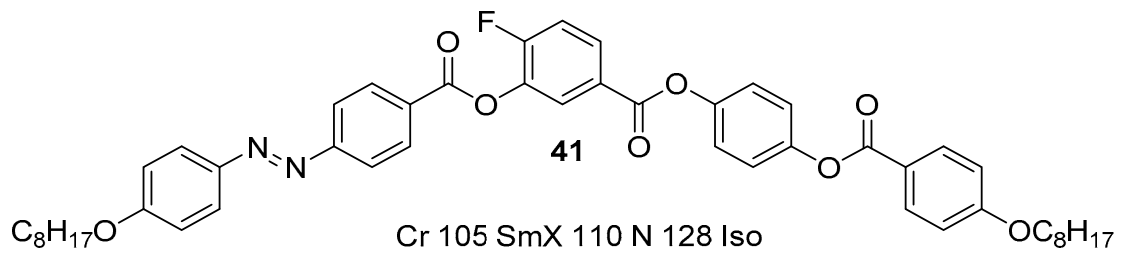

\subsubsection{Substituted 3-Nitrobenzoic Acid}

Several examples of asymmetric azobenzene based BCLCs with five rings derived from substituted 3-nitrobenzoic acid have been reported. In 2017, Prasad et al. reported some photoswitchable BCLCs with five rings incorporating 2-methyl-3-nitrobenzoic acid as the central unit. It was a continuation of the previous work [87] where the earlier synthesized compounds that consisted of $-\mathrm{CH}=\mathrm{N}-$ linkages are found to have too high transition temperature, which is unsuitable for physical studies. The higher homologues of compounds 42 , where $n>10$ exhibited enantiotropic nematic phase and two unidentified $\mathrm{SmX}_{1}$ and $\mathrm{Sm} \mathrm{X}_{2}$ phases (Figure 11). However, the transition temperatures of these compounds were still very high (Table 8$)$ [120].

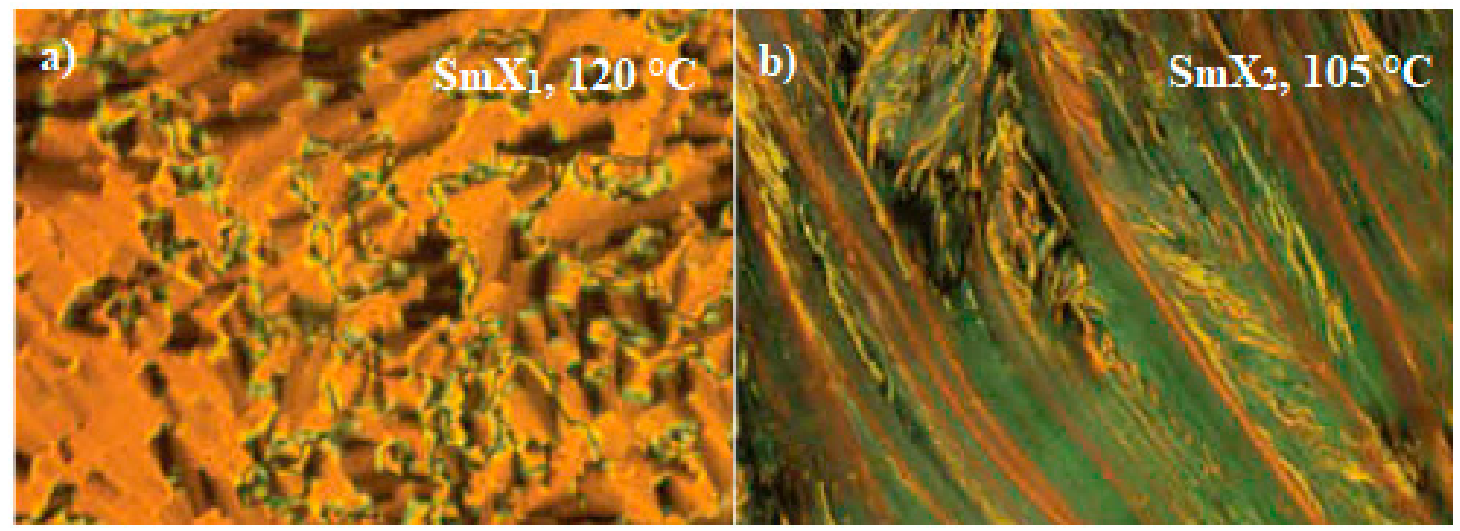

Figure 11. POM textures of compound 42c obtained on cooling from the isotropic: (a) the unidentified $\mathrm{SmX}_{1}$ phase at $\mathrm{T}=120^{\circ} \mathrm{C}$ and $(\mathbf{b})$ the unidentified $\mathrm{SmX}_{2}$ phase at $\mathrm{T}=105^{\circ} \mathrm{C}$ [120]. 
Table 8. Phase transition of compounds 42.

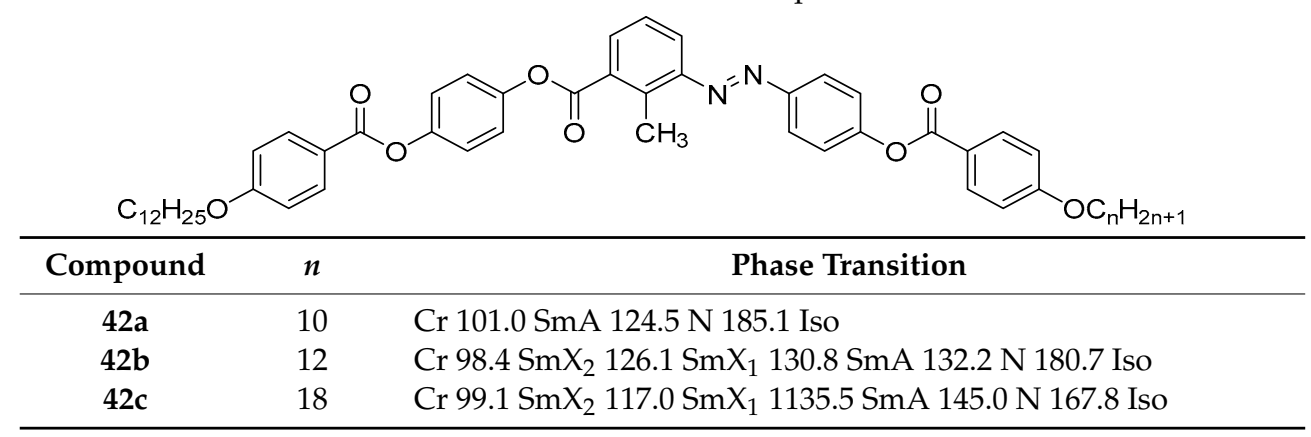

The homologues of compounds 43 and $44(n=10,12,14,16,18)$ were synthesized when one of the arms of compounds 42 is substituted with the lateral methyl group at ortho and meta position with respect to the $-\mathrm{N}=\mathrm{N}-$ unit, respectively. The introduction of lateral substituent decreases the isotropic temperature of series $\mathbf{4 3}$ and $\mathbf{4 4}$ compared to series $\mathbf{4 2}$ (see Tables 8 and 9). The presence of the lateral $-\mathrm{CH}_{3}$ group at the ortho position in homologues of compounds 43 removed the Sm mesophases entirely. For the homologues of 44 , the Sm mesophases are suppressed to some extent but not entirely (Table 9) [120].

Table 9. Phase transition of compounds 43 and 44.

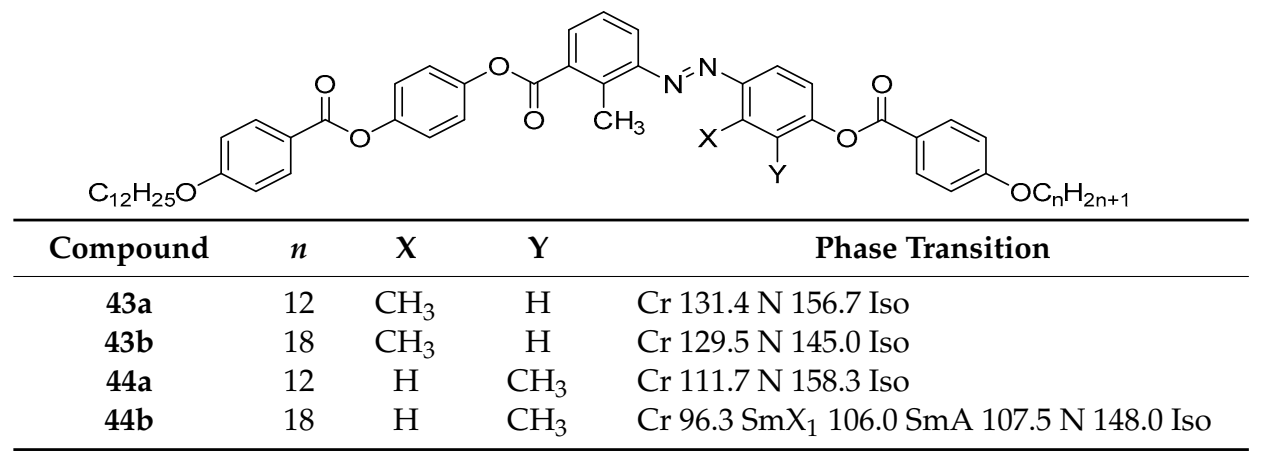

Replacing the lateral $-\mathrm{CH}_{3}$ group with $-\mathrm{Cl}$ group in compounds 43 and 44 results in the formation of compounds 45 and 46, respectively. The homologues of compounds 45 , where $n=10,12,14,16,18$, show the enantiotropic nematic phase, except for the highest homologue $45 \mathrm{~b}$ that has an additional monotropic SmA phase below the nematic phase. In the case of compounds 46 , the phase sequence during the cooling cycle is isotropic-nematic-SmA-SmX $-S m X_{2}$-crystalline phase (Table 10). It can be concluded that the lateral ortho substituents with respect to $-\mathrm{N}=\mathrm{N}-$ stabilize the nematic phase, whereas the lateral meta substituents induce the formation of both the Sm phase and the nematic phase. However, none of these compounds are found to be electrically switchable although they exhibit the nematic phase and some hidden Sm phases [120]. 
Table 10. Phase transition of compounds 45 and 46.

\begin{tabular}{|c|c|c|c|c|}
\hline Compound & $n$ & $X$ & $\mathbf{Y}$ & Phase Transition \\
\hline $45 a$ & 12 & $\mathrm{Cl}$ & $\mathrm{H}$ & Iso $149.0 \mathrm{~N} 114.4 \mathrm{Cr}$ \\
\hline $45 b$ & 18 & $\mathrm{Cl}$ & $\mathrm{H}$ & Iso $139.0 \mathrm{~N} 115.4 \mathrm{SmA} 112.3 \mathrm{Cr}$ \\
\hline $46 a$ & 12 & $\mathrm{H}$ & $\mathrm{Cl}$ & Iso $160.4 \mathrm{~N} 106.7 \mathrm{SmA} 101.0 \mathrm{SmX}_{2} 93.0 \mathrm{Cr}$ \\
\hline $46 b$ & 18 & $\mathrm{H}$ & $\mathrm{Cl}$ & $\begin{array}{l}\text { Iso } 149.0 \mathrm{~N} 119.3 \mathrm{SmA} 111.8 \mathrm{SmX}_{1} 96.4 \\
\mathrm{SmX}_{2} 91.0 \mathrm{Cr}\end{array}$ \\
\hline
\end{tabular}

When the $\mathrm{Cl}$ group in the shortest homologue of compound $45(n=10)$ is changed to the highly electronegative -F group, the BCLC 47 that exhibits ferroelectric $\mathrm{N}_{\text {cybC }}$ and ferrielectric SmC phases are formed. It is worth noting that both electrically switchable nematic and smectic mesophases are found to exist in the same compound for the first time. The formation of the field-induced ferrielectric smectic mesophase is proved by the texture observed under the POM (Figure 12) as well as the appearance of three polarization current peaks for each half cycle at high voltage ( $35 \mathrm{~V}_{\mathrm{pp}} \mu_{\mathrm{m}}^{-1}$ ) (Figure $13 \mathrm{~b}$ ). A proposed model for the occurrence of the ferrielectric state and possible switching mechanism in this state is displayed in Figure 13a. Such ferroelectric $\mathrm{N}_{\mathrm{cybC}}$ and ferrielectric SmC mesophases are of significant interest as they could open a new route in electro-optical devices [121].

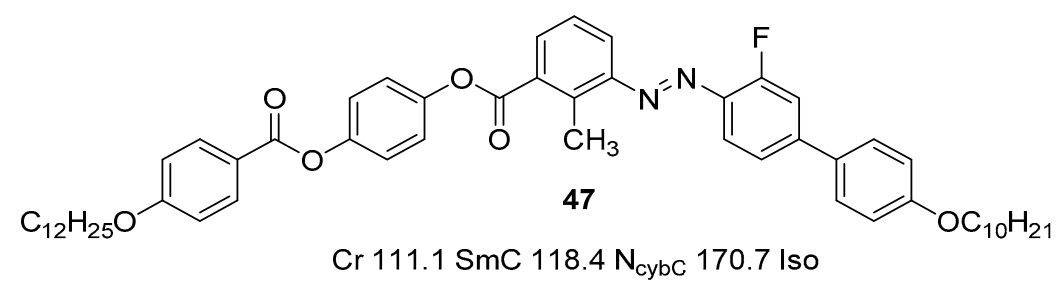
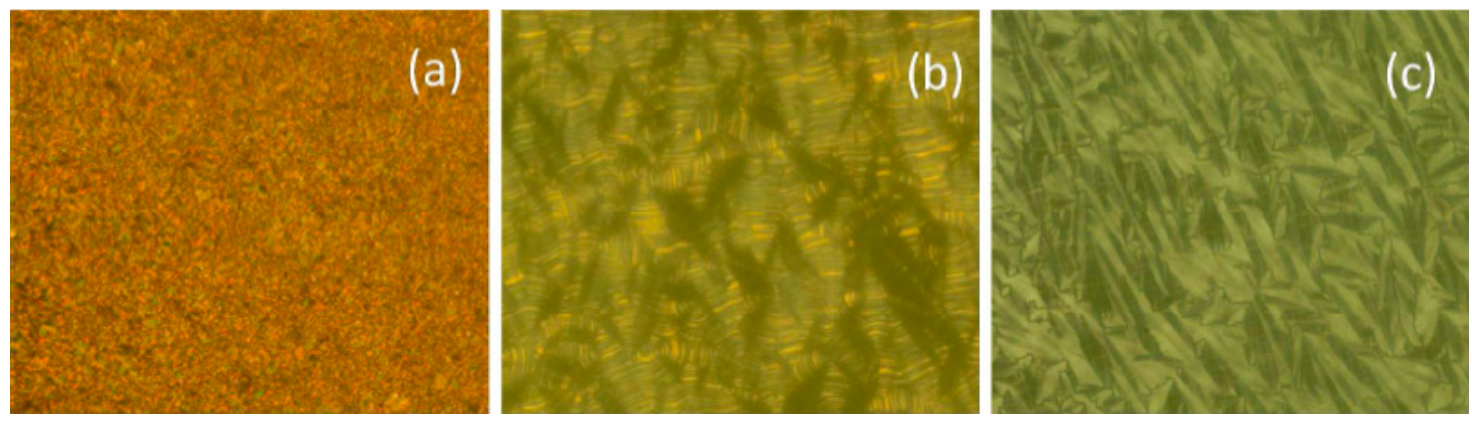

Figure 12. Changes in the texture of the smectic phase in compound 47 observed under a triangular wave at $\mathrm{T}=110{ }^{\circ} \mathrm{C}$ with increasing voltage from (a) $0 \mathrm{~V}_{\mathrm{pp}} \mu \mathrm{m}^{-1}$, (b) $30 \mathrm{~V}_{\mathrm{pp}} \mu^{-1}$ to (c) $35 \mathrm{~V}_{\mathrm{pp}}$ $\mu \mathrm{m}^{-1}$. (Reproduced with permission from ref. [121], copyright American Chemical Society 2018, https://doi.org/10.1021/acs.jpcb.7b11733). 

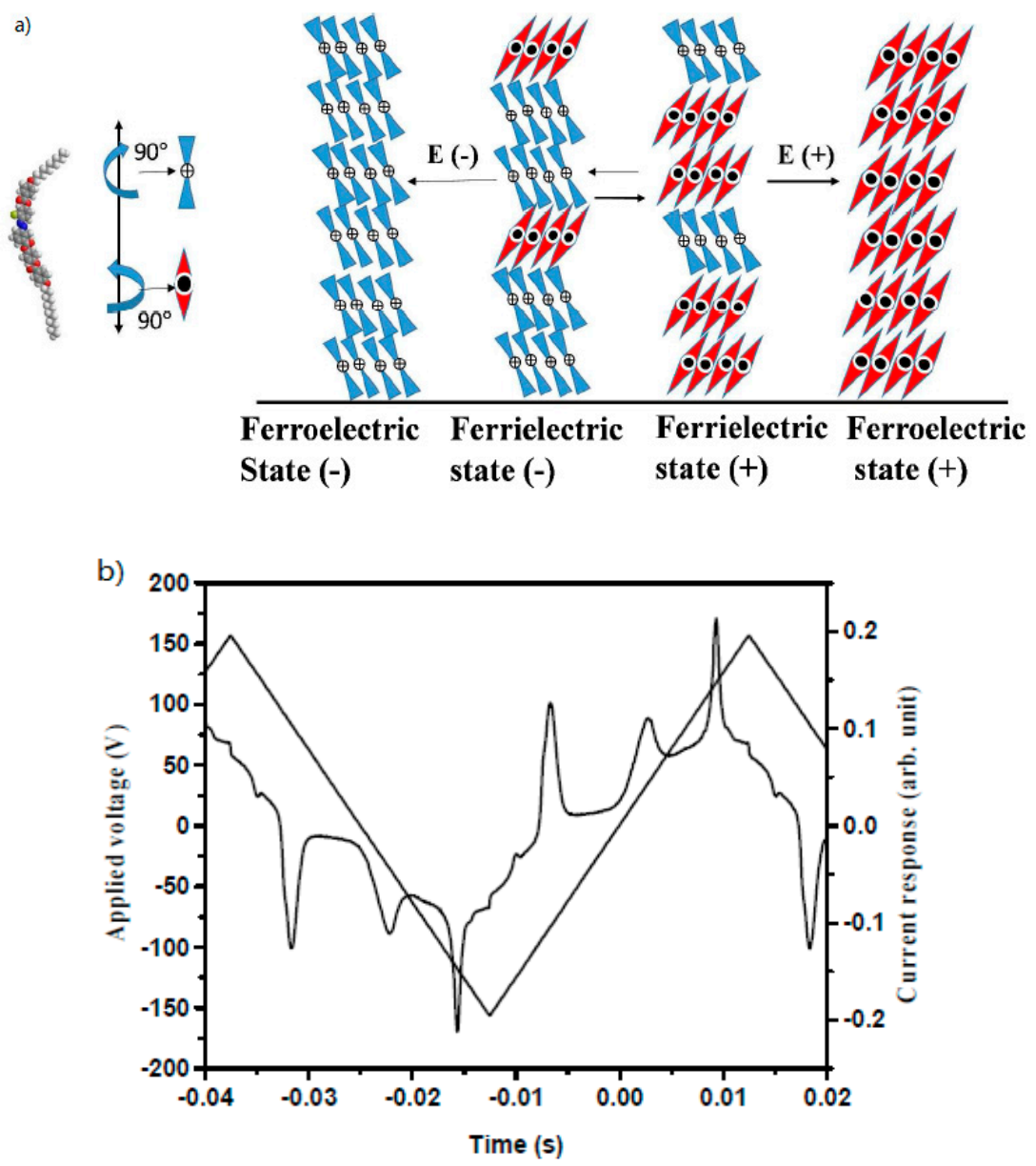

Figure 13. Layout diagram of (a) molecular organization of the layers and possible switching mechanism in ferrielectric state with increasing voltage as follows: Ferroelectric $(-) \rightarrow$ Ferrielectric $(-) \rightarrow$ Ferrielectric $(+) \rightarrow$ Ferroelectric $(+)$ and $(\mathbf{b})$ switching current response of compound 47 in the SmC phase at $\mathrm{T}=110^{\circ} \mathrm{C}$ under the high voltage of $35 \mathrm{~V}_{\mathrm{pp}} \mu \mathrm{m}^{-1}$. (Reproduced with permission from ref. [121], copyright American Chemical Society 2018, https://doi.org/10.1021/acs.jpcb.7b11733).

\subsubsection{Other Aromatic Bent-Core Units}

Some other aromatic bent-core units are also used to synthesized azobenzene containing BCLCs, such as 2,7-dihydroxynaphthalene and 4-chloro-1,3-dinitrobenzene. For example, naphthalene based BCLC monomers incorporated with azobenzene units terminated with double bonds had been investigated by Lutfor et al. All homologues of compounds $48(n=3-9)$ display the enantiotropic $\mathrm{B}_{6}$ phases, except for shorter homologues with $n=1$ and 2 that exhibit the nematic phase (Figure 14). The transition temperature decreases as the length of alkyl chains increases, which is in accordance with previous studies. Besides, the odd-even number of alkyl chains is also an effect on the isotropic temperature of compounds $\mathbf{4 8}$. Compounds $\mathbf{4 8}$ with the even number of alkyl carbon have a higher transition temperature than that of the odd number of the alkyl carbon chain [122-124]. Substituting the fluorine atom at the periphery of the material 48a is results in the formation of compound 49 . The fluorinated compound has a similar phase sequence as the monomer 48a but with the reduced phase transition temperature [123]. 


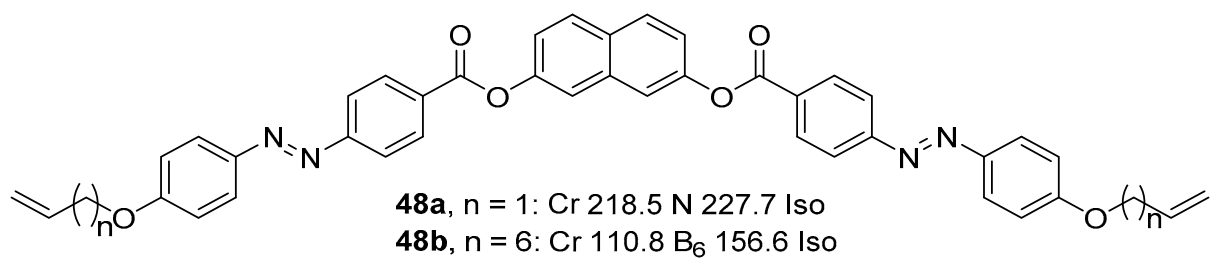<smiles>C=CCOc1ccc(N=NNc2ccc(C(=O)Oc3ccc4ccc(OC(=O)c5ccc(N=Nc6ccc(OCC=C)c(F)c6)cc5)cc4c3)cc2)cc1F</smiles>

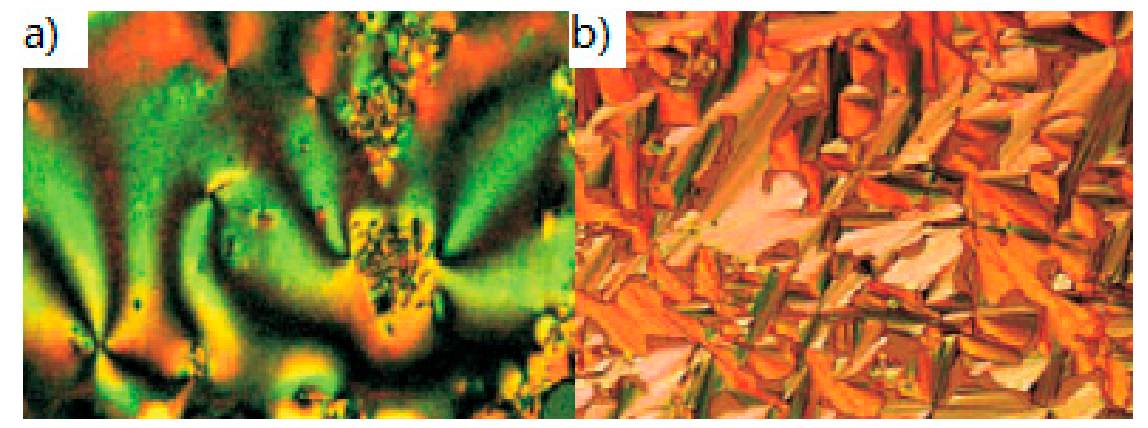

Figure 14. Optical textures taken for (a) compound 48a in the nematic phase at $\mathrm{T}=155{ }^{\circ} \mathrm{C}$ and (b) compound $48 \mathrm{~b}$ in the $\mathrm{B}_{6}$ phase at $\mathrm{T}=142{ }^{\circ} \mathrm{C}$ (Reproduced with permission from ref. [122], copyright John Wiley and Sons 2014, https://doi.org/10.1002/jccs.201300191).

Bajzikova et al. reported BCLCs possessing the 2,7-dihydroxynaphthalene as the central core unit and different aromatic units at one of the terminal ends, aiming to enhance nanosegregation. The results show that the alkyl chain length between the rigid core and the terminal aromatic moiety bring a remarkable effect on the mesomorphic behaviour. The shorter homologue 50a $(n=1)$ showed only the nematic phase, whereas the longer homologue $50 \mathrm{~b}(n=8)$ exhibited the $\mathrm{B}_{1 \mathrm{Rev}}$ phase in addition to the nematic phase [125]. $B_{1 \text { Rev }}$ phase is different from the conventional columnar phase $\left(B_{1}\right)$ phase in terms of the electro-optical response, where the $B_{1 \operatorname{Rev}}$ phase is usually responsive to an applied electric field [24]. When the phenyl ring in the compound 50b is replaced with a thiophene (Th) unit, compound $\mathbf{5 1}$ with the nematic phase is observed. Compounds end-capped with a reactive aromatic/appropriately substituted aromatic group can be used to prepare new types of metallic nanoparticles grafted with organometallic mesogenic ligands in the future [125-128].

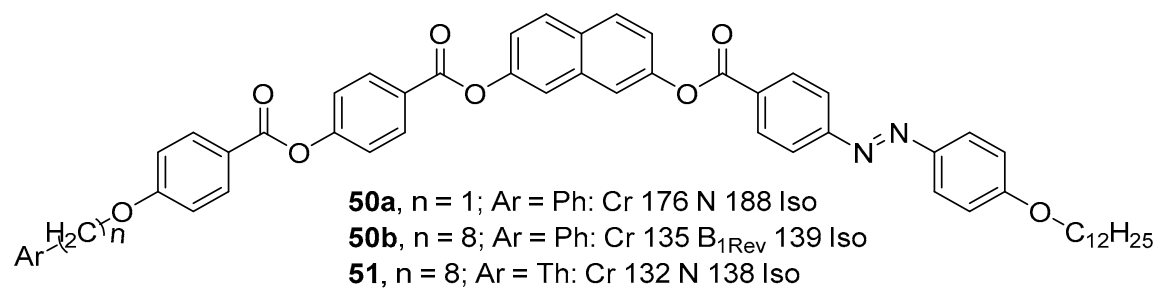

The first study of BCLCs containing two azo units as direct linkages to connect the BU with sidearms was reported by in 2020 by Lu et al. [129]. Previous studies suggest that swapping the position of the azo linker within the sidearm with the ester group of BU does not bring meaningful impact on the mesophase. Moreover, bringing the azo unit close to the BU can even suppress the development of mesophases $[69,130]$. However, these studies only focused on the impact of changing one azo linkage 
with the ester linkage and did not examine the situation of connecting two azo units directly to the BU. Therefore, Lu et al. synthesized the homologues of compounds $52(n=5-12)$ by using the azo linkages to connect the central unit, a 4-chloro-1,3-dinitrobenzene, to the ester-containing sidearms terminated with alkyl groups. This study revealed that compounds $\mathbf{5 2}$ give the lower melting points and broader temperature range of the nematic phase compared to the majority of BCLCs that utilize azo and ester units as linkers within sidearms and direct linkers of BU, respectively. This phenomenon happened because the azo units presented at BU can greatly reduce the electrostatic interactions, which is a controlling factor of mesomorphic properties, especially for the nematic phase. Generally, the phase transition temperatures decreased as the alkyl chain length increased, except for the Sm-N transition [129].

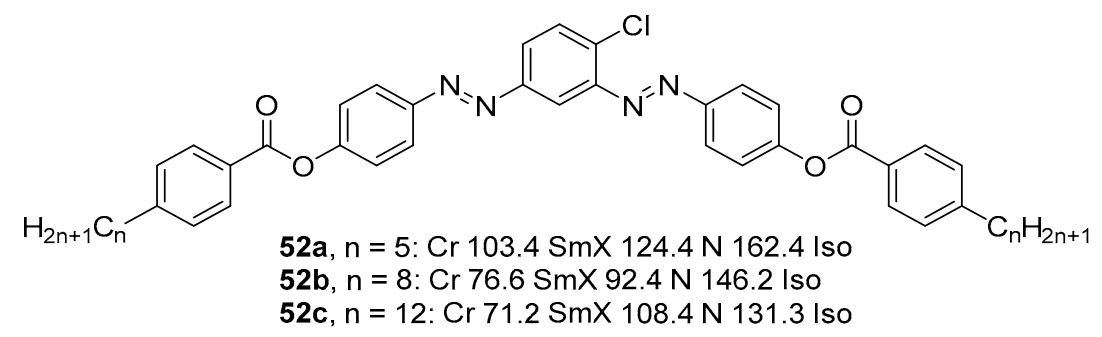

\subsubsection{Heterocyclic Core Unit}

Azobenzene containing bent-core mesogens derived from a heterocyclic core unit is rare. Lutfor et al. reported BCLC monomers $\mathbf{5 3}$ with a 2,6-pyrimidinediol as the BU connecting with the azobenzene-based sidearms terminated with the polymerizable double bond. The shorter homologues 53 ( $n=1$ and 2) do not show mesomorphic behaviour, whereas the longer homologues with $n=3,4$, 5 and 6 display the enantiotropic $\mathrm{B}_{6}$ phase. However, there is an additional $\mathrm{Cr}_{2}$ phase above the $\mathrm{Cr}_{1}$ phase for homologues with an even number of alkyl chains $(n=4$ and 6) [131].

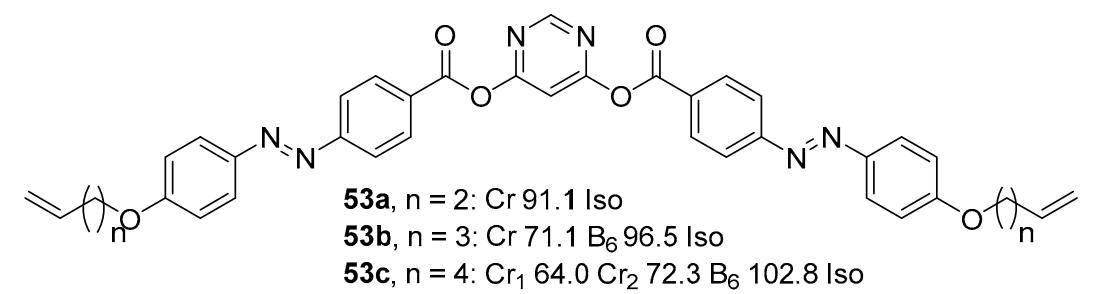

\subsection{V-Shaped BCLCS}

Almost all of the above-discussed BCLCs have a bent angle of approximately $120^{\circ}$ because such angle appears to be a fundamental condition to design the bent-core mesogens. Previously, it was reported that those with bending angles considerably smaller or larger than $120^{\circ}$ form conventional calamitic mesophases such as nematic or smectic phases [111,132]. Later, such compounds are also reported to exhibit banana phases. For example, previous studies reported that some of the V-shaped mesogens derived from the 1,7-naphthalene central core display hexagonal columnar $\left(\mathrm{Col}_{h}\right)$ and $\mathrm{B}_{4}[133,134], \mathrm{B}_{2}$ and $\mathrm{B}_{7}$ [135], cubic [136] and polar switchable SmA mesophases [132].

Hedge et al. reported the first example of a V-shaped compound (54) displaying a conversion from the isotropic phase to a polar biaxial smectic $\mathrm{A}$ phase $\left(\mathrm{SmAP}_{\mathrm{A}}\right)$ directly without having any other mesophase (Table 11). This compound is the first V-shaped compound where the $\mathrm{SmAP}_{\mathrm{A}}$ phase has been characterized thoroughly, owing to the reasonably low transition temperature. Besides, Hedge et al. also presented the first example of the V-shaped mesogen (56) showing the enantiotropic $\mathrm{B}_{5}$ phase. For compound 56 , the $\mathrm{XRD}$ result shows three reflections in the small-angle region with layer spacings of $32.98,16.46$ and $10.97 \AA$ and a diffuse peak in the wide-angle regions. Plus, two extra peaks emerged in the wide-angle region, overlapped by the broad diffuse maxima representing an additional 
in-plane order which is a characteristic feature of a $\mathrm{B}_{5}$ phase, having no correlation between the layers (Figure 15). The chloro substituted V-shaped compound (55) exhibits the monotropic mesophase that is unable to be characterized due to its metastability [111].

Table 11. Phase transition of V-shaped compounds 54-56.
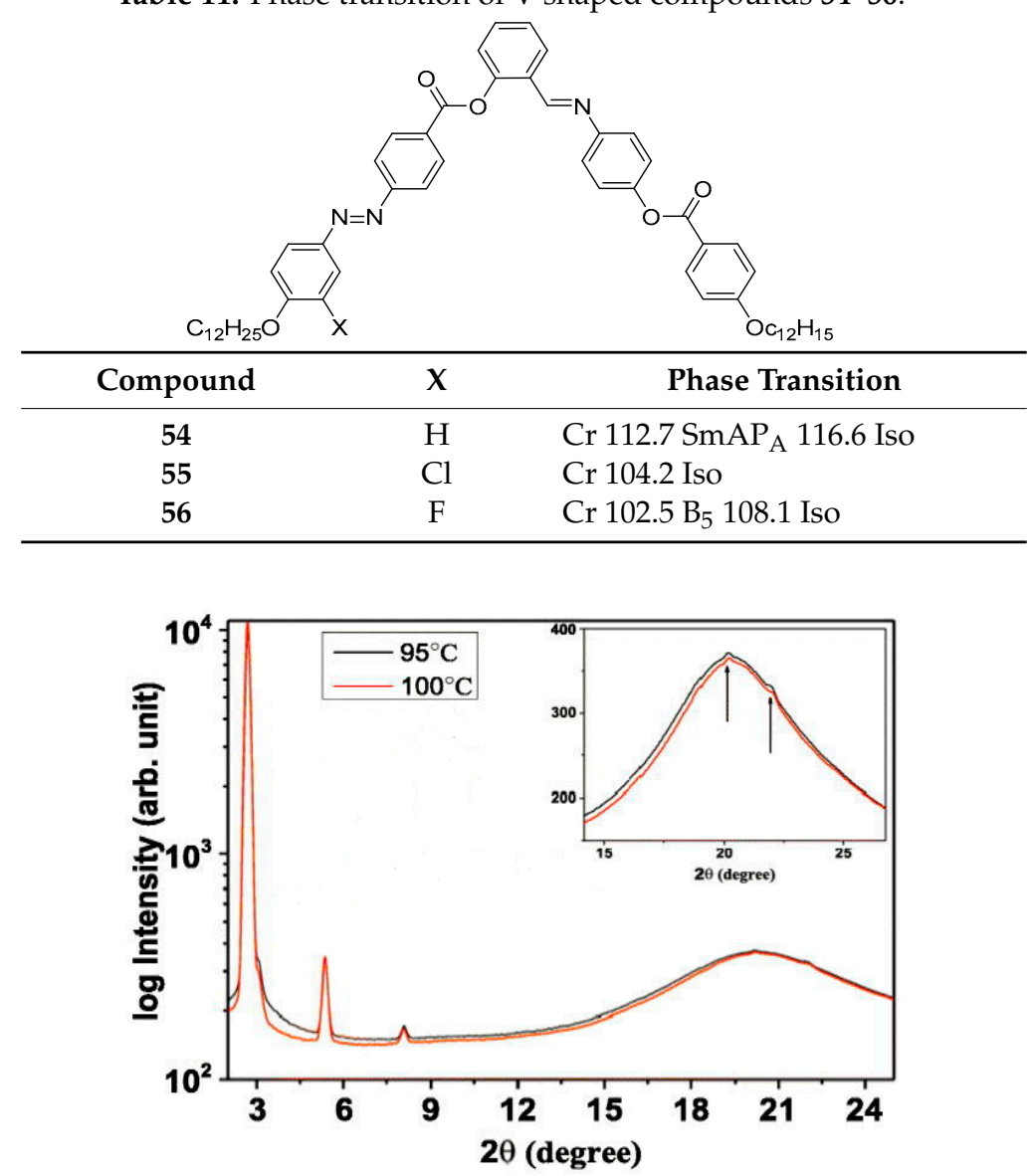

Figure 15. XRD profile of compound 56 at $95{ }^{\circ} \mathrm{C}$ and $100{ }^{\circ} \mathrm{C}$. The inset represents the enlarged area of the wide-angle. (Reproduced with permission from ref. [111], copyright Elsevier 2018, https://doi.org/10.1016/j.molliq.2017.11.024).

\subsection{Hockey-Sick Molecules}

A borderline category of molecular structure between bent-core mesogens and linear rod-like (calamitic) molecules, which is termed as "hockey-stick" molecules, have gained considerable attention in recent years, to understand how spatial correlations of shape-anisometric molecules leading to the novel phase structure formation [137-139]. Hockey-stick liquid crystals (HSLCs) are the asymmetric molecules where the lengths of two side arms of the bent mesogen are not equal [93]. There are two types of HSLCs, as they have been introduced in Section 2. All of the discussed HSLCs in this section belong to the second type of hockey-stick molecules. Although the majority of the reported HSLCs form non-switchable nematic and smectic phases [69,140-143], some of them still can preserve traits of BCLCs, such as the response to the electric field [144-146]. Incorporating hockey-stick molecules with functionalized azobenzene unit is of great interest due to the photosensitivity of azobenzene.

Khan et al. reported BCLCs with four aromatic rings linked by imine, ester and azo units [147]. Inserting the lateral -OH group into the molecular structure along with the terminal polar end group $\left(-\mathrm{F},-\mathrm{Cl}\right.$ and $\left.-\mathrm{NO}_{2}\right)$ in one of the sidearms generated compounds 57 to 59 . The fluoro-substituted compound 57 exhibits the enantiotropic nematic phase, whereas the chloro- (58a) and nitro-substituted (59a) compounds show the smectic phase as well as the nematic phase. The clearing temperature and mesomorphic range of these compounds are varied, relying on the electron-withdrawing ability of 
the polar terminus [147]. The homologue of chloro-substituted compounds (58b) is found to have the cybotactic nematic phase $\left(\mathrm{N}_{\mathrm{Cyb}}\right)$ with no ferroelectric property, whereas the nitro-substituted compound $59 \mathrm{~b}$ has a wide range of SmA phase, but no nematic phase is identified in the phase sequence [148]. According to the study of Khan et al., it is clear that the polar end terminus affects the elastic properties of BCLC, which is the crucial parameter to determine the threshold voltage and sensitivity of electro-optical devices. The compound $\mathbf{5 7}$ has the splay elastic constant $\left(\mathrm{K}_{11}\right)$ more significant than the bend elastic constant $\left(\mathrm{K}_{33}\right)$ as observed in most bent-core nematics, while the other two compounds have $K_{33}>K_{11}$ which is similar to rod-like LCs [147]. The negative elastic anisotropy $\left(\mathrm{K}_{33}-\mathrm{K}_{11}\right)$ of the compound $57 \mathrm{a}$ was later turned to positive by doping with the ferroelectric nanoparticle, $\mathrm{BaTiO}_{3}[149]$.<smiles>CCCCCCCOc1ccc(/C=N/c2cccc(C(=O)Oc3ccc(/N=N/c4ccc(F)cc4)cc3)c2C)c(O)c1</smiles><smiles>COc1ccc(/C=N/c2cccc(C(=O)Oc3ccc(N=Nc4ccc(Cl)cc4)cc3)c2C)c(O)c1</smiles><smiles>CCOc1ccc(/C=N/c2cccc(C(=O)Oc3ccc(/N=N/c4ccc([N+](=O)[O-])cc4)cc3)c2C)c(O)c1</smiles>

Changing the polar moiety to non-polar methyl moiety in compound $58 \mathrm{~b}$ leads to compound $\mathbf{6 0}$ that shows $\mathrm{N}_{\text {Cyb }}$ phases. Similar to compound $\mathbf{5 8 b}$, the $\mathrm{N}_{\mathrm{Cyb}}$ phase of this compound does not show the ferroelectricity [148]. This result is against the previous studies where the $\mathrm{N}_{\text {Cybc }}$ clusters show a ferroelectric-like response in the presence of an external stimulus [150,151].<smiles>CCCCCCCOc1ccc(/C=N/c2cccc(C(=O)Oc3ccc(/N=N/c4ccc(C)cc4)cc3)c2C)c(O)c1</smiles>

When both terminal ends attached to the alkoxy chain, the compound $\mathbf{6 1}$ with SmA and $\mathrm{N}_{\mathrm{cybC}}$ phases is formed. Singh et al. had studied the mechanism of phase transition at the molecular level via the combination of temperature-dependent Fourier transform infrared spectroscopy (FTIR) and density-functional theory (DFT) approach. The results obtained from the spectral analysis of certain functional groups' vibrational bands $\left(\mathrm{OH}, \mathrm{CH}_{2} / \mathrm{CH}_{3}, \mathrm{C}=\mathrm{O}\right.$ and $\left.\mathrm{C}=\mathrm{N}\right)$ reveal the occurrence of $\mathrm{Cr}$ to the SmA phase transition at $125^{\circ} \mathrm{C}$ [152]. 


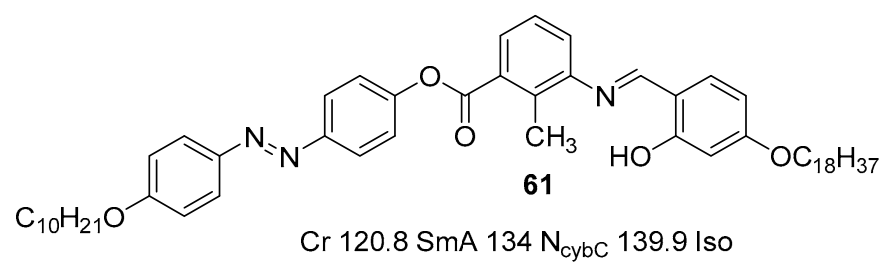

Lateral substituting the $-\mathrm{Cl}$ group on the azobenzene in compounds 58 leads to two series of compounds (62 and 63). All the compounds demonstrate the nematic phase, except for compound $63 \mathrm{~b}$ that exhibits a short-range monotropic SmA phase in addition to the N phase (Table 12). Compounds 63 are found to have supergelation ability which can be used for versatile applications such as photonics, electronic and optoelectronic devices [153].

Table 12. Phase transition of compounds 62 and 63.

\begin{tabular}{ccccl}
$\mathbf{X}$ & $\mathbf{Y}$ & \multicolumn{1}{c}{ Phase Transition } \\
\hline $\mathbf{6 2 a}$ & 4 & $\mathrm{Cl}$ & $\mathrm{H}$ & Iso $147.9 \mathrm{~N} 79.7 \mathrm{Cr}$ \\
$\mathbf{6 2 b}$ & 12 & $\mathrm{Cl}$ & $\mathrm{H}$ & Iso $110.6 \mathrm{~N} 86.0 \mathrm{Cr}$ \\
$\mathbf{6 3 a}$ & 4 & $\mathrm{H}$ & $\mathrm{Cl}$ & Iso $140.3 \mathrm{~N} 97.0 \mathrm{Cr}$ \\
$\mathbf{6 3 b}$ & 12 & $\mathrm{H}$ & $\mathrm{Cl}$ & Iso $113.6 \mathrm{~N} 95.4 \mathrm{SmA} 83.4 \mathrm{Cr}$ \\
\hline
\end{tabular}

In the same year, two series of four-ring BCLCs with methylated azobenzene wings have been prepared by Begum et al. These two series differ from each other in the relative position of the methyl substituent in respect of azo unit in the molecule. Both of them demonstrate the nematic phase during the cooling process from the isotopic state as evident by POM (Figure 16a,b). XRD profiles for both compounds $\mathbf{6 4}$ and $\mathbf{6 5}$ display the small/moderately sharp peak in the small-angle region and wide-angle $\mathrm{Cl}$ with $d=4.71 \AA$ and $4.92 \AA$, respectively (Figure 16c,d). Although the molecular length of these two compounds was almost identical, the $d$-values given by each compound were different. The difference in the $d$-spacing values between them may occur due to the positional variation in the methyl unit neighbouring to the azo linkage [154].

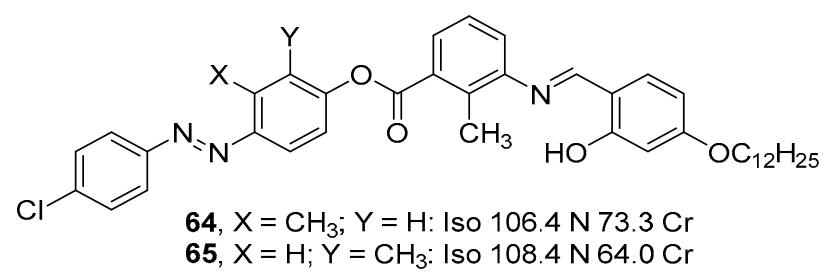



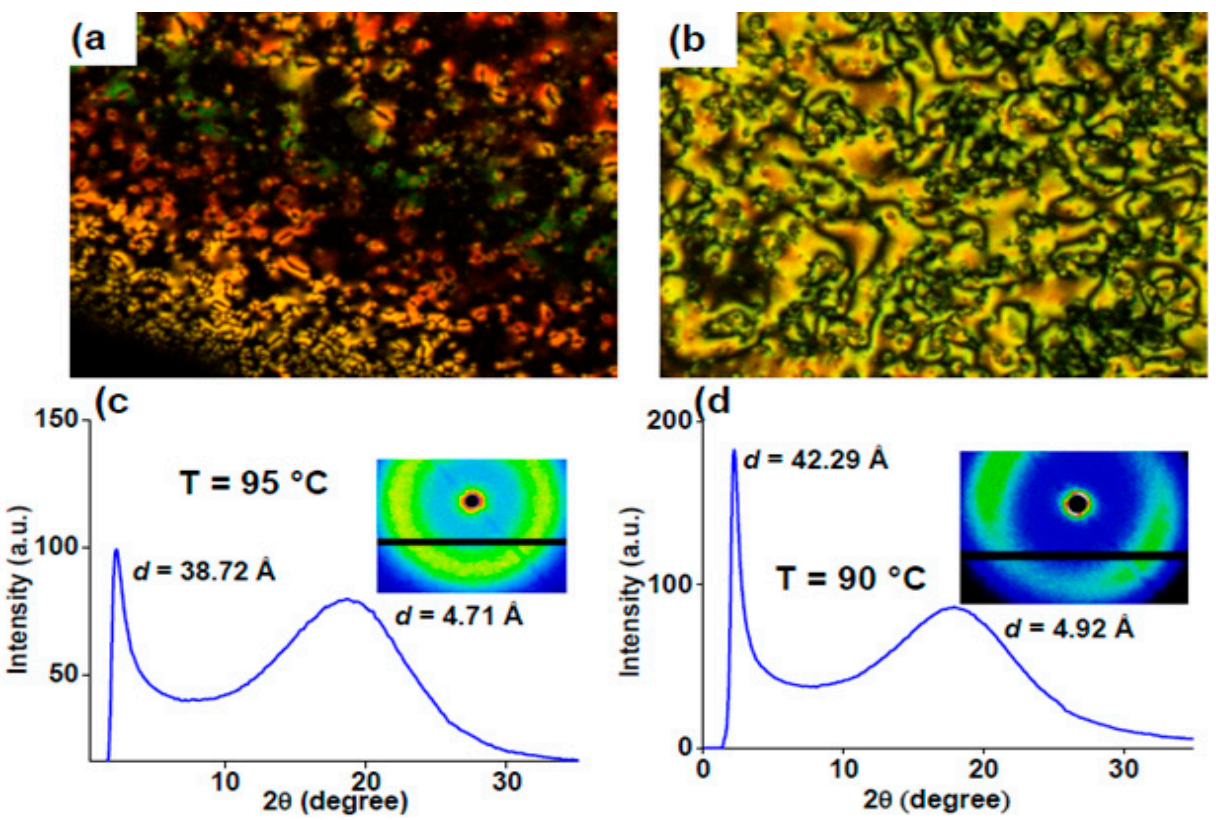

Figure 16. Textures of the nematic phase observed under POM for (a) compound 64 at $\mathrm{T}=104.1^{\circ} \mathrm{C}$ and (b) compound 65 at $\mathrm{T}=92.8^{\circ} \mathrm{C}$; XRD profiles of (c) compound 64 and (d) compound 65, along with their insets indicate 2D images at the specific temperature. (Reproduced with permission from ref. [154], copyright American Chemical Society 2020, https://doi.org/10.1021/acs.jpcc.9b09326).

Replacing the terminal $-\mathrm{Cl}$ group in compound 64 and 65 with the highly electronegative fluoro group is results in the formation of compounds 66 and 67, respectively. Compounds 66 and 67 are bearing the shorter alkoxy chain $\left(\mathrm{OC}_{5} \mathrm{H}_{11}\right)$ on the shorter arm, instead of the longer $\mathrm{OC}_{12} \mathrm{H}_{25}$ chain. They exhibit monotropic nematic phases and their mesophases do not vary much from their analogues bearing with the terminal chloro group (64 and 65). Compound 68 is prepared by substituting the $\mathrm{Y}=\mathrm{CH}_{3}$ with $-\mathrm{Cl}$ group in compound 67 . The nematic phase is also observed in this compound. Compared to the compound having the substitution on the meta-position, the compound with the substituent located at ortho-position to the ester linking group has a higher isotropic phase temperature [155].

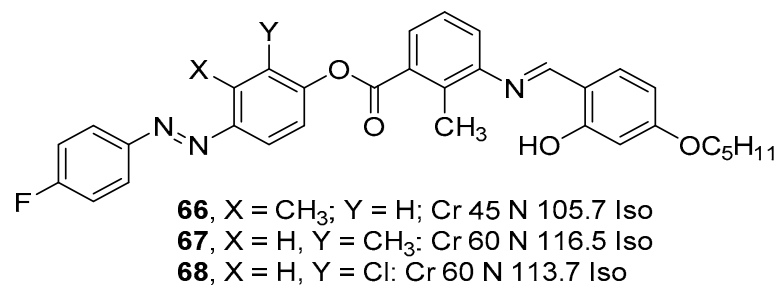

Paul et al. had been designed hockey stick molecule 69 comprising the short arm attached with a reactive double bond, while the azobenzene based lengthening arm consists of methoxy terminus. When the lateral methyl group is substituted at the inner ring of the azobenzene sidearm in compound 69, compounds 70 and 71 are formed. All of them exhibit a similar phase sequence which is $\mathrm{Cr} \rightarrow \mathrm{N} \rightarrow$ Iso. Based on the DFT calculations, variation in the position of the $-\mathrm{CH}_{3}$ substituent does not alter the electronic and spectroscopic properties in a great scale although there is a slight shift of a strong peak in UV-vis absorption spectra. The melting and clearing temperature decrease distinctly when the lateral methyl group presented on the lengthening arm of the mesogen [156]. 


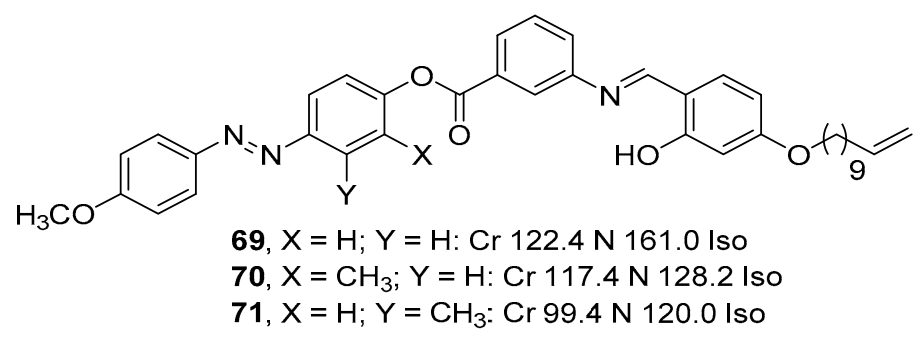

In 2017, Alaasar et al. reported six rings HSLCs derived from 4-cyanoresorcinol with azobenzene side arm opposite to the direction of the $-\mathrm{CN}$ group. Depending on the alkoxy chain length at the shorter ( $m=6$ and 12) and longer sidearm ( $n=2,6$ and 20), various types of enantiotropic mesophases with phase sequences are produced. Compound $\mathbf{7 2 b}$ with very short ethoxy chain shows the SmA phase and $\mathrm{N}_{\mathrm{CybA}}$ phase, while compounds $72 \mathrm{a}$ and $72 \mathrm{c}$ additionally form synclinic $\mathrm{SmC}$ phase $\left(\mathrm{SmC}_{\mathrm{s}}\right)$ and antichlinic SmC phase $\left(\mathrm{SmC}_{\mathrm{a}}\right)$. The transition between $\mathrm{SmC}_{\mathrm{s}}$ and $\mathrm{SmC}_{\mathrm{a}}$ phase is a typical characteristic of hockey-stick mesogens [66,141,143,157-159], as shown in Figure 17. This transition is accompanied by nucleation of domain walls with opposite tilt of the director in the $\mathrm{SmC}_{\mathrm{s}}$ phase and disappearance of the Meyer domains at the transition to the anticlinic SmCa phase. When the alkoxy chain length attached at the shorter arm increases, the temperature range of the $\mathrm{SmC}_{\mathrm{s}}$ phase is broadened $(\mathbf{7 2 a} \rightarrow$ 72c). On the other hand, the chain elongation occurs at a longer side arm causes the emergence of $\mathrm{SmC}_{\mathrm{s}}$ phase $(\mathbf{7 2 b} \rightarrow \mathbf{7 2 c})$. It can be concluded that the chain elongation occurs at both shorter and longer sidearms favour the synclinic interlayer correlation, and therefore, the development of $\mathrm{SmC}_{\mathrm{s}}$ phase is preferential. This result is in line with the previous report [158]. However, further increasing the alkoxy chain length at the elongated sidearm (72d) causes the nematic and $\mathrm{SmC}_{\mathrm{a}}$ phases to be removed entirely [93].
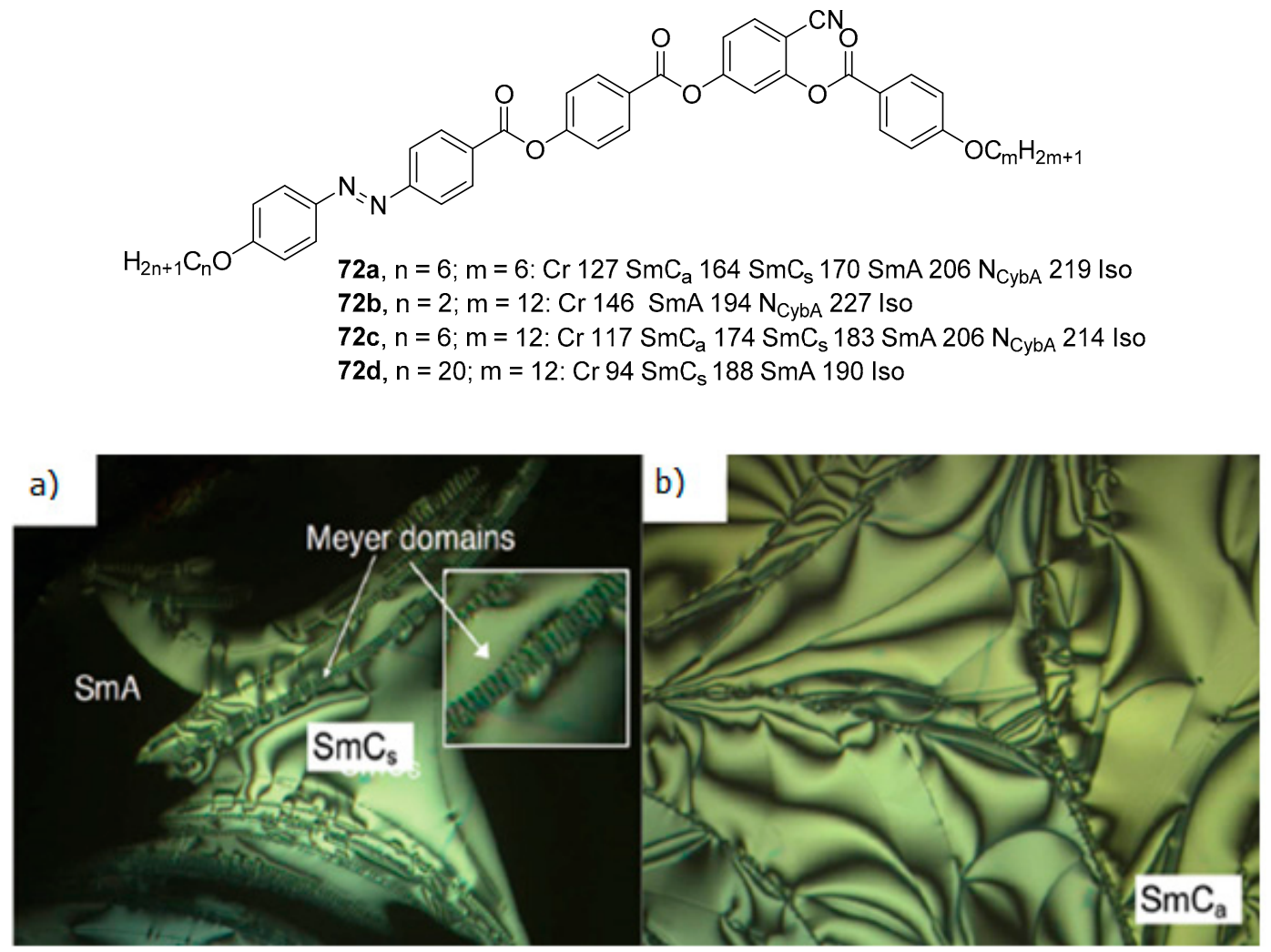

Figure 17. POM images of a freely suspended film of compound 72a (a) in the $\mathrm{SmA}-\mathrm{SmC}_{\mathrm{s}}$ transition at $\mathrm{T}=170{ }^{\circ} \mathrm{C}$, showing the Meyer domains growing from the layer steps and $(\mathbf{b})$ in the $\mathrm{SmC}_{\mathrm{a}}$ phase at $\mathrm{T}=147^{\circ} \mathrm{C}$. (Reproduced with permission from ref. [93], copyright The Royal Society of Chemistry 2017, https://doi.org/10.1039/C7TC01816A). 
Changing the orientation of the $\mathrm{CN}$ group at the resorcinol core in compound $72 \mathrm{c}$ is results in the formation of isomeric compound $\mathbf{7 3}$ with the reduced melting and clearing temperatures. Besides, the SmA and SmC phases are eliminated in this compound when the position of the CN group is altered. The nematic phase is the only mesophase observed for this compound [93].

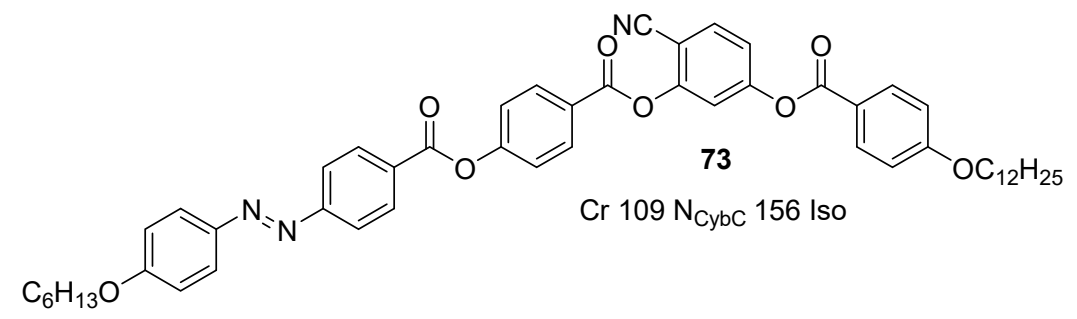

\subsection{Heterocyclic Aromatic Core}

The hockey-stick molecules with 6-oxoverdazyl radical as the BU and the end of the short arm are terminated with either $-\mathrm{CH}_{3}, \mathrm{CF}_{3}$ and $\mathrm{CN}$ groups were reported in 2017 by Szymon et al. The results revealed that only the $\mathrm{CN}$ derivative $\mathbf{7 4}$ showed the mesogenic behaviour, that is the nematic phase [160].

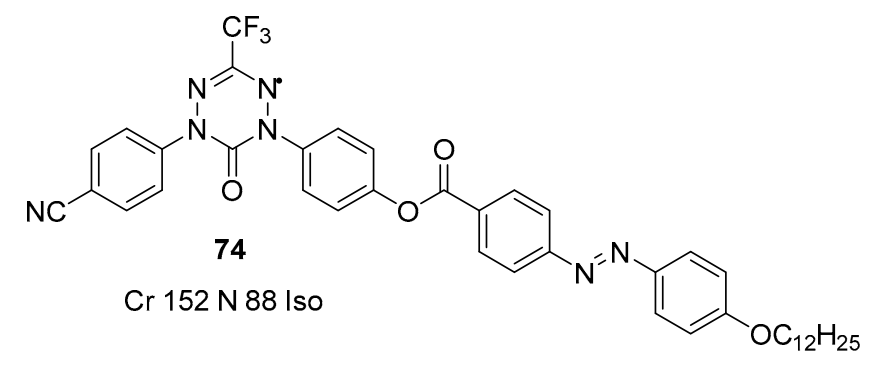

\section{Photoisomerization}

Incorporation of photoswitches, molecules that undergo structural changes in response to light illumination, in the liquid crystal network has emerged a promising and exciting class of materials for achieving optical to mechanical energy conversion [62,161-164]. The azobenzene represents a classic example of photoswitchable material that finds tremendous applications in different fields, especially in the photonics, as it is mentioned in the introduction section. Therefore, most of the photoswitchable LC materials incorporate the azobenzene in their molecular structure substantially responsible for exhibiting photoresponsive behaviour. The azobenzene undergoes a reversible trans-cis photoisomerization under the appropriate UV-light illumination, as shown in Figure 18. This phenomenon will later bring about a geometrical change at the molecular level that disrupt liquid crystallinity and effectively promote disorder, causing a significant change in the physical property of azobenzene based materials [62]. As mentioned earlier, the cis-trans isomerization can occur in two ways, either by removing the source of irradiation or keeping the excited trans isomers in the dark condition, which is known as thermal back relaxation. The relative thermal stability of the two isomers can differ significantly among the different system. The cis/Z isomer of some compounds can alter quickly into their trans/E isomers, while the cis/Z isomer can have appreciable thermal stability in other systems. The longer thermal back relaxation (higher thermal stability) is very crucial when considering applications in technologies such as optical data and real-time information transfer [165]. Photoisomerization (trans $\rightarrow$ cis) and thermal isomerization (cis $\rightarrow$ trans) of the azobenzene are well-separated in time because the former process takes place considerably faster than the latter one. The photoisomerization behaviour of certain compounds that are mentioned in the previous sections will be discussed in this section. 


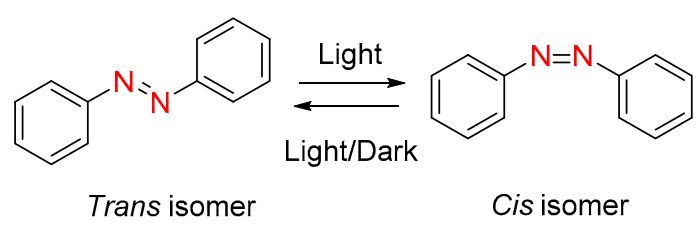

Figure 18. Photoisomerization process of azobenzene under light irradiation or in dark condition.

Many research groups have studied the photoisomerization behaviour of azobenzene-containing BCLCs either in solution, solid, LC or mixture state under the UV-visible irradiation. The photoisomerization and thermal back relaxation of BCLCs are performed by measuring the UV-vis absorption spectra. For example, BCLC $\mathbf{7 1}$ is dissolved in the chloroform solution, and the changes in UV-vis absorption spectra were measured at three different circumstances: freshly prepared sample, the sample was irradiated with the light source with $\lambda=366 \mathrm{~nm}$ and the sample was kept in the dark. Upon the UV exposure, the absorption peak at $\lambda \sim 346 \mathrm{~nm}$, which is corresponding to $\pi-\pi^{*}$ transition of energetically more stable trans-isomers decreases. On the other hand, the intensity of the absorption peak at $\lambda \sim 438 \mathrm{~nm}$ corresponding to $\mathrm{n}-\pi^{*}$ transition of cis-isomers gradually increases (Figure 19). This phenomenon indicates the conversion of stable trans isomers into the thermodynamically unstable cis isomers at the photo equilibrium state during the photoisomerization process. The unstable cis isomers are isomerized back to the stable trans isomers when it is placed in dark condition, which defines the thermal back relaxation (Figure 19) $[57,156]$. The other simple method to detect the photoisomerization process is observing the number of spots coming from the thermally equilibrated sample or irradiation with UV light on the thin-layer chromatography (TLC) [14].

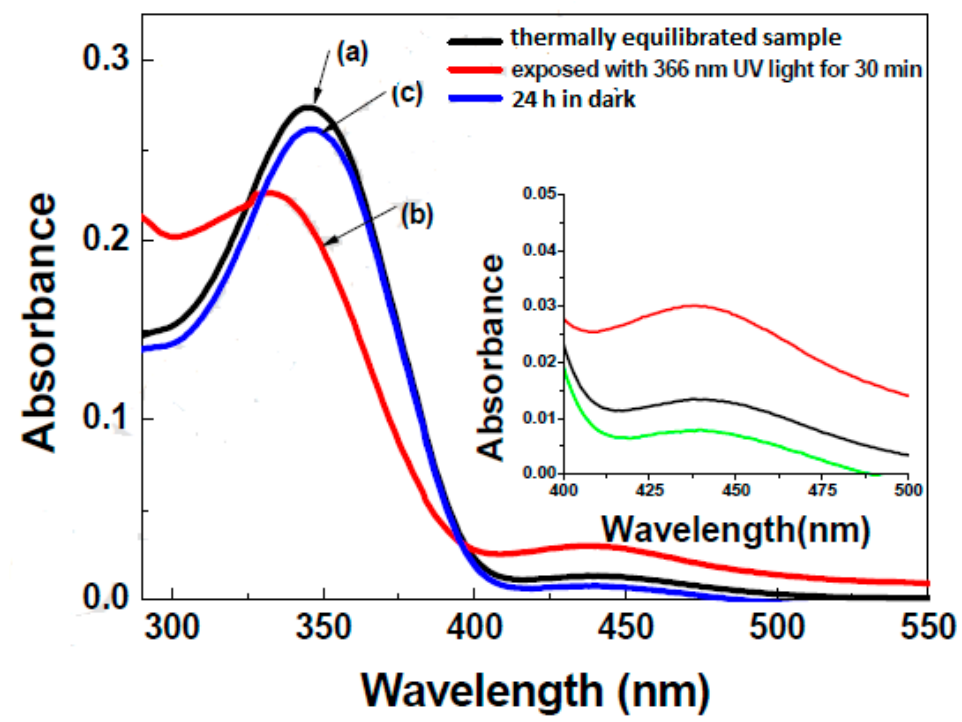

Figure 19. The UV-vis absorption spectra of compounds 71 (a) before the light illumination, (b) upon the UV light exposure $(\lambda=365 \mathrm{~nm})$ for $30 \mathrm{~min}$ and (c) after keeping in the dark for $24 \mathrm{~h}$. The inset indicates the enlarged area of 400-500 nm (Reproduced with permission from ref. [156], copyright Elsevier 2020, https://doi.org/10.1016/j.dyepig.2018.12.028).

Although the photoswitching of azobenzene mesogens in solution is essential, the photoswitching effect in the solid-state is vital for practical applications, especially for the field in rewritable printing and imaging solid-state bistable compounds $[166,167]$. The photochromism of compound $\mathbf{6 3 \mathbf { b }}$ in the solid-state was performed with UV-vis spectroscopic studies through the reflectance mode in $\mathrm{KBr}$ medium (Figure 20c). A prominent shift in the spectral behaviour has been observed upon illumination of light $(\lambda=365 \mathrm{~nm})$, revealing the solid-state isomerization. Upon the light illumination, the $\pi-\pi^{*}$ band in the thermally equilibrated sample is shifted from $351 \mathrm{~nm}$ to the lower wavelength of $\lambda=320 \mathrm{~nm}$ and the intensity of $\mathrm{n}-\pi^{*}$ band increases. The compound $\mathbf{6 3 \mathrm { b }}$ was also dissolved in chloroform to 
reinforce the photochromism in the solid-state. The sample was passed under UV light for $\sim 4 \mathrm{~h}$ followed by evaporating and drying of the solvent under vacuum. The colour of the compound was changed from a yellowish-orange to red (Figure 20d). The photoswitching effect in the solid-state can be further confirmed by performing XRD studies. Without the light irradiation, the XRD spectra in the thermally equilibrated sample showed many narrow peaks in small- and wide-angle regions (Figure 20a). Upon the illumination of light, the spectra still exhibited many narrow peaks in smalland wide-angle regions, but these peaks were found to be broader, as shown in Figure 20b [153].
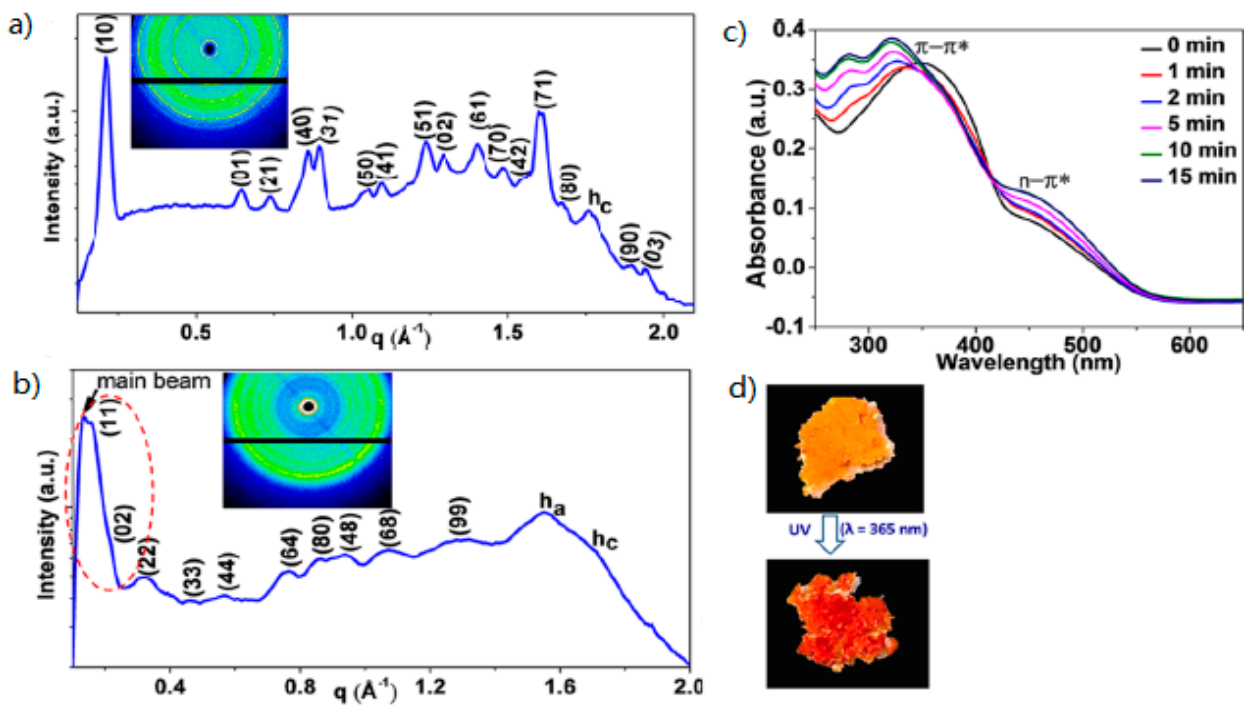

Figure 20. The XRD pattern of compound $63 \mathbf{b}$ in the solid-state $(a, b)$ before and after the UV illumination, (c) the solid-state UV-vis experiment before and after UV irradiation and (d) the photochromism in solid-state changes the colour of solid before and after the light exposure. (Reproduced with permission from ref. [153], copyright American Chemical Society 2019, https://doi.org/10.1021/acs.jpcb.9b01456).

When the azobenzene moiety is applied in the LC environment, it plays a vital function in modifying the phase structure. It has been witnessed that the compound $20 \mathrm{~d}$ showed the transformation from the $\mathrm{SmC}_{\mathrm{A}} \mathrm{P}_{\mathrm{A}}$ phase to the isotropic upon the illumination with UV light. Without the light illumination, a sharp maximum in a region of small scattering angles is detected, indicating the long-range of the lamellar structure in the smectic phase. When the compound $20 \mathrm{~d}$ is exposed to UV light, the peak intensity is reduced by several orders of magnitude, which revealed the melting of the smectic structure into the liquid (Figure 21) [110]. For compound $\mathbf{6 3 b}$, the photoswitchable ability in the LC state was performed in situ-observed by POM. It was fixed in the middle of a glass plate and a coverslip before heating it to the isotropic phase. During the experiment, the red filter was fixed on the POM to eliminate the UV component in the visible light released from the tungsten-halogen incandescent lamp of the POM. The Schlieren texture feature of the N phase (Figure 22a) emerged upon the cooling process from the isotropic state. This feature vanished immediately under the UV light illumination and leaving the dark image (Figure 22b) that represents the order-nematic phase is tuned to the disorder-isotropic phase. When the UV light is removed, the Schlieren texture reappeared slowly (Figure 22c). The same condition is observed when the compound $\mathbf{6 3 b}$ is further cooling from the $\mathrm{N}$ phase to the SmA phase (Figure 22d-f) [153]. 


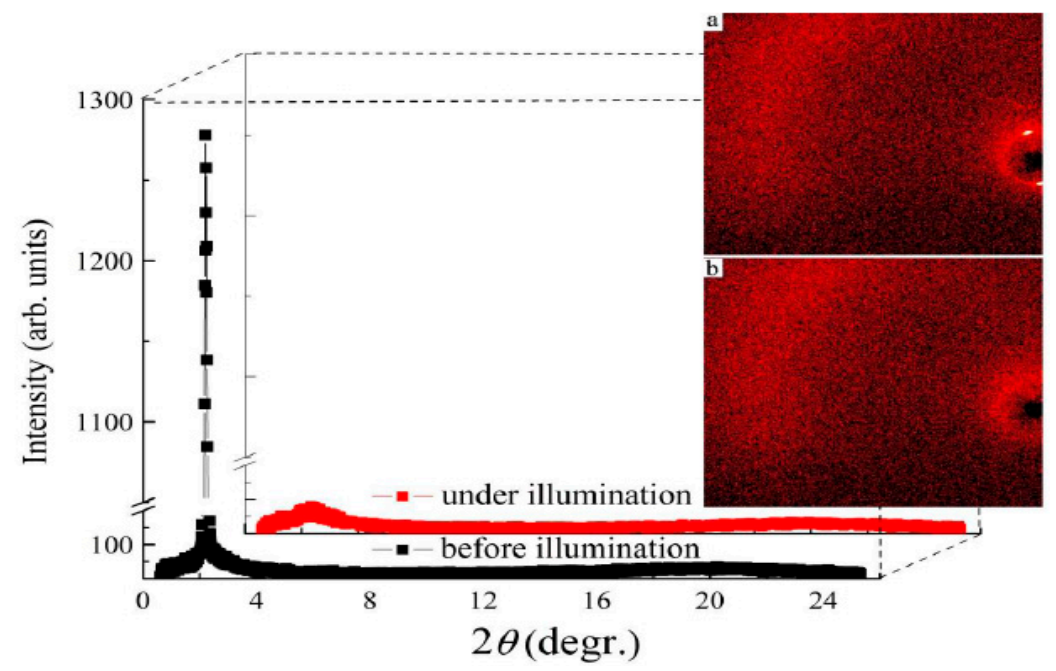

Figure 21. The $\mathrm{XRD}$ of compound $20 \mathrm{~d}$ in the $\mathrm{SmC}_{\mathrm{A}} \mathrm{P}_{\mathrm{A}}$ phase at $\mathrm{T}=100{ }^{\circ} \mathrm{C}$ before (black line) and under the irradiation of light with $\lambda=365 \mathrm{~nm}$. The inset represents 2D XRD (a) before, and (b) under the irradiation of light with $\lambda=365 \mathrm{~nm}$. (Reproduced with permission from ref. [110], copyright of Elsevier 2020, https://doi.org/10.1016/j.molliq.2020.112743).
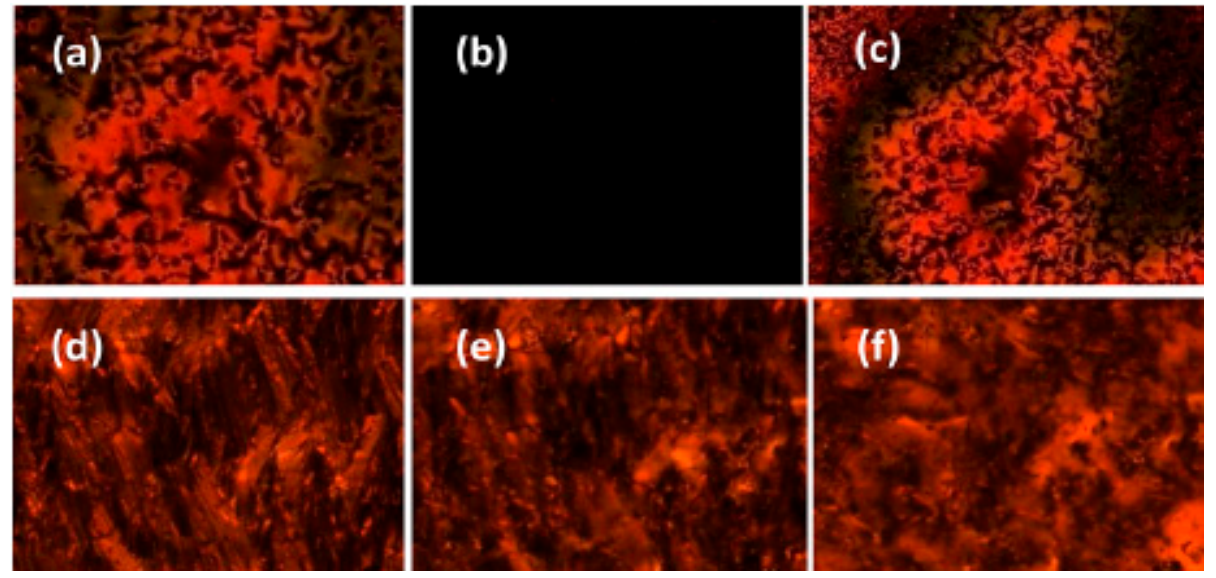

Figure 22. The photoinduced phase transition of compound $63 \mathrm{~b}$ observed under POM with a red filter, (a) the nematic phase upon cooling to $\mathrm{T}=113^{\circ} \mathrm{C}$ before the UV illumination, (b) transition to isotropic state at $\mathrm{T}=113^{\circ} \mathrm{C}$ upon the UV irradiation with $\lambda=365 \mathrm{~nm}$, (c) recovered nematic phase when the UV light is removed, (d) the SmA phase at T $=94.9^{\circ} \mathrm{C}$, (e) the coexistence of SmA and nematic phase under the UV light exposure at $\mathrm{T}=94.9^{\circ} \mathrm{C}$, and (f) conversion to the nematic phase at $94.9^{\circ} \mathrm{C}$ (Reproduced with permission from ref. [153], copyright American Chemical Society 2019, https://doi.org/10.1021/acs.jpcb.9b01456).

The impact of light on the phase transition temperature of BCLCs based on azobenzene has been studied. When the compound 41 is exposed to UV light at $\lambda=365 \mathrm{~nm}$ in the nematic phase region $\left(T_{\mathrm{sm}}\right.$ $<T_{N}<T_{\text {iso }}$ ), the transition temperature of isotropic, $T_{\text {iso, }}$ decreases gradually owing to the growing number of cis-form isomers. When the concentration of cis-form isomers reaches the threshold level, $T_{\text {iso }}\left(125^{\circ} \mathrm{C}\right)$ becomes lower than the transition temperature of nematics, $T_{N}\left(128{ }^{\circ} \mathrm{C}\right)$ (Figure $\left.23 \mathrm{a}\right)$, causing a nematic-to-isotropic isothermal phase transition in the irradiated area (Figure 23e). Similarly, the nematic phase can be recovered faster upon cooling from the isotropic phase when the sample is illuminated with visible light $(\lambda=457 \mathrm{~nm})$, as shown in Figure 23c. The application of visible light on the sample in the isotropic phase facilitates the oriented liquid crystalline state. Thus, it induces an isotropic-to-nematic phase transition in the illuminated region (Figure 23g) [119]. 


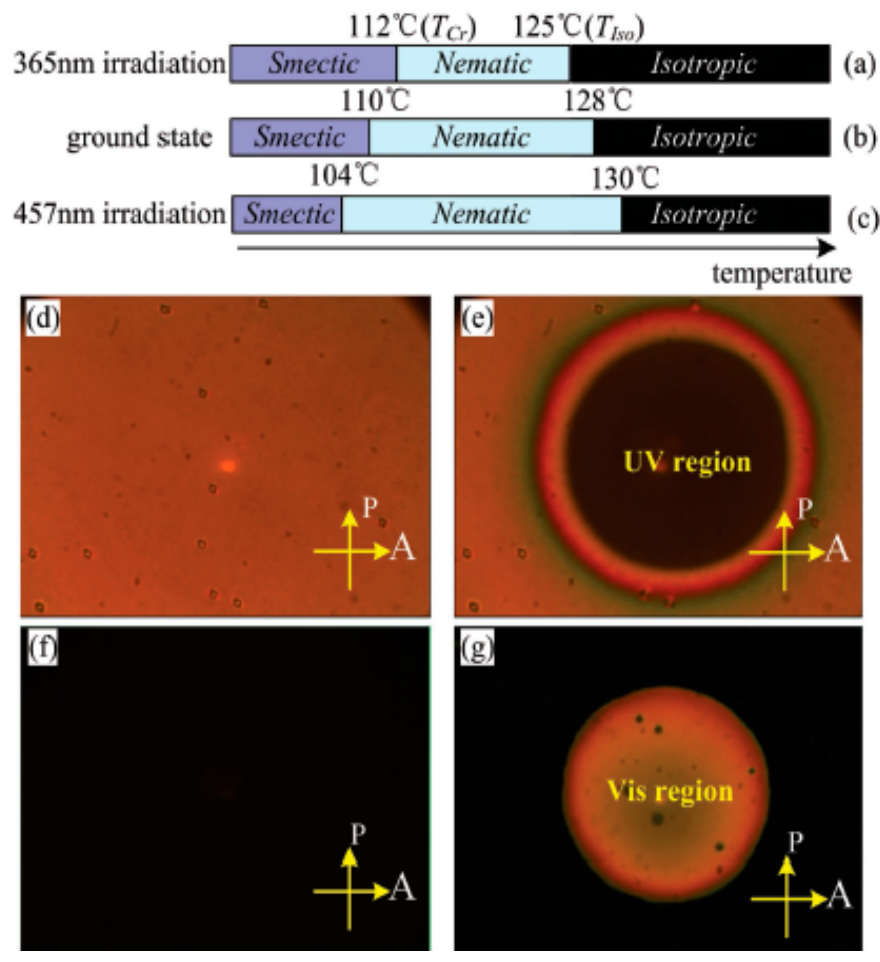

Figure 23. Phase transition of compound 41 (a) under UV light $(\lambda=365 \mathrm{~nm})$ illumination, (b) without illumination, (c) under visible light illumination $(\lambda=457 \mathrm{~nm})$, POM micrograph of $(\mathbf{d})$ the nematic phase at $\mathrm{T}=125^{\circ} \mathrm{C}$ without the light exposure, (e) the nematic-to-isotopic isothermal transition at $\mathrm{T}=125^{\circ} \mathrm{C}$ upon UV light $(\lambda=365 \mathrm{~nm})$ illumination for $2 \mathrm{~s}$, (f) the isotopic phase at $\mathrm{T}=129^{\circ} \mathrm{C}$ without the light illumination, (g) the isotopic-to-nematic isothermal transition at $\mathrm{T}=129^{\circ} \mathrm{C}$ upon visible light $(\lambda=457 \mathrm{~nm})$ illumination for $120 \mathrm{~s}$. Once the illumination of visible light $(\lambda=457 \mathrm{~nm})$ is off, compound 41 took 3 s to restore to isotopic phase. (Reproduced with permission from ref. [119], copyright John Wiley and Sons 2019, https://doi.org/10.1002/adom.201801790).

Besides, the photoisomerization brings effect to the electric properties upon light exposure. In the case of compound 65, the threshold value $\left(U_{\text {th }}\right)$ for Frèedericksz transition (FT) to occur decreases as the intensity of UV light $\left(I_{365}\right)$ increases (Figure $24 a$ ). From a practical view, a high $U_{\text {th }}$ restrict the application of $\mathrm{BCNs}$, and therefore, decreasing $U_{\text {th }}$ is highly desirable. Previously, Frèedericksz transition, which is the most fundamental mechanism for applying nematics as display and information processing components [168], are investigated by the electric stimuli only. In the study of Begun et al., the FT effect of BCN material (compound 65) is explored additionally by the light stimuli. The lower $U_{\text {th }}$ value is attributed by the photoisomerization of compound 65 , where the compound 65 changes the shape from trans isomer (unsymmetrical V-shape) to distorted Z-shaped cis isomer (Figure 24b). When the UV light is removed, it changes back to the original structure that causes the recovery of $U_{\text {th }}$ value [154]. Similarly, the behaviour of flexoelectric domains (FDs) in the bent-core nematic of compound 41 can also be modulated by different wavelengths and intensity of light. The electric threshold and periodicity of FDs can be adjusted by changing the ratio of trans-cis isomers upon the illumination of light. So far, most of the research studied on FDs highlight the electrical characteristics of FDs (threshold voltage and voltage-dependent periodicity) [169-171], and the possibility of tuning the properties of FDs by light irradiation has not yet been reported. Therefore, the novel phenomenon of contactless light-control tunability found in compound $\mathbf{4 1}$ serves as a guideline to improve the performance of certain traditional electric-field-induced photonic devices by additional light fields [119]. 

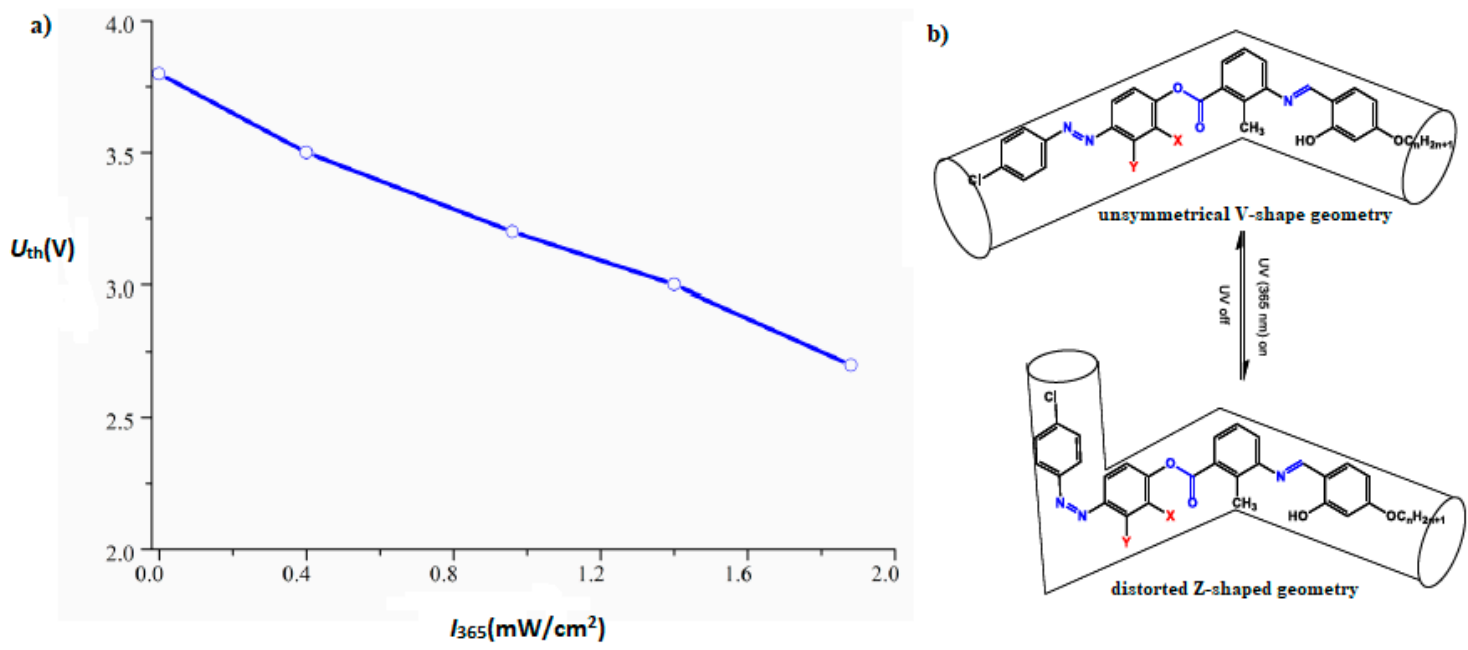

Figure 24. (a) The relationship between the threshold $U_{\text {th }}$ of electric-field-induced FT effect and the intensity of UV $\left(I_{365}\right)$ demonstrated by compound 65, (b) trans-cis photoisomerization that brings about changes in the molecular shape of compound 65 from unsymmetrical V-shaped to distorted Z-shape (Reproduced with permission from ref. [154], copyright American Chemical Society 2020, https://doi.org/10.1021/acs.jpcc.9b09326).

The first case of the photoinduced alteration of the switching mode under the electric field was found in the compound 18a due to the existence of the azobenzene unit in its molecular structure. The compound 18a was placed in a $6 \mu \mathrm{m}$ ITO cell on a temperature-controlled heating stage and irradiated with light $(\lambda=405 \mathrm{~nm})$ at $\mathrm{T}=101^{\circ} \mathrm{C}$, which is close to the $\mathrm{SmC}_{\mathrm{S}} \mathrm{P}_{\mathrm{AR}}-\mathrm{SmC}_{\mathrm{S}} \mathrm{P}_{\mathrm{R}}{ }^{[*]}$ transition temperature, for $2 \mathrm{~s}$. As shown in Figure $25 \mathrm{f}-\mathrm{g}$, the AF-like double peaks switching is changed into the FE-like single peak switching upon the light illumination. When the light source is off, the FE-like single peak switching is relaxed back to the AF-like mode. Similarly, the reversible photoinduced on-off-switching of chirality was demonstrated for the first time by the compound $\mathbf{1 6 b}(n=16)$. Upon the light irradiation with $\lambda=405 \mathrm{~nm}$, the chiral $\mathrm{SmC}_{\mathrm{s}}{ }^{[*]}$ phase of the compound $\mathbf{1 6 b}$ switched to the achiral SmA phase (Figure 25a-c). The chirality was restored after switching off the light, but the positions of the chiral domains change (Figure 25c-e). The occurrence of the photoinduced on-off -switching of chirality (16b) and the photoinduced change of switching mode between the ferroelectric-like and antiferroelectric-like (18a) is attributed to the trans-cis photoisomerization. During the trans-cis photoisomerization, compounds $16 \mathrm{~b}$ and $18 \mathrm{a}$ change from a well-defined bent-shape to a more non-specific one. This process causes the reduction in packing density and coherence length of polar order below a critical value that eventually changes the mode of polar switching and photoinduced on-off switching of chirality in compounds 18a and 16b, respectively [91]. 

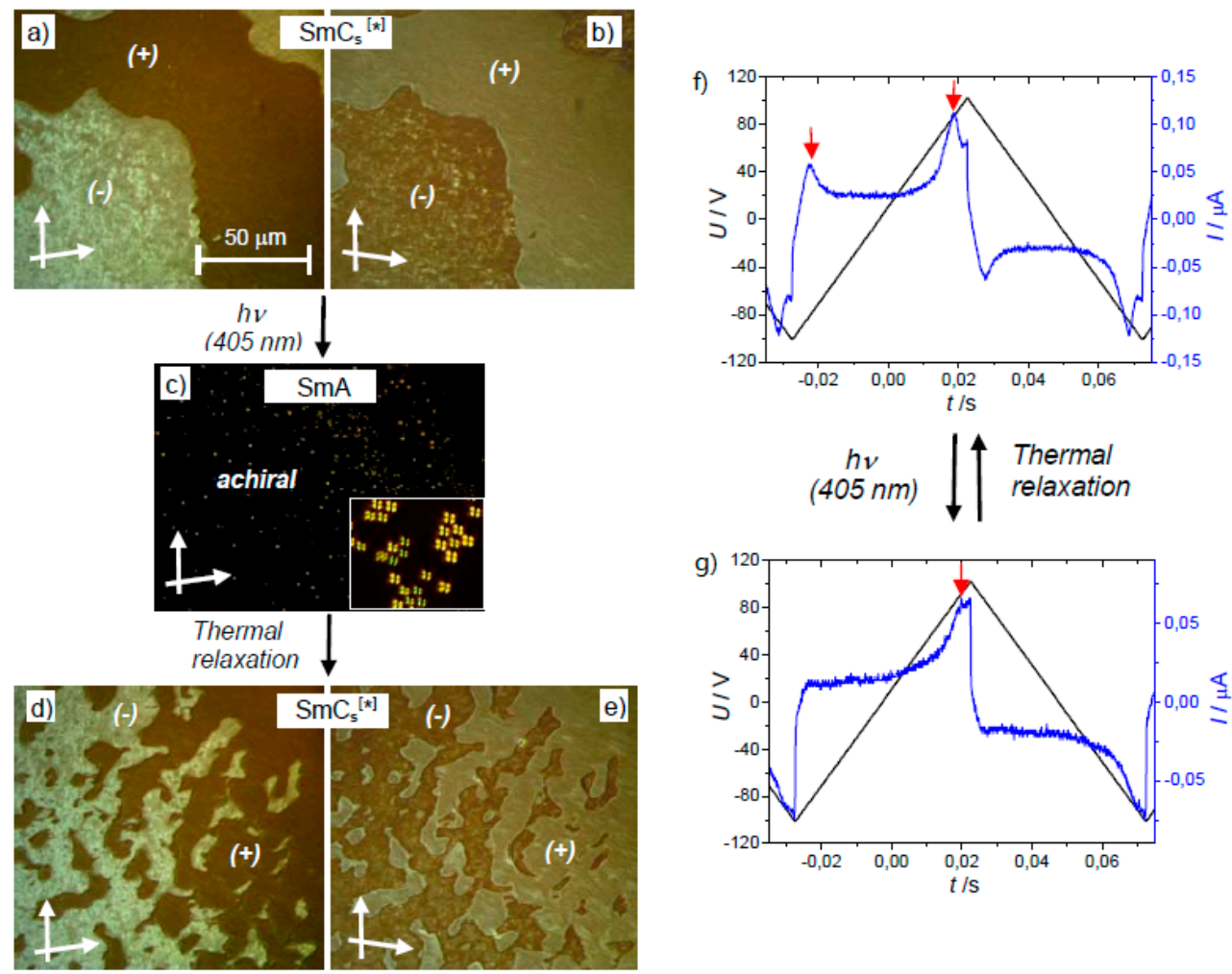

Figure 25. The optical texture of compound 16b exhibiting: (a-e) the isothermal photoinduced on-off-switching of chirality at $\mathrm{T}=152{ }^{\circ} \mathrm{C}$ in a homeotropic cell. The inset indicates a magnified area of Maltese crosses as typical for defects in homotropic SmA phases; The isothermal switching of compound 18a between (f) antiferroelectric-like and (g) ferroelectric-like switching in the paraelectric SmC phase range at $\mathrm{T}=101{ }^{\circ} \mathrm{C}$ in a $6 \mu \mathrm{m}$ ITO cell. (Reproduced with permission from ref. [90], copyright John Wiley and Sons 2017, https://doi.org/10.1002/chem.201806180).

\section{Potential Applications and Challenges}

As the discovery of cis-trans photoisomerization, azobenzene functionalized BCLCs have been exploited extensively for potential applications in enantioselective syntheses, photonics and nonlinear optics (NLO). However, numerous scientific issues concerning these photoresponsive BCLCs still need to be examined. One of the crucial aspects that still represent a difficulty in the use of these photosensitive BCLCs concerns bulk phase alignment. It is challenging to obtain a proper alignment in the case of BCLCs since the procedures that generally used for the calamitic LCs are not applicable in the BCLC system [27,57]. It is vital to obtain a breakthrough in this aspect because the proper sample alignment is a target not only for applications but also for basic research purpose. In developing new applications based on the photosensitive BCLCs with a wide range of chiral or polar stabilized mesophases at room temperature, the mesomorphic behaviour of bent-core mesogens should be maintained at room temperature or as close to room temperature as possible. Third, it is difficult to predict an ideal criterion to design the biaxial nematic phase $\left(\mathrm{N}_{\mathrm{b}}\right)$, a potential candidate for the application in the next generation of ultrafast and wide-angle display devices due to the fast switching response, compared to the uniaxial nematic phase. The nature of the reported $\mathrm{N}_{\mathrm{b}}$ in azobenzene containing BCLCs still open the question to be answered. Fouth, although there is a massive amount of reported BCLCs, the requirement for more BCLCs with enhanced NLO properties is still high because they might yield a broad range of applications [57]. Despite the promising effects and possible applications are given by the reported azobenzene based BCLCs, most of them are only used for basic and theoretical research as the problems mentioned earlier limit the practical applications. Therefore, further explorations on the possible practical applications of BCLCs should be intensified in the future. 


\section{Conclusions}

A review of the recently designed photoresponsive azobenzene based BCLCs exhibiting numerous types of mesophases including bent-core nematics with cybotactic clusters $\left(\mathrm{N}_{\mathrm{cybC}}\right.$ and $\left.\mathrm{N}_{\mathrm{cybA}}\right)$, polar and non-polar Sm phases and chiral sponge and $\mathrm{HNC}$ phases $\left(\mathrm{DC}_{1}{ }^{*}\right.$ and $\left.\mathrm{DC}_{2}{ }^{*}\right)$ as well as the conventional nematic and smectic phases has been provided. It was concluded that the mesogenic properties of BCLCs could be altered by minor structural change, for instance, type of BU unit, the overall length of the molecular structure, types and orientation of linking groups and the lateral substitution on BU or sidearms in addition to types and length of terminal chains. The substitution of the BU unit, especially in position 4 , has been proved to be beneficial in producing the new mesophases, such as the $\mathrm{SmC}_{\mathrm{a}} \mathrm{P}_{\mathrm{AR}}$ phase generated from the 4-cyanoresorcinol. Although BCLCs are presently at the interesting research stage, the field looks sufficiently mature that more ambitious projects can be proposed for these materials owing to their remarkable and unique properties. They can certainly be put forward as novel tools to be used in developing new, smart and often with multifunctional for electronic, magnetic and photonic devices. Therefore, further investigations should be undertaken to achieve practical applications based on BCLCs in the future. Hopefully, the different examples of discussed BCLCs in this paper can provide insights to researchers to conduct their own studies.

Author Contributions: Writing—review and editing, T.X.T., M.L.R. and M.S.S. All authors have read and agreed to the published version of the manuscript.

Funding: This research was funded by an UMS open access grant (GUG0351-1/2019).

Acknowledgments: This research was supported by UMSGreat (GUG0351-1/2019).

Conflicts of Interest: The authors declare no conflict of interest.

\section{References}

1. Niori, T.; Sekine, T.; Watanabe, J.; Furukawa, T.; Takezoe, H. Distinct ferroelectric smectic liquid crystals consisting of banana shaped achiral molecules. J. Mater. Chem. 1996, 6, 1231-1233. [CrossRef]

2. Link, D.R.; Natale, G.; Shao, R.; Maclennan, J.E.; Clark, N.A.; Körblova, E.; Walba, D.M. Spontaneous Formation of Macroscopic Chiral Domains in a Fluid Smectic Phase of Achiral Molecules. Science 1997, 278, 1924-1927. [CrossRef]

3. Vorländer, D. Die Richtung der Kohlenstoff-Valenzen in Benzol-Abkömmlingen. Ber. Dtsch. Chem. Ges. 1929, 62, 2831-2835. [CrossRef]

4. Vorländer, D.; Apel, A. Die Richtung der Kohlenstoff-Valenzen in Benzolabkömmlingen (II.). Ber. Dtsch. Chem. Ges. 1932, 65, 1101-1109. [CrossRef]

5. Iglesias, W.; Jákli, A. Applications of Bent-Core Mesogens. In Handbook of Liquid Crystals; Wiley: Hoboken, NJ, USA, 2014; pp. 1-19.

6. Jákli, A. Liquid crystals of the twenty-first century-nematic phase of bent-core molecules. Liq. Cryst. Rev. 2013, 1, 65-82. [CrossRef]

7. Meyer, R.; Liebert, L.; Strzelecki, L.; Keller, P. Ferroelectric liquid crystals. J. Phys. Lett. 1975, 36, L69. [CrossRef]

8. Barbera, J.; Iglesias, R.; Serrano, J.; Sierra, T.; De La Fuente, M.; Palacios, B.; Perez-Jubindo, M.; Vazquez, J. Switchable columnar metallomesogens. New helical self-assembling systems. J. Am. Chem. Soc. 1998, 120, 2908-2918. [CrossRef]

9. Scherowsky, G.; Chen, X.H. New switchable columnar liquid crystals. Liq. Cryst. 1994, 17, 803-810. [CrossRef]

10. Bock, H.; Helfrich, W.J.L.C. Ferroelectrically switchable columnar liquid crystal. Liq. Cryst. 1992, 12, 697-703. [CrossRef]

11. Palffy-Muhoray, P.; Lee, M.A.; Petschek, R.G. Ferroelectric Nematic Liquid Crystals: Realizability and Molecular Constraints. Phys. Rev. Lett. 1988, 60, 2303-2306. [CrossRef]

12. Petschek, R.G.; Wiefling, K.M. Novel ferroelectric fluids. Phys. Rev. Lett. 1987, 59, 343-346. [CrossRef]

13. Tredgold, R. Ferroelectric liquid crystals do not have to be chiral. J. Phys. D Appl. Phys. 1990, 23, 119. [CrossRef] 
14. Lee, J.; Lee, S.-D. Ferroelectric liquid crystalline ordering of rigid rods with dipolar interactions. Mol. Cryst. Liq. Cryst. 1994, 254, 395-403. [CrossRef]

15. Cladis, P.; Brand, H.R. Electrooptic response of smectic O and smectic O. Liq. Cryst. 1993, 14, 1327-1349. [CrossRef]

16. Tournilhac, F.; Blinov, L.; Simon, J.; Yablonsky, S. Ferroelectric liquid crystals from achiral molecules. Nature 1992, 359, 621-623. [CrossRef]

17. Watanabe, J.; Nakata, Y.; Simizu, K. Frustrated bilayer smectic phase in main-chain polymers with two different spacers. J. Phys. II 1994, 4, 581-588. [CrossRef]

18. Akutagawa, T.; Matsunaga, Y.; Yasuhara, K. Mesomorphic behaviour of 1, 3-phenylene bis [4-(4-alkoxyphenyliminomethyl) benzoates] and related compounds. Liq. Cryst. 1994, 17, 659-666. [CrossRef]

19. Matsunaga, Y.; Miyamoto, S. Mesomorphic behavior of 2, 4-bis-(4-alkoxybenzylidene) cyclopentanones and related compounds. Mol. Cryst. Liq. Cryst. Sci. Technol. Sect. A Mol. Cryst. Liq. Cryst. 1993, 237, 311-317. [CrossRef]

20. Takezoe, H.; Watanabe, J. Ferroelectricity in liquid crystals. Mol. Cryst. Liq. Cryst. Sci. Technol. Sect. A Mol. Cryst. Liq. Cryst. 1999, 328, 325-332. [CrossRef]

21. Watanabe, J.; Hirose, Y.; Tokita, M.; Watanabe, T.; Miyata, S. Polar structure in polypeptide cholesteric liquid crystals evidenced from observation of second-harmonic generation due to the helicoidal cavity effect. Macromolecules 1998, 31, 5937-5939. [CrossRef]

22. Park, B.; Kinoshita, Y.; Takezoe, H.; Watanabe, J. Ferroelectricity in the lyotropic cholesteric phase of poly L-glutamate. Jpn. J. Appl. Phys. 1998, 37, L136. [CrossRef]

23. Terentjev, E.; Osipov, M.; Sluckin, T. General, Ferroelectric instability in semiflexible liquid crystalline polymers of directed dipolar chains. J. Phys. A Math. Gen. 1994, 27, 7047. [CrossRef]

24. Takezoe, H.; Takanishi, Y. Bent-Core Liquid Crystals: Their Mysterious and Attractive World. Jpn. J. Appl. Phys. 2006, 45, 597-625. [CrossRef]

25. Tschierske, C.; Dantlgraber, G. From antiferroelectricity to ferroelectricity in smectic mesophases formed by bent-core molecules. J. Phys. 2003, 61, 455-481. [CrossRef]

26. Ros, M.B.; Serrano, J.L.; de La Fuente, M.R.; Folcia, C.L. Banana-shaped liquid crystals: A new field to explore. J. Mater. Chem 2005, 15, 5093-5098. [CrossRef]

27. Etxebarria, J.; Blanca Ros, M. Bent-core liquid crystals in the route to functional materials. J. Mater. Chem. 2008, 18, 2919-2926. [CrossRef]

28. Eremin, A.; Jákli, A. Polar bent-shape liquid crystals - from molecular bend to layer splay and chirality. Soft Matter 2013, 9, 615-637. [CrossRef]

29. Tschierske, C.; Photinos, D. Biaxial nematic phases. J. Mater. Chem. 2010, 20, 4263-4294. [CrossRef]

30. Gleeson, H.F.; Kaur, S.; Görtz, V.; Belaissaoui, A.; Cowling, S.; Goodby, J. The nematic phases of bent-core liquid crystals. Chemphyschem 2014, 15, 1251. [CrossRef]

31. Görtz, V. Chiral resolution in bent-core nematic liquid crystals. Liq. Cryst. Today 2010, 19, 37-48. [CrossRef]

32. Yelamaggad, C.V.; Shashikala, I.S.; Hiremath, U.S.; Liao, G.; Jakli, A.; Rao, D.S.S.; Prasad, S.K.; Li, Q. Fluorine containing nonsymmetrical five-ring achiral banana-shaped compounds with columnar and synclinic antiferroelectric layered phases. Soft Matter 2006, 2, 785-792. [CrossRef]

33. Kohout, M.; Alaasar, M.; Poryvai, A.; Novotná, V.; Poppe, S.; Tschierske, C.; Svoboda, J. Photosensitive bent-core liquid crystals based on methyl substituted 3-hydroxybenzoic acid. RSC Adv. 2017, 7, 35805-35813. [CrossRef]

34. Podruczna, M.; Hofmańska, A.; Niezgoda, I.; Pociecha, D.; Galewski, Z. Influence of terminal groups on liquid-crystalline polymorphism of selected azobenzene derivatives. Liq. Cryst. 2014, 41, 113-125. [CrossRef]

35. Bogojawlensky, A.; Winogradow, N. Über das Verhalten von Schmelz- und Klärungskurven der flüssigen Kristalle und ihrer Mischungen. J. Z. für Phys. Chemie. 1907, 60U, 433.

36. Prasad, V.; Rao, D.S.S.; Prasad, S.K. A novel class of banana-shaped azo compounds exhibiting antiferroelectric switching behaviour. Liq. Cryst. 2001, 28, 643-646. [CrossRef]

37. Prasad, V.; Kang, S.-W.; Kumar, S. Novel examples of achiral bent-core azo compounds exhibiting B1 and anticlinic-antiferroelectric B2 mesophases. J. Mater. Chem. 2003, 13, 1259-1264. [CrossRef]

38. Prasad, V.; Jákli, A. Achiral bent-core azo compounds: Observation of photoinduced effects in an antiferroelectric tilted smectic mesophase. Liq. Cryst. 2004, 31, 473-479. [CrossRef] 
39. Prasad, S.K.; Nair, G.G.; Hegde, G. Dynamic Self-Assembly of the Liquid-Crystalline Smectic A Phase. Adv. Mater. 2005, 17, 2086-2091. [CrossRef]

40. Ikeda, T.; Tsutsumi, O. Optical Switching and Image Storage by Means of Azobenzene Liquid-Crystal Films. Science 1995, 268, 1873-1875. [CrossRef]

41. Ikeda, T. Photomodulation of liquid crystal orientations for photonic applications. J. Mater. Chem. 2003, 13, 2037-2057. [CrossRef]

42. Rahman, L.; Kumar, S.; Tschierske, C.; Israel, G.; Ster, D.; Hegde, G. Synthesis and photoswitching properties of bent-shaped liquid crystals containing azobenzene monomers. Liq. Cryst. 2009, 36, 397-407. [CrossRef]

43. Bandara, H.M.D.; Burdette, S.C. Photoisomerization in different classes of azobenzene. Chem. Soc. Rev. 2012, 41, 1809-1825. [CrossRef]

44. Kim, D.Y.; Tripathy, S.K.; Li, L.; Kumar, J. Laser-induced holographic surface relief gratings on nonlinear optical polymer films. Appl. Phys. Lett. 1995, 66, 1166-1168. [CrossRef]

45. Rochon, P.; Batalla, E.; Natansohn, A. Optically induced surface gratings on azoaromatic polymer films. Appl. Phys. Lett. 1995, 66, 136-138. [CrossRef]

46. Ichimura, K. Photoalignment of Liquid-Crystal Systems. Chem. Rev. 2000, 100, 1847-1874. [CrossRef]

47. Haus, H.A. Linearity of optical amplifiers and the Tomonaga approximation. J. Opt. Soc. Am. B 2001, 18, 1777-1779. [CrossRef]

48. Natansohn, A.; Rochon, P. Photoinduced Motions in Azo-Containing Polymers. Chem. Rev. 2002, 102, 4139-4176. [CrossRef]

49. Manickasundaram, S.; Kannan, P.; Hassan, Q.M.A.; Palanisamy, P.K. Azo dye based poly(alkyloxymethacrylate)s and their spacer effect on optical data storage. J. Mater. Sci. Mater. Electron. 2007, 19, 1045. [CrossRef]

50. Saravanan, C.; Senthil, S.; Kannan, P. Click chemistry-assisted triazole-substituted azobenzene and fulgimide units in the pendant-based copoly(decyloxymethacrylate)s for dual-mode optical switches. J. Polym. Sci. Part A Polym. Chem. 2008, 46, 7843-7860. [CrossRef]

51. Gan, S.M.; Yuvaraj, A.R.; Lutfor, M.R.; Mashitah, M.Y.; Gurumurthy, H. Synthesis, liquid crystal characterization and photo-switching studies on fluorine substituted azobenzene based esters. RSC Adv. 2015, 5, 6279-6285. [CrossRef]

52. Alaasar, M.; Prehm, M.; Tschierske, C. New azobenzene containing bent-core liquid crystals based on disubstituted resorcinol. Liq. Cryst. 2014, 41, 126-136. [CrossRef]

53. Martínez-Abadía, M.; Robles-Hernández, B.; de la Fuente, M.R.; Giménez, R.; Ros, M.B. Photoresponsive Cyanostilbene Bent-Core Liquid Crystals as New Materials with Light-Driven Modulated Polarization. Adv. Mater. 2016, 28, 6586-6591. [CrossRef]

54. Jákli, A.; Prasad, V.; Shankar Rao, D.S.; Liao, G.; Jánossy, I. Light-induced changes of optical and electrical properties in bent-core azo compounds. Phys. Rev. E 2005, 71, 021709. [CrossRef]

55. Nagaveni, N.G.; Prasad, V.; Roy, A. Azo functionalised achiral bent-core liquid crystals: Observation of photo-induced effects in B7 and B2 mesophases. J. Liq. Cryst. 2013, 40, 1405-1416. [CrossRef]

56. Nair, G.G.; Prasad, S.K.; Hiremath, U.S.; Yelamaggad, C. Effect of light on the polarization of a banana-shaped achiral compound doped with a photoactive azobenzene material. J. Appl. Phys. 2001, 90, 48-52. [CrossRef]

57. Alaasar, M. Azobenzene-containing bent-core liquid crystals: An overview. Liq. Cryst. 2016, 43, $2208-2243$. [CrossRef]

58. Zep, A.; Sitkowska, K.; Pociecha, D.; Gorecka, E. Photoresponsive helical nanofilaments of B4 phase. J. Mater. Chem. C 2014, 2, 2323-2327. [CrossRef]

59. Ueda, T.; Masuko, S.; Araoka, F.; Ishikawa, K.; Takezoe, H. A General Method for the Enantioselective Formation of Helical Nanofilaments. Angew. Chem. Int. Ed. 2013, 52, 6863-6866. [CrossRef]

60. Nagaveni, N.G.; Roy, A.; Prasad, V. Achiral bent-core azo compounds: Effect of different types of linkage groups and their direction of linking on liquid crystalline properties. J. Mater. Chem. 2012, 22, 8948-8959. [CrossRef]

61. Horčic, M.; Kozmík, V.; Svoboda, J.; Novotná, V.; Pociecha, D. Transformation from a rod-like to a hockey-stick-like and bent-shaped molecule in 3, 4'-disubstituted azobenzene-based mesogens. J. Mater. Chem. C 2013, 1, 7560-7567. [CrossRef]

62. Iamsaard, S.; Anger, E.; Aßhoff, S.J.; Depauw, A.; Fletcher, S.P.; Katsonis, N. Fluorinated azobenzenes for shape-persistent liquid crystal polymer networks. Angew. Chem. 2016, 128, 10062-10066. [CrossRef] 
63. Takanishi, Y.; Izumi, T.; Watanabe, J.; Ishikawa, K.; Takezoe, H.; Iida, A. Field-induced molecular reorientation keeping a frustrated structure in an achiral bent-shaped liquid crystal. J. Mater. Chem. 1999, 9, 2771-2774. [CrossRef]

64. Dingemans, T.J.; Murthy, N.S.; Samulski, E.T. Javelin-, Hockey Stick- and Boomerang-Shaped Liquid Crystals. Structural Variations on p-Quinquephenyl. J. Phys. Chem. B 2001, 105, 8845-8860. [CrossRef]

65. Stannarius, R.; Li, J.; Weissflog, W. Ferroelectric Smectic Phase Formed by Achiral Straight Core Mesogens. Phys. Rev. Lett. 2003, 90, 025502. [CrossRef] [PubMed]

66. Das, B.; Grande, S.; Weissflog, W.; Eremin, A.; Schröder, M.W.; Pelzl, G.; Diele, S.; Kresse, H. Structural and conformational investigations in SmA and different SmC phases of new hockey stick-shaped compounds. Liq. Cryst. 2003, 30, 529-539. [CrossRef]

67. Reddy, R.A.; Tschierske, C. Bent-core liquid crystals: Polar order, superstructural chirality and spontaneous desymmetrisation in soft matter systems. J. Mater. Chem. 2006, 16, 907-961. [CrossRef]

68. Nagaveni, N.G.; Prasad, V.; Roy, A. Azo-functionalised liquid crystalline dimers composed of bent-core and rod-like moieties: Synthesis and mesomorphic properties. Liq. Cryst. 2013, 40, 1001-1015. [CrossRef]

69. Monika, M.; Prasad, V.; Nagaveni, N.G. Hockey stick-shaped azo compounds: Effect of linkage groups and their direction of linking on mesomorphic properties. Liq. Cryst. 2015, 42, 1490-1505. [CrossRef]

70. Srinivasa, H.T. New symmetric azobenzene molecules of varied central cores: Synthesis and characterisation for liquid crystalline properties. Liq. Cryst. 2017, 44, 1384-1393. [CrossRef]

71. Prasad, V. Liquid crystalline compounds with V-shaped molecular structures: Synthesis and characterization of new azo compounds. Liq. Cryst. 2001, 28, 145-150. [CrossRef]

72. Prasad, V. Bent-Shaped Achiral Azo Compounds Exhibiting Banana Mesophases. Mol. Cryst. Liq. Cryst. Sci. Technol. Sect. A Mol. Cryst. Liq. Cryst. 2001, 363, 167-179. [CrossRef]

73. Pelzl, G.; Wirth, I.; Weissflog, W. The first 'banana phase' found in an original Vorländer substance. Liq. Cryst. 2001, 28, 969-972. [CrossRef]

74. Wirth, I.; Diele, S.; Eremin, A.; Pelzl, G.; Grande, S.; Kovalenko, L.; Pancenko, N.; Weissflog, W. New variants of polymorphism in banana-shaped mesogens with cyano-substituted central core. J. Mater. Chem. 2001, 11, 1642-1650. [CrossRef]

75. Gesekus, G.; Dierking, I.; Gerber, S.; Wulf, M.; Vill, V. Chiral banana liquid crystals derived from sugars. Liq. Cryst. 2004, 31, 145-152. [CrossRef]

76. Torgova, S.; Geivandova, T.; Francescangeli, O.; Strigazzi, A. Banana-shaped 1, 2, 4-oxadiazoles. J. Phys. 2003, 61, 239-248. [CrossRef]

77. Dingemans, T.J.; Samulski, E.T. Non-linear boomerang-shaped liquid crystals derived from 2,5-bis(p-hydroxyphenyl)-1,3,4-oxadiazole. Liq. Cryst. 2000, 27, 131-136. [CrossRef]

78. Pelzl, G.; Diele, S.; Weissflog, W. Banana-Shaped Compounds-A New Field of Liquid Crystals. Adv. Mater. 1999, 11, 707-724. [CrossRef]

79. Shen, D.; Tschierske, C.; Diele, S.; Wirt, I. A novel class of non-chiral banana-shaped liquid crystals with ferroelectric properties. Chem. Commun. 1998, 23, 2573-2574. [CrossRef]

80. Sadashiva, B.; Raghunathan, V.; Pratibha, R.J.F. Evidence of columnar structure in compounds composed of banana-shaped molecules. Ferroelectrics 2000, 243, 249-260. [CrossRef]

81. Murthy, H.N.S.; Sadashiva, B.K. Banana-shaped mesogens: Effect of lateral substituents on seven-ring esters containing a biphenyl moiety. Liq. Cryst. 2002, 29, 1223-1234. [CrossRef]

82. Weissflog, W.; Nádasi, H.; Dunemann, U.; Pelzl, G.; Diele, S.; Eremin, A.; Kresse, H. Influence of lateral substituents on the mesophase behaviour of banana-shaped mesogens. J. Mater. Chem. 2001, 11, 2748-2758. [CrossRef]

83. Walba, D.M.; Körblova, E.; Shao, R.; Maclennan, J.E.; Link, D.R.; Glaser, M.A.; Clark, N.A. A ferroelectric liquid crystal conglomerate composed of racemic molecules. Science 2000, 288, 2181-2184. [CrossRef] [PubMed]

84. Rouillon, J.; Marcerou, J.; Laguerre, M.; Nguyen, H.; Achard, M. New banana-shaped thiobenzoate liquid crystals with B6, B1 and B2 phases. J. Mater. Chem. 2001, 11, 2946-2950. [CrossRef]

85. Shen, D.; Pegenau, A.; Diele, S.; Wirth, I.; Tschierske, C. Molecular design of nonchiral bent-core liquid crystals with antiferroelectric properties. J. Am. Chem. Soc. 2000, 122, 1593-1601. [CrossRef] 
86. Lutfor, M.R.; Hegde, G.; Kumar, S.; Tschierske, C.; Chigrinov, V.G. Synthesis and characterization of bent-shaped azobenzene monomers: Guest-host effects in liquid crystals with azo dyes for optical image storage devices. Opt. Mater. 2009, 32, 176-183. [CrossRef]

87. Keith, C.; Lehmann, A.; Baumeister, U.; Prehm, M.; Tschierske, C. Nematic phases of bent-core mesogens. Soft Matter 2010, 6, 1704-1721. [CrossRef]

88. Eremin, A.; Floegel, M.; Kornek, U.; Stern, S.; Stannarius, R.; Nádasi, H.; Weissflog, W.; Zhu, C.; Shen, Y.; Park, C.S.; et al. Transitions between paraelectric and ferroelectric phases of bent-core smectic liquid crystals in the bulk and in thin freely suspended films. Phys. Rev. E 2012, 86, 051701. [CrossRef]

89. Alaasar, M.; Prehm, M.; Poppe, M.; Nagaraj, M.; Vij, J.K.; Tschierske, C. Development of polar order and tilt in lamellar liquid crystalline phases of a bent-core mesogen. Soft Matter 2014, 10, 5003-5016. [CrossRef]

90. Alaasar, M.; Prehm, M.; Poppe, S.; Tschierske, C. Development of Polar Order by Liquid-Crystal Self-Assembly of Weakly Bent Molecules. Chem. A Eur. J. 2017, 23, 5541-5556. [CrossRef]

91. Alaasar, M.; Prehm, M.; Belau, S.; Sebastián, N.; Kurachkina, M.; Eremin, A.; Chen, C.; Liu, F.; Tschierske, C. Polar Order, Mirror Symmetry Breaking, and Photoswitching of Chirality and Polarity in Functional Bent-Core Mesogens. Chem. Eur. J. 2019, 25, 6362-6377. [CrossRef]

92. Tschierske, C. Mirror symmetry breaking in liquids and liquid crystals. Liq. Cryst. 2018, 45, $2221-2252$. [CrossRef]

93. Alaasar, M.; Poppe, S.; Kerzig, C.; Klopp, C.; Eremin, A.; Tschierske, C. Cluster phases of 4-cyanoresorcinol derived hockey-stick liquid crystals. J. Mater. Chem. C 2017, 5, 8454-8468. [CrossRef]

94. Alaasar, M.; Schmidt, J.-C.; Darweesh, A.F.; Tschierske, C. Azobenzene-based supramolecular liquid crystals: The role of core fluorination. J. Mol. Liq. 2020, 310, 113252. [CrossRef]

95. Alaasar, M.; Prehm, M.; Tamba, M.-G.; Sebastián, N.; Eremin, A.; Tschierske, C. Development of Polar Order in the Liquid Crystal Phases of a 4-Cyanoresorcinol-Based Bent-Core Mesogen with Fluorinated Azobenzene Wings. ChemPhysChem 2016, 17, 278-287. [CrossRef] [PubMed]

96. Francescangeli, O.; Vita, F.; Ferrero, C.; Dingemans, T.; Samulski, E.T. Cybotaxis dominates the nematic phase of bent-core mesogens: A small-angle diffuse X-ray diffraction study. J. Soft Matter 2011, 7, 895-901. [CrossRef]

97. Galerne, Y. Comment on “Thermotropic Biaxial Nematic Liquid Crystals”. Phys. Rev. Lett. 2006, 96, 219803. [CrossRef]

98. Lee, J.-H.; Lim, T.-K.; Kim, W.-T.; Jin, J.-I. Dynamics of electro-optical switching processes in surface stabilized biaxial nematic phase found in bent-core liquid crystal. J. Appl. Phys. 2007, 101, 034105. [CrossRef]

99. Prasad, V.; Kang, S.-W.; Suresh, K.A.; Joshi, L.; Wang, Q.; Kumar, S. Thermotropic Uniaxial and Biaxial Nematic and Smectic Phases in Bent-Core Mesogens. J. Am. Chem. Soc. 2005, 127, 17224-17227. [CrossRef]

100. Harden, J.; Mbanga, B.; Éber, N.; Fodor-Csorba, K.; Sprunt, S.; Gleeson, J.T.; Jakli, A. Giant flexoelectricity of bent-core nematic liquid crystals. Phys. Rev. Lett. 2006, 97, 157802. [CrossRef]

101. Francescangeli, O.; Stanic, V.; Torgova, S.I.; Strigazzi, A.; Scaramuzza, N.; Ferrero, C.; Dolbnya, I.P.; Weiss, T.M.; Berardi, R.; Muccioli, L.; et al. Ferroelectric Response and Induced Biaxiality in the Nematic Phase of Bent-Core Mesogens. Adv. Funct. Mater. 2009, 19, 2592-2600. [CrossRef]

102. Tschierske, C. Microsegregation: From Basic Concepts to Complexity in Liquid Crystal Self-Assembly. Isr. J. Chem. 2012, 52, 935-959. [CrossRef]

103. Hird, M. Fluorinated liquid crystals_properties and applications. Chem. Soc. Rev. 2007, 36, $2070-2095$. [CrossRef] [PubMed]

104. Guittard, F.; Taffin de Givenchy, E.; Geribaldi, S.; Cambon, A. Highly fluorinated thermotropic liquid crystals: An update. J. Fluor. Chem. 1999, 100, 85-96. [CrossRef]

105. Goodby, J.W.; Saez, I.M.; Cowling, S.J.; Gasowska, J.S.; MacDonald, R.A.; Sia, S.; Watson, P.; Toyne, K.J.; Hird, M.; Lewis, R.A.; et al. Molecular complexity and the control of self-organising processes. Liq. Cryst. 2009, 36, 567-605. [CrossRef]

106. Gomola, K.; Guo, L.; Pociecha, D.; Araoka, F.; Ishikawa, K.; Takezoe, H. An optically uniaxial antiferroelectric smectic phase in asymmetrical bent-core compounds containing a 3-aminophenol central unit. J. Mater. Chem. 2010, 20, 7944-7952. [CrossRef]

107. Alaasar, M.; Prehm, M.; Tschierske, C. Mirror symmetry breaking in fluorinated bent-core mesogens. RSC Adv. 2016, 6, 82890-82899. [CrossRef] 
108. Dunemann, U.; Schröder, M.W.; Reddy, R.A.; Pelzl, G.; Diele, S.; Weissflog, W. The influence of lateral substituents on the mesophase behaviour of banana-shaped mesogens. Part II. J. Mater. Chem. 2005, 15, 4051-4061. [CrossRef]

109. Weissflog, W.; Murthy, H.N.S.; Diele, S.; Pelzl, G. Relationships between molecular structure and physical properties in bent-core mesogens. Philos. Trans. R. Soc. A 2006, 364, 2657-2679. [CrossRef]

110. Šmahel, M.; Poryvai, A.; Xiang, Y.; Pociecha, D.; Troha, T.; Novotná, V.; Svoboda, J.; Kohout, M. Photosensitive bent-core nematic liquid crystals with various linking units in the side arms: Structure-properties relationships. J. Mol. Liq. 2020, 306, 112743. [CrossRef]

111. Hegde, R.S.; Kumar, J.; Prasad, V.; Monika, M. The first examples of V-shaped compounds exhibiting a B5 mesophase and a direct transition from the isotropic to a polar biaxial smectic A mesophase. J. Mol. Liq. 2018, 249, 97-105. [CrossRef]

112. Hough, L.E.; Jung, H.T.; Krüerke, D.; Heberling, M.S.; Nakata, M.; Jones, C.D.; Chen, D.; Link, D.R.; Zasadzinski, J.; Heppke, G.; et al. Helical Nanofilament Phases. Science 2009, 325, 456-460. [CrossRef] [PubMed]

113. Alaasar, M.; Prehm, M.; Tschierske, C. Helical Nano-crystallite (HNC) Phases: Chirality Synchronization of Achiral Bent-Core Mesogens in a New Type of Dark Conglomerates. Chem. A Eur. J. 2016, 22, 6583-6597. [CrossRef] [PubMed]

114. Lintuvuori, J.S.; Yu, G.; Walker, M.; Wilson, M.R. Emergent chirality in achiral liquid crystals: Insights from molecular simulation models of the behaviour of bent-core mesogens. Liq. Cryst. 2018, 45, 1996-2009. [CrossRef]

115. Hegde, R.S.; Kumar, J.; Prasad, V. Achiral bent-core salicylaldimine compounds exhibiting dark conglomerate and B2 mesophases: Effect of linkage groups and lateral substituents. Liq. Cryst. 2019, 46, 1091-1107. [CrossRef]

116. Prasad, V.; Kang, S.-W.; Qi, X.; Kumar, S. Photo-responsive and electrically switchable mesophases in a novel class of achiral bent-core azo compounds. J. Mater. Chem. 2004, 14, 1495-1502. [CrossRef]

117. Hegde, R.S.; Sunil, B.N.; Hegde, G.; Prasad, V. Influence of alkyl and alkoxy groups on photoresponsive behaviour of bent-core azo mesogens: Synthesis, mesomorphic and photoswitching properties. J. Mol. Liq. 2020, 309, 113091. [CrossRef]

118. Alaasar, M.; Prehm, M.; Brautzsch, M.; Tschierske, C. 4-Methylresorcinol based bent-core liquid crystals with azobenzene wings-A new class of compounds with dark conglomerate phases. J. Mater. Chem. C 2014, 2, 5487-5501. [CrossRef]

119. Jing, H.; Xu, M.; Xiang, Y.; Wang, E.; Liu, D.; Poryvai, A.; Kohout, M.; Éber, N.; Buka, Á. Light Tunable Gratings Based on Flexoelectric Effect in Photoresponsive Bent-Core Nematics. Adv. Opt. Mater. 2019, 7, 1801790. [CrossRef]

120. Prasad, V.; Nagendrappa Gowdru, N.; Manjunath, M. Thermally stable azo-substituted bent-core nematogens: Observation of chiral domains in the nematic mesophases composed of smectic nano clusters. Liq. Cryst. 2018, 45, 666-679. [CrossRef]

121. Kumar, J.; Prasad, V. Ferroelectric Nematic and Ferrielectric Smectic Mesophases in an Achiral Bent-Core Azo Compound. J. Phys. Chem. B 2018, 122, 2998-3007. [CrossRef]

122. Rahman, M.L.; Yusoff, M.M.; Hegde, G.; Malek, M.N.F.A.; Samah, N.A.; Srinivasa, H.T.; Kumar, S. Synthesis and Characterization of Naphthalene-Based Banana-Shaped Liquid Crystals for Photoswitching Properties. J. Chin. Chem. Soc. 2014, 61, 571-577. [CrossRef]

123. Rahman, M.L.; Asik, J.; Kumar, S.; Tschierske, C. Liquid crystalline banana-shaped monomers derived from 2,7-naphthalene: Synthesis and properties. Liq. Cryst. 2008, 35, 1263-1270. [CrossRef]

124. Lutfor, M.R.; Yusoff, M.M.; Hegde, G.; Fazli, M.N.; Malek, A.; Samah, N.A.; Srinivasa, H.T. Synthesis of Banana-Shaped Liquid Crystals for Photoswitching Properties. Mol. Cryst. Liq. Cryst. 2013, 587, 41-53. [CrossRef]

125. Bajzíková, K.; Svoboda, J.; Novotná, V.; Pociecha, D.; Gorecka, E. Bent-core mesogens with an aromatic unit at the terminal position. New J. Chem. 2017, 41,4672-4679. [CrossRef]

126. Vazquez, H.; Skouta, R.; Schneebeli, S.; Kamenetska, M.; Breslow, R.; Venkataraman, L.; Hybertsen, M.S. Probing the conductance superposition law in single-molecule circuits with parallel paths. Nat. Nanotechnol. 2012, 7, 663-667. [CrossRef] [PubMed] 
127. Khobragade, D.; Stensrud, E.S.; Mucha, M.; Smith, J.R.; Pohl, R.; Stibor, I.; Michl, J. Preparation of Covalent Long-Chain Trialkylstannyl and Trialkylsilyl Salts and an Examination of their Adsorption on Gold. Langmuir 2010, 26, 8483-8490. [CrossRef] [PubMed]

128. Kaletová, E.; Kohutová, A.; Hajduch, J.; Kaleta, J.; Bastl, Z.; Pospíšil, L.; Stibor, I.; Magnera, T.F.; Michl, J. The Scope of Direct Alkylation of Gold Surface with Solutions of C1-C4 n-Alkylstannanes. J. Am. Chem. Soc. 2015, 137, 12086-12099. [CrossRef]

129. Jinying, L.; Zelong, Z.; Daoren, Y.; Zhiyong, Z.; Jintao, G.; Junfei, Q. Synthesis of 4-Chloro-1,3-Diazobenzene Bent-Cores Liquid Crystals and Characterizations of Their Mesogenic Behaviors and Photoisomerization Phenomena. ChemRxiv 2020. [CrossRef]

130. Nagaveni, N.G.; Raghuvanshi, P.; Roy, A.; Prasad, V. Azo-functionalised achiral bent-core liquid crystalline materials: Effect of presence of $-\mathrm{N}=\mathrm{N}-$ linkage at different locations in the molecular architecture. Liq. Cryst. 2013, 40, 1238-1254. [CrossRef]

131. Rahman, M.L.; Hegde, G.; Yusoff, M.M.; Malek, M.N.F.A.; Srinivasa, H.T.; Kumar, S. New pyrimidine-based photo-switchable bent-core liquid crystals. New J. Chem. 2013, 37, 2460-2467. [CrossRef]

132. Lee, S.K.; Li, X.; Kang, S.; Tokita, M.; Watanabe, J. Formation of banana phases in bent-shaped molecules with unusual bent angles as low as $60^{\circ}$. J. Mater. Chem. 2009, 19, 4517-4522. [CrossRef]

133. Li, X.; Zhan, M.S.; Wang, K. A hexagonal columnar phase formed in lateral fluorinated bent-shaped molecules based on a 1,7-naphthalene central core. New J. Chem. 2012, 36, 1133-1136. [CrossRef]

134. Lee, E.-W.; Hattori, M.; Uehara, F.; Tokita, M.; Kawauchi, S.; Watanabe, J.; Kang, S. Smectic A-hexagonal columnar-B7 phase transition of acute-angle bent-core molecules. J. Mater. Chem. C 2015, 3, 2266-2273. [CrossRef]

135. Lee, E.-W.; Takimoto, K.; Tokita, M.; Watanabe, J.; Kang, S. Bent Molecules with a $60^{\circ}$ Central Core Angle that Form B7 and B2 Phases. Angew. Chem. 2014, 53, 8216-8220. [CrossRef] [PubMed]

136. Kang, S.; Harada, M.; Li, X.; Tokita, M.; Watanabe, J. Notable formation of a cubic phase from small bent-angle molecules based on the 1,7-naphthalene central core and alkylthio tails. Soft Matter 2012, 8, 1916-1922. [CrossRef]

137. Alaasar, M.; Prehm, M.; May, K.; Eremin, A.; Tschierske, C. 4-Cyanoresorcinol-Based Bent-Core Mesogens with Azobenzene Wings: Emergence of Sterically Stabilized Polar Order in Liquid Crystalline Phases. Adv. Funct. Mater. 2014, 24, 1703-1717. [CrossRef]

138. Westphal, E.; Gallardo, H.; Caramori, G.F.; Sebastián, N.; Tamba, M.-G.; Eremin, A.; Kawauchi, S.; Prehm, M.; Tschierske, C. Polar Order and Symmetry Breaking at the Boundary between Bent-Core and Rodlike Molecular Forms: When 4-Cyanoresorcinol Meets the Carbosilane End Group. Chem. A Eur. J. 2016, 22, 8181-8197. [CrossRef]

139. Ocak, H.; Poppe, M.; Bilgin-Eran, B.; Karanlık, G.; Prehm, M.; Tschierske, C. Effects of molecular chirality on self-assembly and switching in liquid crystals at the cross-over between rod-like and bent shapes. Soft Matter 2016, 12, 7405-7422. [CrossRef]

140. Kang, S.; Saito, Y.; Watanabe, N.; Tokita, M.; Takanishi, Y.; Takezoe, H.; Watanabe, J. Low-Birefringent, Chiral Banana Phase below Calamitic Nematic and/or Smectic C Phases in Oxadiazole Derivatives. J. Phys. Chem. B 2006, 110, 5205-5214. [CrossRef]

141. Yu, F.C.; Yu, L.J. Mesophases of Achiral Bent Molecules. Chem. Mater. 2006, 18, 5410-5420. [CrossRef]

142. Matharu, A.S.; Grover, C.; Komitov, L.; Andersson, G. Ferro-, ferri- and antiferro-electric behaviour in a bent-shaped mesogen. J. Mater. Chem. 2000, 10, 1303-1310. [CrossRef]

143. Weissflog, W.; Dunemann, U.; Findeisen-Tandel, S.; Tamba, M.G.; Kresse, H.; Pelzl, G.; Diele, S.; Baumeister, U.; Eremin, A.; Stern, S.; et al. At the boundary to banana-shaped liquid crystals: Polar properties of phases formed by new asymmetric achiral four-ring bent-core mesogens. Soft Matter 2009, 5, 1840-1847. [CrossRef]

144. Deb, R.; Nath, R.K.; Paul, M.K.; Rao, N.V.S.; Tuluri, F.; Shen, Y.; Shao, R.; Chen, D.; Zhu, C.; Smalyukh, I.I.; et al. Four-ring achiral unsymmetrical bent core molecules forming strongly fluorescent smectic liquid crystals with spontaneous polar and chiral ordered B7 and B1 phases. J. Mater. Chem. 2010, 20, 7332-7336. [CrossRef]

145. Ki Yoon, D.; Deb, R.; Chen, D.; Körblova, E.; Shao, R.; Ishikawa, K.; Rao, N.V.S.; Walba, D.M.; Smalyukh, I.I.; Clark, N.A. Organization of the polarization splay modulated smectic liquid crystal phase by topographic confinement. Proc. Natl. Acad. Sci. USA 2010, 107, 21311-21315. [CrossRef] 
146. Nath, R.K.; Sarkar, D.D.; Shankar Rao, D.S.; Nandiraju, V.S.R. Influence of polar substituents on the mesomorphism of non-symmetrical achiral four-ring bent-core compounds: Synthesis and characterisation. Liq. Cryst. 2012, 39, 889-902. [CrossRef]

147. Khan, R.K.; Turlapati, S.; Begum, N.; Mohiuddin, G.; Rao, N.V.S.; Ghosh, S. Impact of terminal polar substitution on elastic, electro-optic and dielectric properties of four-ring bent-core nematic liquid crystals. RSC Adv. 2018, 8, 11509-11516. [CrossRef]

148. Patranabish, S.; Mohiuddin, G.; Begum, N.; Laskar, A.R.; Pal, S.K.; Rao, N.V.S.; Sinha, A. Cybotactic nematic phase of achiral unsymmetrical bent-core liquid crystals-Quelling of polar ordering and the influence of terminal substituent moiety. J. Mol. Liq. 2018, 257, 144-154. [CrossRef]

149. Khan, R.; Turlapati, S.; Rao, N.; Ghosh, S. Elastic and dielectric properties of ferroelectric nanoparticles/bent-core nematic liquid crystal blend. Eur. Phys. J. E 2017, 40, 75. [CrossRef]

150. Shanker, G.; Prehm, M.; Nagaraj, M.; Vij, J.K.; Weyland, M.; Eremin, A.; Tschierske, C. 1,2,4-Oxadiazole-Based Bent-Core Liquid Crystals with Cybotactic Nematic Phases. ChemPhysChem 2014, 15, 1323-1335. [CrossRef]

151. Ghosh, S.; Begum, N.; Turlapati, S.; Roy, S.K.; Das, A.K.; Rao, N.V.S. Ferroelectric-like switching in the nematic phase of four-ring bent-core liquid crystals. J. Mater. Chem. C 2014, 2, 425-431. [CrossRef]

152. Singh, S.; Singh, H.; Tandon, P.; Chakraborty, N.; Rao, N.V.S.; Ayala, A.P. Study of $\mathrm{Cr} \rightarrow \mathrm{SmA}$ phase transition and hydrogen bonding in four-ring bent-core liquid crystal. Spectrochim. Acta Part A Mol. Biomol. Spectrosc. 2017, 178, 142-150. [CrossRef] [PubMed]

153. Begum, N.; Kaur, S.; Mohiuddin, G.; Nandi, R.; Gupta, S.P.; Rao, N.V.S.; Pal, S.K. Structural Understanding, Photoswitchability, and Supergelation of a New Class of Four Ring-Based Bent-Shaped Liquid Crystal. J. Phys. Chem. B 2019, 123, 4443-4451. [CrossRef] [PubMed]

154. Begum, N.; Kaur, S.; Xiang, Y.; Yin, H.; Mohiuddin, G.; Rao, N.V.S.; Pal, S.K. Photoswitchable Bent-Core Nematic Liquid Crystals with Methylated Azobenzene Wing Exhibiting Optic-Field-Enhanced Fréedericksz Transition Effect. J. Phys. Chem. C 2020, 124, 874-885. [CrossRef]

155. Turlapati, S.; Sunil, B.N.; Vishwakarma, V.K.; Achalkumar, A.S.; Hegde, G. Influence of lateral methyl/chloro substituents on the liquid crystalline and photoswitching behaviour of bent-core mesogens bearing azobenzene wings: Synthesis and characterization. New J. Chem. 2020, 44, 5731-5738. [CrossRef]

156. Paul, M.K.; Saha, S.K.; Kalita, G.; Bhattacharya, B.; Sarkar, U. Low-temperature nematic phase in azo functionalised reactive hockey stick mesogens possessing lateral methyl group. Dyes Pigment. 2020, 173, 107233. [CrossRef]

157. Yu, F.C.; Yu, L.J. Mesophases of hockey stick mesogens. Liq. Cryst. 2008, 35, 799-813. [CrossRef]

158. Enz, E.; Findeisen-Tandel, S.; Dabrowski, R.; Giesselmann, F.; Weissflog, W.; Baumeister, U.; Lagerwall, J. On the balance between syn- and anticlinicity in smectic phases formed by achiral hockey-stick mesogens with and without chiral dopants. J. Mater. Chem. 2009, 19, 2950-2957. [CrossRef]

159. Novotná, V.; Žurek, J.; Kozmík, V.; Svoboda, J.; Glogarová, M.; Kroupa, J.; Pociecha, D. Novel hockey-stick mesogens with the nematic, synclinic and anticlinic smectic $C$ phase sequence. Liq. Cryst. 2008, 35, 1023-1036. [CrossRef]

160. Kapuściński, S.; Wojciechowska, A.; Urbaniak, K.; Kaszyński, P.; Jasiński, M. Hockey-stick liquid crystalline 6-oxoverdazyl. Liq. Cryst. 2017, 44, 1093-1103. [CrossRef]

161. Mahimwalla, Z.; Yager, K.G.; Mamiya, J.-I.; Shishido, A.; Priimagi, A.; Barrett, C. Azobenzene photomechanics: Prospects and potential applications. Polym. Bull. 2012, 69, 967-1006. [CrossRef]

162. White, T.J.; Broer, D. Programmable and adaptive mechanics with liquid crystal polymer networks and elastomers. J. Nat. Mater. 2015, 14, 1087-1098. [CrossRef] [PubMed]

163. de Haan, L.T.; Schenning, A.P.; Broer, D. Programmed morphing of liquid crystal networks. Polymer 2014, 55, 5885-5896. [CrossRef]

164. Iamsaard, S.; Villemin, E.; Lancia, F.; A $\beta$ hoff, S.-J.; Fletcher, S.P.; Katsonis, N. Preparation of biomimetic photoresponsive polymer springs. Nat. Protoc. 2016, 11, 1788-1797. [CrossRef] [PubMed]

165. Crespi, S.; Simeth, N.A.; König, B. Heteroaryl azo dyes as molecular photoswitches. Nat. Rev. Chem. 2019, 3, 133-146. [CrossRef]

166. Hadjoudis, E.; Mavridis, I.M. Photochromism and thermochromism of Schiff bases in the solid state: Structural aspects. Chem. Soc. Rev. 2004, 33, 579-588. [CrossRef] 
167. Devi, S.; Gaur, A.K.; Gupta, D.; Saraswat, M.; Venkataramani, S. Tripodal N-Functionalized Arylazo-3, 5-dimethylpyrazole Derivatives of Trimesic Acid: Photochromic Materials for Rewritable Imaging Applications. ChemPhotoChem 2018, 2, 806-810. [CrossRef]

168. De Gennes, P.-G.; Prost, J. The Physics of Liquid Crystals; Oxford University Press: Oxford, UK, 1993; Volume 83.

169. Xiang, Y.; Jing, H.-Z.; Zhang, Z.-D.; Ye, W.-J.; Xu, M.-Y.; Wang, E.; Salamon, P.; Éber, N.; Buka, Á. Tunable optical grating based on the flexoelectric effect in a bent-core nematic liquid crystal. Phys. Rev. Appl. 2017, 7, 064032. [CrossRef]

170. Xu, D.; Tan, G.; Wu, S.-T. Large-angle and high-efficiency tunable phase grating using fringe field switching liquid crystal. Opt. Express 2015, 23, 12274-12285. [CrossRef]

171. Chen, H.; Tan, G.; Huang, Y.; Weng, Y.; Choi, T.-H.; Yoon, T.-H.; Wu, S.-T. A Low Voltage Liquid Crystal Phase Grating with Switchable Diffraction Angles. Sci. Rep. 2017, 7, 39923. [CrossRef]

(C) 2020 by the authors. Licensee MDPI, Basel, Switzerland. This article is an open access article distributed under the terms and conditions of the Creative Commons Attribution (CC BY) license (http://creativecommons.org/licenses/by/4.0/). 